SAND95-1205

Unlimited Release

Printed June 1995

\title{
Environmentally Conscious Manufacturing Solvent Substitution Program/Switch Tube Assemblies Final Report*
}

\author{
E. P. Lopez, J. A. Ohlhausen and D. E. Peebles \\ Sandia National Laboratories \\ Organic Materials Processing Department \\ Albuquerque, New Mexico 87185-0368 \\ M. G. Benkovich \\ formerly of Allied Signal-Kansas City Division \\ Now: Technical Director \\ ERA Systems Inc. \\ The MESERAN Company \\ P.O. Box 3609 \\ Chatanooga, TN 37404-0609
}

\begin{abstract}
:
As part of an Environmentally Conscious Manufacturing (ECM) Program, a study was conducted at Sandia National Laboratories to identify an alternative cleaning process that would effectively replace trichloroethylene (TCE) for cleaning mechanical piece parts of Switch Tube assemblies. Eight aqueous alkaline cleaners, as well as an isopropyl alcohol and isopropyl alcohol/Cyclohexane cleaning process, were studied as potential replacements. Cleaning efficacy, materials compatibility, etch rate and corrosion studies were conducted and used to screen potential candidates. Cleaning efficacy was determined using visual examination, goniometer/contact angle measurements, Auger electron spectroscopy, X-ray Photoelectron spectroscopy and an evaporative rate analysis technique known as MESERAN Surface Analysis. Several cleaners were identified as potential replacements for TCE, based solely on the cleaning efficacy results. Some of the cleaners, however, left undesirable residues behind. After all studies were completed, Brulin 815GD (an aqueous alkaline cleaner) was selected as the replacement for TCE.
\end{abstract}




\section{Contents}

Tables.

iii

Figures

vi

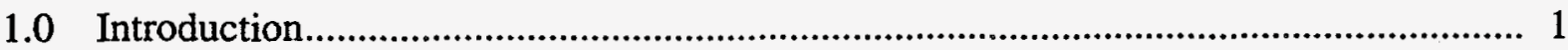

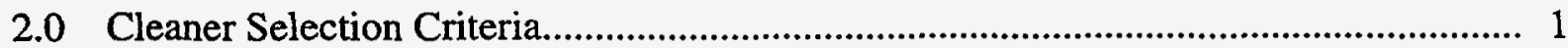

3.0 Material Selection and Sample Preparation.......................................................... 2

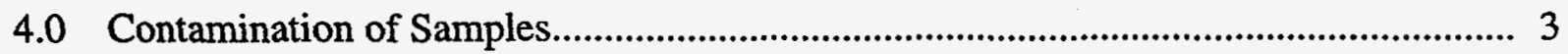

5.0 Candidate Cleaners.................................................................................. 3

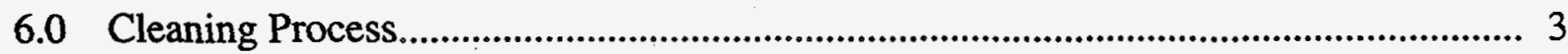

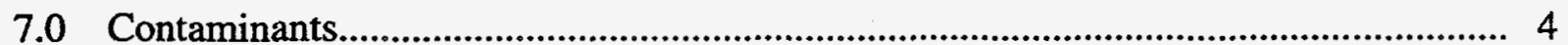

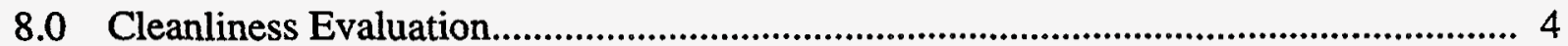

9.0 Contact Angle Results and Discussion/OFHC Copper........................................ 6

10.0 Contact Angle Results and Discussion/Aluminum 1100.................................... 6

11.0 Auger Analysis Results and Discussion........................................................ 7

12.0 Auger Analysis Recommendations...................................................................... 8

13.0 MESERAN Study Results and Discussion..................................................... 8

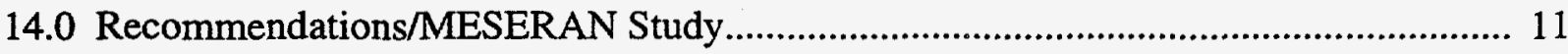

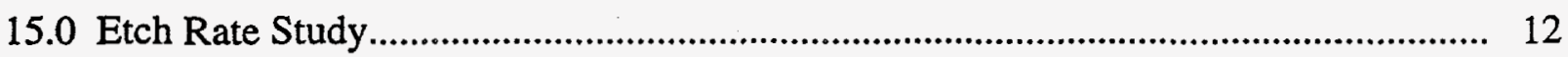

16.0 Cleaner Down-Selection Process........................................................................ 12

17.0 Materials Compatibility Tests........................................................................ 13

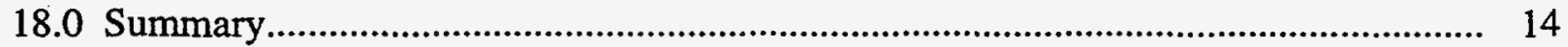




\section{DISCLAIMER}

This report was prepared as an account of work sponsored by an agency of the United States Government. Neither the United States Government nor any agency thereof, nor any of their employees, make any warranty, express or implied, or assumes any legal liability or responsibility for the accuracy, completeness, or usefulness of any information, apparatus, product, or process disclosed, or represents that its use would not infringe privately owned rights. Reference herein to any specific commercial product, process, or service by trade name, trademark, manufacturer, or otherwise does not necessarily constitute or imply its endorsement, recommendation, or favoring by the United States Government or any agency thereof. The views and opinions of authors expressed herein do not necessarily state or reflect those of the United States Government or any agency thereof. 


\section{DISCLAIMER}

Portions of this document may be illegible in electronic image products. Images are produced from the best available original document. 
Tables

1. Contamination of Samples..................................................................................... 17

2. Candidate Cleaner pH Values................................................................................ 18

3. Auger Estimated Detection Limits and Measurement Errors........................................ 19

4. Contact Angle Measurements/OFHC Cu...................................................................... 20

5. Contact Angle Measurements/Aluminum 1100 Coupons............................................... 21

6. TCE Auger Elemental Analysis.................................................................................... 22

7. Igepal CO-710-710 Auger Elemental Analysis........................................................... 22

8. Daraclean 212 Auger Elemental Analysis.................................................................... 23

9. Daraclean 235 Auger Elemental Analysis..................................................................... 23

10. Daraclean 282 Auger Elemental Analysis.................................................................... 24

11 Brulin 815GD Auger Elemental Analysis.................................................................... 24

12. Micro Cleaner Auger Elemental Analysis................................................................. 25

13. Oakite NST Auger Elemental Analysis................................................................... 25

14. Armakleen E2001A Auger Elemental Analysis............................................................ 26

15. Isopropyl Alcohol Auger Elemental Analysis............................................................... 26

16. Isopropyl Alcohol/Cyclohexane Auger Elemental Analysis....................................... 27

17. Average Elemental Residue By Cleaner................................................................... 28

18. MESERAN Results/TCE........................................................................................ 29

19. MESERAN Results/Igepal CO-710 ........................................................................ 30

20. MESERAN Results/Daraclean 212 ........................................................................ 31

21. MESERAN Results/Daraclean 235 ...................................................................... 32

22. MESERAN Results/Daraclean 282.................................................................... 33

23. MESERAN Results/Brulin 815GD .................................................................... 34

24. MESERAN Results/Micro Cleaner............................................................................ 35

25. MESERAN Results/Oakite NST ................................................................................ 36

26. MESERAN Results/Isopropyl Alcohol................................................................... 37 
27. MESERAN Results/Isopropyl Alcohol-Cyclohexane

28. Average MESERAN Numbers and Standard

Deviations for Cleaners Tested.

29. Switch Tube Etch Rate Study

30. 17 Hour Immersion Test In TCE

on Gold, Kapton, $\mathrm{Sn} / \mathrm{Pb}$, and Alumina.

31. 17 Hour Immersion Test In TCE

on Aluminum, Copper, Kovar, and Palco.

32. 17 Hour Immersion Test In TCE on Molybdenum and Niobium.

33. 17 Hour Immersion Test In Brulin 815GD

on $\mathrm{Sn} / \mathrm{Pb}$, Kapton and Alumina.

34. 17 Hour Immersion Test In Brulin 815GD

on Aluminum and Gold.

35. 17 Hour Immersion Test In Brulin 815GD

on Aluminum, Copper, Kovar, and Palco.

36. 17 Hour Immersion Test In Brulin 815GD on Molybdenum and Niobium.

37. 17 Hour Immersion Test In Oakite NST

on $\mathrm{Sn} / \mathrm{Pb}$, Kapton and Alumina.

38. 17 Hour Immersion Test In Oakite NST

on Copper, Gold, and Molybdenum.

39. 17 Hour Immersion Test In Oakite NST

on Niobium, and Palco.

40. Clean Test With TCE on Palco Wire, Aluminum Slugs,

Molybdenum, Kovar, and 304L SS.

41. Clean Test With Brulin $815 \mathrm{GD}$ on $\mathrm{Sn} / \mathrm{Pb}$, Kapton, and Alumina.

42. Clean Test With Brulin 815 GD on Palco Wire,

Aluminum Slugs, Molybdenum, Kovar, and 304L SS..................................... 46

43. Clean Test With Oakite NST on $\mathrm{Sn} / \mathrm{Pb}$, Kapton, and Alumina.......................... 46

44. Clean Test With Oakite NST on Palco Wires,

Aluminum Slugs, Molybdenum, Kovar, and 304L SS 
45. Average \% Weight Change for Immersion Test for TCE, Brulin 815GD, and Oakite NST.

46. Average $\%$ Weight Change for Clean Test

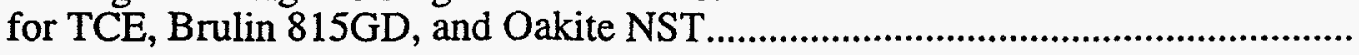




\section{Figures}

1a. Process Flow Diagram............................................................................. 2

1. Contact Angle Measurements For Igepal CO-710_.............................................. 49

2. Contact Angle Measurements For Daraclean 212........................................... 50

3. Contact Angle Measurements For Daraclean 235 ................................................ 51

4. Contact Angle Measurements For Daraclean 282 …............................................. 52

5. Contact Angle Measurements For Brulin 815GD............................................... 53

6. Contact Angle Measurements For Micro Cleaner.................................................. 54

7. Contact Angle Measurements For Oakite NST..................................................... 55

8. Contact Angle Measurements For TCE............................................................. 56

9. Representative Auger Survey............................................................................ 57

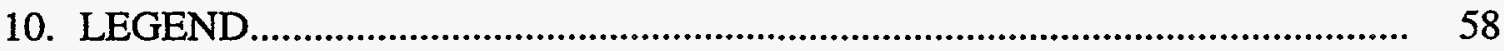

11. Auger Analysis For Igepal CO-710 .......................................................... 59

12. Auger Analysis For Daraclean 212 ................................................................ 60

13. Auger Analysis For Daraclean 235 ................................................................. 61

14. Auger Analysis For Daraclean 282 …........................................................... 62

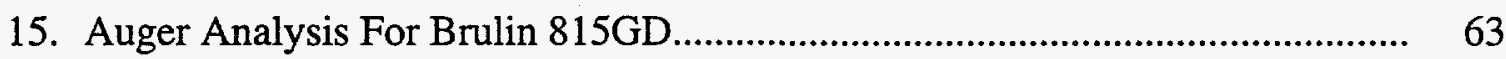

16. Auger Analysis For Micro Cleaner.................................................................... 64

17. Auger Analysis For Oakite NST..................................................................... 65

18. Auger Analysis For Isopropyl Alcohol............................................................... 66

19. Auger Analysis For Isopropyl Alcohol/Cyclohexane.......................................... 67

20. Auger Analysis For Armakleen E2001A.......................................................... 68

21. Auger Analysis For TCE............................................................................. 69

22. Cleaning Consistency of Each Cleaner............................................................. 70

23. Auger Survey of a Representative Sample Cleaned

With Armakleen E2001A........................................................................... 71

24. Representative Sample Cleaned With Armakleen E2001A, XPS Oxygen Region. 
25. Representative Sample Cleaned With Armakleen

E2001A, XPS Silicon 2p Region.

26. Average Residual Barium Concentration for Each Cleaner............................. 74

27. Average Residual Carbon Concentration for Each Cleaner............................. 75

28. Average Residual Chlorine Concentration for Each Cleaner........................... 76

29. Average Residual Copper Concentration for Each Cleaner............................. 77

30. Average Residual Nitrogen Concentration for Each Cleaner.......................... 78

31. Average Residual Oxygen Concentration for Each Cleaner............................ 79

32. Average Residual Silicon Concentration for Each Cleaner............................. 80

33. Average Residual Sodium Concentration for Each Cleaner............................. 81

34. Average Residual Sulfur Concentration for Each Cleaner.............................. 82

35. $\mathrm{pH}$ of Each Cleaner at Working Concentrations............................................ 83

36. Average Copper Concentration for Each Cleaner Versus pH.......................... 84

37. Average Residual Barium Concentration for Each Lubricant......................... 85

38. Average Residual Carbon Concentration for Each Lubricant.......................... 86

39. Average Residual Chlorine Concentration for Each Lubricant....................... 87

40. Average Residual Copper Concentration for Each Lubricant......................... 88

41. Average Residual Nitrogen Concentration for Each Lubricant....................... 89

42. Average Residual Oxygen Concentration for Each Lubricant........................ 90

43. Average Residual Silicon Concentration for Each Lubricant.......................... 91

44. Average Residual Sodium Concentration for Each Lubricant........................ 92

45. Average Residual Sulfur Concentration for Each Lubricant.......................... 93 


\section{Introduction}

Sandia National Laboratories (SNL) has traditionally used chlorinated and fluorinated organic solvents for metal degreasing applications. Many of these solvents have been labeled by the Federal Government, as ozone depleting chemicals or as toxic and/or suspected carcinogens, and as such will no longer be recommended for use within the DOE weapons complex. In an effort to address this problem, "The Environmentally Conscious Manufacturing Program" (ECM) was established. The ECM develops the technology required to manufacture Sandia designed non-nuclear weapon hardware in a manner which respects both the worker and the environment. It focuses on enabling manufacturing technologies which are required for high quality manufacturing of long-lived electronic, electromechanical, energetic, and structural components.

In this case study, trichloroethylene (TCE) is currently being used as the primary degreasing solvent for removing machining type lubricants from switch tube piece parts. A switch tube is an arc discharge device that discharges capacitors into exploding bridgewires or neutron generators. TCE is still considered by some organizations to be a suspected animal carcinogen. Furthermore, it is considered a toxic hazardous substance by agencies such as the Environmental Protection Agency and the American Council For Government Industrial Hygienists and as such, is no longer being recommended for use within the DOE weapons complex. Alternate cleaning technologies, including aqueous alkaline cleaners, isopropyl alcohol (IPA) ultrasonic/vapor \& IPA/Cyclohexane immersion/vapor degreasing, have been studied as potential replacements for TCE. This report discusses the choices and the methodology that were used to select a cleaning alternative. The main criteria used to screen potential alternatives included cleaning efficacy, materials compatibility, etch rate, and corrosion studies. Other factors, such as worker safety, recycling, waste disposal issues, and cost, were addressed.

\section{Cleaner Selection Criteria}

During the cleaner selection process, certain criteria had to be fulfilled. The following criteria were either suggested by the customer or by the principal investigator: (1) First and foremost, the recommended cleaner had to clean as well as or better than the existing TCE baseline cleaning process, (2) The cleaning process could not leave undesirable residues behind, such as sulfur, that could be detrimental to subsequent processes. For example, residues of sulfur left on a surface can potentially lead to electrical failures. Silicate residues are unacceptable, because they can impede subsequent bonding and encapsulation procedures. Chlorine residues should be minimized because of the potential to form hydrochloric acid under high temperatures and humidities, (3) Materials compatibility issues of the various solutions with the different materials that comprise the switch tube was of critical concern, i.e. how do the different materials react to the candidate solutions, (4) Other factors such as corrosion, worker safety, recycling capability, waste disposal and cost are considered very important, (5) Not as critical in the selection process were the etch rates of the various alkaline solutions, particularly on aluminum 1100. Solutions that etch in the micron range were not of great concern, however, etching in the mil range could cause tolerance problems, and therefore was of concern. Furthermore, the aesthetics of a surface becomes important when it is being inspected (i.e. an aluminum surface can appear stained and can often be rejected on that basis) and, (6) As part of the ECM program, certain Environmental, Safety and Health criteria had to be met. For example, the cleaner that is recommended should be environmentally friendly. This means that the cleaner should not be an ozone depleting chemical, smog contributor or Resource Conservation and Recovery Act (RCRA) waste. A RCRA waste, in this case, is defined as an aqueous alkaline cleaner with a $\mathrm{pH}$ of 12.5 or greater. Aqueous alkaline cleaners were identified as primary candidates based on their chemistries that were well suited for removing the types of contaminants (organic) that were of particular interest in this study. Figure 1a shows the general process flow and criteria that were used to select an alternative cleaner. 


\section{Figure 1a \\ Cleaner Selection Criteria \\ Process Flow Diagram}

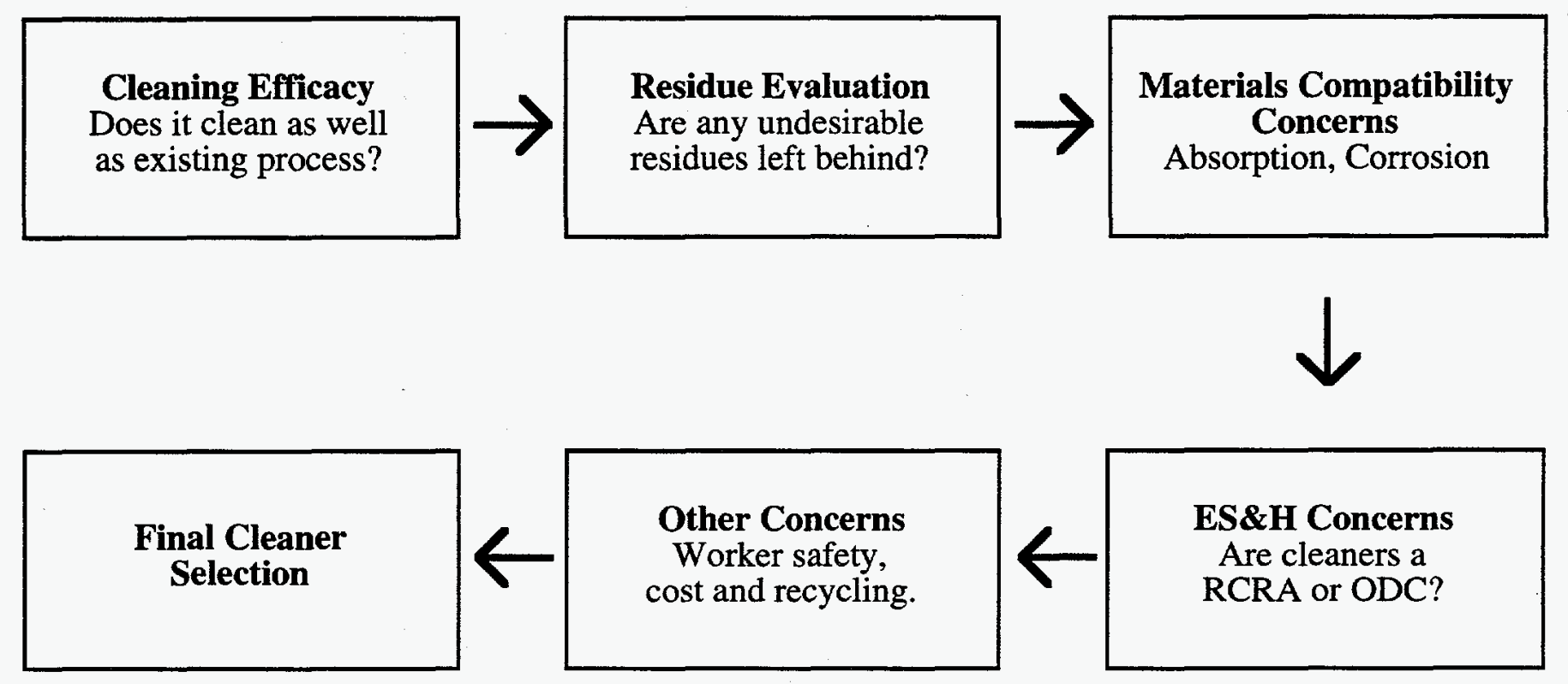

\section{Material Selection And Sample Preparation}

Many metals (e.g., Copper, Aluminum, Molybdenum, Kovar, Palco, Gold, Nicoro, Nioro etc.) are used in the fabrication of a switch tube. For ease of testing purposes, and because of the difficulty in obtaining sufficient amounts of each material, Oxygen Free High Conductivity Copper (OFHC Cu) was selected as the primary test material for most of the contact angle, Auger and X-ray photoelectron spectroscopy (XPS) studies. In one case, aluminum 1100 was used for contact angle measurements. It is recognized that the various contaminants in this study, can have different affinities for the different materials that are used and can give different results. On the other hand, the relative comparisons on copper were considered sufficient in determining whether a cleaner cleaned as well as or better than TCE. Aluminum 6061 was selected as the test material for the MESERAN study. OFHC Cu test coupons were cut from 10 mil wrought sheet. The test geometry was nominally 1 " square for contact angle samples, 0.39 " square for the Auger and XPS samples and 3" square for the MESERAN samples.

To provide an initial uniform, reproducible, baseline surface for analysis, OFHC Cu samples were pre-cleaned by degreasing in TCE, rinsed with IPA and blown dry with filtered dry nitrogen. After the degreasing process, the $\mathrm{Cu}$ samples were etched with concentrated sulfuric acid for 1 minute, rinsed with flowing deionized water for 1 minute, and rinsed with IPA for 1 minute before blow drying with filtered dry nitrogen.

The aluminum 1100 samples $(0.39 "$ square) prepared for contact angle measurements were first pre-cleaned with TCE and IPA. The Al samples were then taken through an alkaline nonetch cleaning step with a solution comprised of $\mathrm{NaSiO}_{3}$ and $\mathrm{Na}_{2} \mathrm{CO}_{3}$ in $\mathrm{H}_{2} \mathrm{O}$ at $149^{\circ} \mathrm{F}$. This was followed with a flowing deionized water rinse, an acid deoxidize cleaning step with a solution of $\mathrm{NH}_{4} \mathrm{HF}_{2}$ and $\mathrm{HNO}_{3}$ at room temperature, a deionized water rinse and a final blow dry with filtered nitrogen. This procedure produced an initial uniform surface for analysis.

The aluminum panels prepared for the MESERAN Test Study were nominally 3" square and were cleaned and handled in the following manner at Allied Signal-Kansas City Division (AS-KCD) prior to being contaminated with the lubricants: (1) the protective backing was removed from the aluminum panels, (2) the panels were scrubbed with TCE soaked 
AccuDry wipes, (3) the panels were alternately ultrasonically cleaned in TCE for 1 minute at 40 $\mathrm{kHz}$ and vapor degreased for 1 minute in TCE for a total of three cycles, (4) the panels were vacuum baked for a minimum of 1 hour at $165^{\circ} \mathrm{F},(5)$ the panels were visually inspected for scratches, residues, and stains so that only the best panels were chosen for this evaluation, (6) the panels were then allowed to cool and air dry in a clean bench prior to being placed in clean petri dishes, packaged, and sent to SNL where they were contaminated with the lubricants. Five samples of each contaminant were evaluated with the following cleaners for the MESERAN study: Igepal CO-710, Daraclean 212, Daraclean 235, Daraclean 282, Brulin 815GD, Micro Cleaner, Oakite NST, and TCE. Three samples of each contaminant were evaluated with IPA and $80 \%$ IPA/20\% Cyclohexane.

\section{Contamination of Samples}

The OFHC Cu (1" X 1") and the aluminum test samples (0.39" square) used in the contact angle study were further prepared by contaminating each with $0.2 \mathrm{cc}$ and $0.1 \mathrm{cc}$ respectively of lubricant. OFHC Cu samples ( $0.39^{\prime \prime}$ square) to be analyzed by Auger and XPS were contaminated with $0.1 \mathrm{cc}$ of lubricant. Aluminum samples for the MESERAN Study were contaminated with $0.5 \mathrm{cc}$ of lubricant. All samples were placed on a hot plate whereupon the lubricant was applied with a syringe. The panels were heated (with the exception of the Ivory Snow/Lanolin lubricant) for 5 minutes at $\sim 150^{\circ} \mathrm{F}$, to simulate the heat that might occur during a machining process. The heating of the Ivory/Lanolin lubricant was discontinued when visible signs of oxidation were noticed. After heating, the samples were allowed to air dry for 1 hour before cleaning.

The aluminum 6061 panels used for the MESERAN study were contaminated by depositing $0.5 \mathrm{cc}$ of lubricant on each of the panels. As before, the panels were placed on a hot plate and heated for 5 minutes at $150^{\circ} \mathrm{F}$. The panels were then allowed to air dry for 1 hour before cleaning. Ivory Snow/Lanolin was not baked on the panels and was only allowed to air dry for 5 minutes prior to cleaning because it stained the aluminum panels.

Depending on the cleaning test performed, the size of the sample and the amount of lubricant that was applied to each substrate differed. However, the amounts of lubricant applied within a specific group were the same. Table 1 shows the analytical methods used for determining cleanliness levels, the substrate materials used, the total number of samples cleaned per solution volume, the total amount of contamination applied per sample, the total surface area cleaned and the total amount of solution used per batch.

\section{Candidate Cleaners}

Eight aqueous alkaline cleaners were selected as potential candidates and compared to the baseline cleaner TCE. The cleaners were selected as potential candidates based on previous experience with the cleaners or as a result of a manufacturer's recommendation. All but one of the selected aqueous cleaners (Armakleen E2001A), were specifically formulated for cleaning greases and oils. Armakleen E2001A was specifically formulated for the removal of rosin solder fluxes, however, it was included in the study upon request by the manufacturer. Also chosen as potential candidates were an IPA ultrasonic/vapor degreasing process and an IPA/Cyclohexane immersion/vapor degreasing process. The vapor degreasing processes were performed at S\&K Products. The cleaners selected for this study are listed in Table 2 . The main constituents of each cleaner are given. In some cases, the formulation is proprietary and no constituents are listed. The measured $\mathrm{pH}$ values of the aqueous alkaline cleaners at $10 \%$ by volume ranged from 7.3 to 11.5 and the $\mathrm{pH}$ values listed in the MSDS's ranged from 6 to 12 depending on whether they were in the concentrate form or in a $10 \%$ by volume solution. The organic cleaners were assigned a relative $\mathrm{pH}$ of 7.0 .

\section{Cleaning Process}

The samples that were cleaned with the aqueous alkaline cleaners were:

(1) ultrasonically cleaned using a NEY Prosonik Ultrasonic Cleaner for 5 minutes. The

Daraclean 212, Daraclean 235, Daraclean 282, Brulin 815GD, and Micro Cleaner panels were 
ultrasonically cleaned for 5 minutes at $135^{\circ} \mathrm{F}$. The Oakite NST panels were ultrasonically cleaned for 5 minutes at $120^{\circ} \mathrm{F},(2)$ all of the samples were then rinsed in room temperature, flowing deionized water for 2 minutes, (3) the panels were then ultrasonically rinsed with IPA to expedite drying, and (4) the panels were blown dry with filtered dry nitrogen.

The Igepal CO-710 panels were ultrasonically cleaned for 5 minutes at $122^{\circ} \mathrm{F}$ and then ultrasonically cleaned for another 5 minutes in a clean $0.5 \%$ Igepal CO-710 solution. The Igepal CO-710 cleaned samples were then rinsed in hot flowing tap water for 1 minute, rinsed in room temperature flowing deionized water for 1 minute, ultrasonically cleaned in IPA for 30-60 seconds ( 2 times) to expedite drying, and finally blown dry with filtered dry nitrogen. This Igepal process is currently being used at EG\&G, Salem.

The TCE cleaning process performed at SNL/NM consisted of vapor degreasing the panels for 4 minutes in TCE, followed by ultrasonic cleaning in TCE for 5 minutes, ultrasonic cleaning in IPA for 30-60 seconds to expedite drying, and finally blow drying with filtered dry nitrogen. This is the same cleaning process that is currently being used at EG\&G Salem.

The IPA and IPA/Cyclohexane cleaning processes were performed at S\&K Products International Inc. in Chestnut Ridge, New York using S \& K's IG-200 Cleaning, Degreasing, and Drying System. The IPA cleaning process consisted of ultrasonically cleaning the panels in boiling IPA $\left(190^{\circ} \mathrm{F}\right)$ for 3 minutes followed by IPA vapor degreasing for 45 seconds. The IPA/Cyclohexane cleaning process consisted of immersing the panels in boiling

IPA/Cyclohexane for 3 minutes followed by IPA/Cyclohexane vapor degreasing for 45 seconds.

After the panels were cleaned, they were placed in clean petri dishes, packaged, and sent to the AS-KCD for MESERAN cleanliness measurements.

\section{Contaminants}

The following eight machining type lubricants (which are used by the various shops that machine switch tube piece parts) were identified as potential contaminants:

(1) Cook's 4625

(2) Cook's 4639D

(3) Cook's S697

(4) 3-B Oil

(5) $\mathrm{H} \& \mathrm{~B} 50 \%$ Lard/50\% Mineral Oil

(6) Ivory Snow/Lanolin

(7) Cimtap

(8) Boelube

\section{Cleanliness Evaluation}

Several methods were used to determine cleaning efficacy. These methods included a visual examination, an analysis of surface wettability with a contact angle goniometer, an analysis of the residual surface composition by Auger electron spectroscopy (AES) and X-ray Photoelectron Spectroscopy (XPS) and a measure of residual organic contamination with a MESERAN Surface Analysis technique.

A Ramé Hart Model 100/Contact Angle Goniometer was used to determine surface wettability of OFHC Cu and aluminum 1100 substrates. This test measures the contact (tangent) angle that is formed between a drop of water and its supporting surface, in this case a $\mathrm{Cu}$ substrate. In general, the cleaner and less oxidized the surface, the lower the contact angle measurement. The method is a qualitative test.

Residual surface contamination on $\mathrm{Cu}$ samples was measured by scanning AES, using a Perkin Elmer Physical Electronics (PHI) 3067 system. Spectra were taken with a single-pass cylindrical mirror energy analyzer at $0.6 \%$ resolution, using a $5 \mathrm{keV}, 1 \mu \mathrm{A}$ electron beam of $\approx 3$ $\mu \mathrm{m}$ diameter for excitation. Spectra were digitally acquired in integral mode from 0 to $2000 \mathrm{eV}$ at $1 \mathrm{eV} / \mathrm{step}$ using voltage-frequency-conversion detection. Spectra were taken in point mode at two discrete positions on the sample, and the average composition was calculated from these points for each sample. Compositions were calculated by using peak-to-peak height after 
differentiation using a smoothing quadratic derivative ${ }^{1-3}$ and standard handbook sensitivity factors. 4

Some samples were also analyzed by XPS, using a modified PHI 548/3027 system. Spectra were taken with a double-pass cylindrical mirror energy analyzer with an average detection angle of $45^{\circ}$ from the sample normal. Excitation was provided by a dual anode Aluminum source $(1486.6 \mathrm{eV})$ operated at $15 \mathrm{keV}$ and $600 \mathrm{~W}$, with an analysis area of about 2.5 $\mathrm{mm}$ diameter. Spectra were digitally acquired for survey, C 1s, O 1s, S 2p, Cl 2p, Si 2p, Ni 1s and $\mathrm{Cu} 2 \mathrm{p}$ regions simultaneously. With the exception of the survey region, each spectrum was acquired with a $50 \mathrm{eV}$ pass energy and $0.1 \mathrm{eV} / \mathrm{step}$. For the survey region, spectra were acquired at $100 \mathrm{eV}$ pass energy and $1.0 \mathrm{eV} / \mathrm{step}$. A linear background and contributions arising from extraneous X-ray satellites were subtracted from each spectrum. Each spectrum was then smoothed using a Savitzky-Golay convolution procedure ${ }^{1-3}$ of quadratic/cubic order. Binding energies were referenced by setting the $\mathrm{C} 1 \mathrm{~s}$ peak energy to $284.7 \mathrm{eV}$, appropriate for adventitious hydrocarbons (i.e. adsorbed hydrocarbon species) on the surface. ${ }^{5}$ Sample compositions were determined from peak areas using standard handbook sensitivity factors. 5

Table 3 lists the estimated detection limits and measurement errors for the atomic concentration determinations by AES. Detection limit values are in atomic percentages. Error values are listed as percentages of reported values. The detection limit is determined by calculating the minimum peak found by the automatic peak finding software algorithm, which is larger than spectral noise. The measurement errors are determined by calculating the effect of the combined errors due to spectral noise and uncertainty in sensitivity values. The spectral noise contributes little to no error to the measurement. AES error in atomic percent can be calculated for each value by multiplying the reported atomic percentages by the error percent.

The MESERAN Surface Analyzer was yet another technique that was used for cleanliness verification purposes. It provides one of the few non-destructive methods available for inprocess organic contaminant detection and measurement. ${ }^{6}$ The principle of operation is based on the technology of Evaporative Rate Analysis. It involves measuring the rate of evaporation of a carbon-14 tagged radioactive chemical from a surface by a Geiger counter. The Carbon-14 labeled radiochemical used in this process is "Exempt" from United States Nuclear Regulatory Commission licensing requirements. Past work at AS-KCD has indicated that MESERAN numbers less than 100 indicate good cleaning effectiveness (suitably clean surface). MESERAN numbers between 100 and 200 indicate moderate cleaning effectiveness (islands of contamination are present). MESERAN numbers greater than 200 indicate poor cleaning effectiveness (gross contamination is present). These cleanliness levels have been determined to correspond to electrical and adhesive failures. Electrical failures have been observed when MESERAN numbers were greater than $100.6^{6}$ Catastrophic adhesive failures have been observed when final MESERAN numbers were greater than 200.6 Direct measurement on production parts is possible. Generally, for direct measurements, this technique needs to be performed on flat or concave surfaces to achieve the best results. In-direct measurements via solvent extraction can be used on almost any type of parts.

Common practice for the MESERAN technique, has always been to use the radiochemical that is the most sensitive (best detects) for each contaminant being tested. ${ }^{6}$ Certain radiochemicals are used to best detect nonpolar residues, other radiochemicals are used to best detect slightly polar residues, and yet other radiochemicals are used to best detect polar residues. Sensitivity factor differences between each of the three radioactive solvents used in this study have never been calculated, but the differences are thought to be small. The slight differences that may exist between the radiochemical solvents have never been a problem in the past. The MESERAN Surface Analyzer has never been used to determine exact amounts of contamination. Instead, it has been used as a comparative technique to determine "go" or "no go" for evaluating and comparing cleaning methods and cleanliness levels needed to produce quality product. For example, this technique was one of the methods successfully used on the "W89 Fireset Study"8 as a screening tool for selecting an alternate cleaner replacement for trichloroethylene. 
In this study, the total counts method was used to analyze MESERAN data. ${ }^{6,7}$ This method involves counting the number of radioactive counts that reach the Geiger-Mueller detector for a given time period. Using the total counts method, residues can be defined down to approximately 50 nanograms $/ \mathrm{cm}^{2}$. For the tests performed in this evaluation, the time period was 112 seconds (a standard developed and used at AS-KCD for over 20 years). The degree of retention of the radioactive chemical is a measure of contamination present. The lower the number of radioactive counts for a given time period, the cleaner the surface. What is being looked at is the evaporative process of a radioactive labeled compound and not the labeling of the residue itself. When the radiochemical is deposited onto a clean surface, it evaporates quickly (30-40 seconds). As the radiochemical evaporates, the nitrogen flowing between the surface and the detector face sweeps away the volatilized radiochemical. The Geiger-Mueller detector assembly detects only the beta emissions of the radiochemical remaining on the surface. Therefore, regardless of whether there is any organic contamination or not, there will be a certain number of radioactive counts detected by the Geiger-Mueller detector assembly for a clean surface. When there is organic contamination on the surface, the radiochemical evaporates much slower because it dissolves into the preexisting organic contamination. Since evaporation of a molecule can only occur if that molecule exists in the surface layer, the higher the percentage of non-volatile molecules on the surface (organic contamination), the slower the rate of evaporation.

\section{Contact Angle Results and Discussion/OFHC Copper}

For statistical purposes, three (3) Cu coupons were tested for each condition to determine average contact angle measurements. The average contact angle and the standard deviation were calculated and are shown for each contaminant and cleaner in Table 4. Contact angle measurements were not performed for the two IPA cleaning processes. The overall average contact angle and standard deviation for the removal of all contaminants per cleaner is shown in bold. The contact angle results indicate, that in a few cases, Micro Cleaner cleaned specific contaminants better than the TCE process. However, none of the candidates, including Micro Cleaner, cleaned all of the contaminants as well as the TCE baseline cleaning process. An average contact angle of $25.0^{\circ}$ was recorded for the removal of all contaminants using the TCE baseline process and an average of $26.9^{\circ}$ was recorded for the Micro Cleaner process. The next best cleaners in order of efficiency, were, Daraclean $282\left(33.0^{\circ}\right)$, Igepal $710\left(35.7^{\circ}\right)$, Oakite NST $\left(36.8^{\circ}\right)$, Brulin 815GD $\left(38.6^{\circ}\right)$, Daraclean $212\left(45.0^{\circ}\right)$ and Daraclean $235\left(46.8^{\circ}\right)$. With the exception of Daraclean 282 and TCE, standard deviations were relatively high. For comparison purposes, the average contact angle measurement of $\mathrm{Cu}$ coupons prepared by degreasing with TCE and IPA and etched with concentrated $\mathrm{H}_{2} \mathrm{SO}_{4}$ (prior to contamination) was $\sim 18^{\circ}$. This value represented a clean uniform surface prior to contamination. Contact angle data are shown in Table 4 and in Figures 1-8.

\section{Contact Angle Results and Discussion/Aluminum 1100}

Contact angle measurements on aluminum 1100 were not performed until the candidate cleaners chosen for this study had been narrowed down to Brulin 815GD, Oakite NST and Daraclean 212. The average contact angle measurement for aluminum 1100 after precleaning and prior to application of the lubricants was $26.5^{\circ}$ with a standard deviation of $6^{\circ}$. The average contact angle measurements for the TCE cleaning process were very sporadic and ranged from $15.0^{\circ}$ to $64.3^{\circ}$, depending on the contaminant being removed (Table 5). Some lubricants proved to be harder to remove than others. The contact angle measurements for Brulin 815GD and Oakite NST were significantly better than the TCE cleaning process and the pre-clean measurements. The numbers ranged from $1.6^{\circ}$ to $11.0^{\circ}$ for Brulin $815 \mathrm{GD}$ and $6.8^{\circ}$ to $22.6^{\circ}$ for Oakite NST. The standard deviations for Brulin and Oakite were much tighter on aluminum 1100 than they were for OFHC Cu. It appears that Brulin 815GD and Oakite NST are slightly etching or polishing the aluminum surface so that bare metal is exposed and is thus yielding better contact angle measurements. Aluminum is normally not as thermodynamically stable as 
copper in a basic solution. All the other cleaners were not tested. Contact angle data for aluminum 1100 can be seen in Table 5 .

\section{Auger Analysis Results \& Discussions}

AES was used to analyze contaminants on 0.39 " square $\mathrm{Cu}$ coupons. A representative AES spectrum is included as Figure 9. From the Auger spectra, atomic composition of the surface species were calculated and can be seen in Tables 6-16. The average elemental residue by cleaner can be seen in Table 17. For each cleaner, stacked bar graph series plots (Figures 11-21) were made from the atomic compositions after cleaning as a function of lubricant. The legend for these plots is included as Figure 10. For comparison, the results for pre-cleaned $\mathrm{Cu}$ before any contaminants were used appears as the leftmost bar on each plot. A solid horizontal line at $60 \%$ gives an indication of the relative cleanliness related to pre-cleaned $\mathrm{Cu}$. From these graphs, it can be seen that the cleaners remove the different lubricants to varying degrees. The degree of variation in total contamination for each cleaner is calculated by taking the standard deviation across all lubricants for each atomic contaminant and averaging across all contaminants. The resulting number (variability index) gives a measure of consistency in cleaning and is plotted versus cleaner in Figure 22. The higher the number, the less uniformly a cleaner performs over the entire range of lubricants in this study. This number does not, however, tell how well overall a cleaner cleans, but only shows the degree of variations from sample to sample. Daraclean 235, Daraclean 212, Daraclean 282, IPA ultrasonic/vapor, and Oakite NST, are the most consistent across all lubricants in this study, while Armakleen 2001A, TCE, and Igepal 710 have the worst variability in cleaning effectiveness. Brulin $815 \mathrm{GD}$, Micro Cleaner, and IPA/Cyclohexane immersion/vapor are midrange in this scale.

The samples cleaned with the IPA and IPA/Cyclohexane processes were not handled the same way following contamination as the other sets of samples. These samples were contaminated at SNL, sent to S \&K Products Inc. to be cleaned and were left in shipping containers for approximately two weeks before degreasing. This prolonged exposure to the water-based lubricants led to visual oxidation of several samples and caking of Ivory Snow residue on the sample cleaned with the IPA/Cyclohexane immersion/vapor process. This sample was subsequently not analyzed by AES. Therefore, the elemental surface analysis results were not available for this sample and not used in further averaging calculations.

The Auger elemental atomic percentages of contaminant species were averaged over all lubricants for each cleaner and a separate graph was made for each element. These graphs show the average residues for all contaminants found in this study as a function of the cleaning process. The order of the cleaners were sorted by decreasing copper percentage with the most copper seen on the left (most clean) and the least on the right. This ordering ranks the cleaners in order of overall effectiveness. As seen, five cleaners in this study are better than TCE (Figures 26-34). It should be noted that the percentages of sulfur, oxygen, and silicon seem to increase with increasing copper. Conversely, carbon and nitrogen decrease with increasing copper.

Sodium, chlorine and barium do not show a trend with copper. Aqueous cleaners usually consist of sulfur-containing amine or silicon-containing ions. Therefore, it may be that the silicon-based cleaners generally clean better or leave less residue than amine-based cleaners.

From the plots, some observations can be made: Daraclean 282 leaves the most sulfur (4.4\%) (Fig. 34). Oakite NST, Armakleen E2001A, Micro, and Brulin 815GD leave roughly four times less sulfur than Daraclean 282. All the other cleaners leave $0.8 \%$ or less sulfur. TCE leaves the most chlorine behind (3\%) probably as residue from unevaporated solvent (Fig. 28). All other cleaners leave little to no chlorine (less than 0.5\%). Daraclean 212, Daraclean 235 and IPA ultra/vapor leave the most nitrogen (Fig. 30) (4-5\%). The nitrogen in the Daraclean cleaners could be due to amines from the cleaners. The IPA process should leave no nitrogen, and the nitrogen seen could be due to impurities in the IPA bath or improper sample handling. Armakleen E2001A has the most oxygen (13\%) and silicon (15\%) (Figs. 37 and 32). Brulin 815 GD leaves a little silicon $(<1 \%)$. A representative sample cleaned by Armakleen E2001A was further analyzed by XPS to determine the chemical composition of the silicon and oxygen seen by AES. The AES plot (Fig. 23) shows the presence of silicon while the XPS regions 
reveal the types of oxygen and silicon present (Figs. 24 and 25). The black bars at the top of the XPS spectra correspond to reported peak energies. The oxygen present could be from silicones, silicates, and $\mathrm{Cu}^{+2}$; with some $\mathrm{H}_{2} \mathrm{O},(\mathrm{CuOH})_{2}$ or $\mathrm{CuO}$ also present. The silicon present is probably due to silica, silicates, or silicones. These results suggest the presence of silicates commonly used in aqueous cleaners which were not fully rinsed off. Cook's S697 is the only lubricant with barium containing rust inhibitors. TCE leaves the most barium (2\%) on the surface contaminated with Cook's S697 (Fig. 26). All the other cleaners leave no detectable barium. Since most of the cleaners are ion-based aqueous detergents, it is not surprising that sodium is often present (Fig. 33). IPA and IPA/Cyclohexane vapors show significant amounts of sodium. This contamination could be due to fingerprints caused by improper handling of the specimens or sodium contaminated vapors. Other than the vapor cleaners, Brulin $815 \mathrm{GD}$ leaves the most average sodium residue $(0.1 \%)$, with Oakite NST as second $(0.1 \%)$, but since each individual data point is less than $0.4 \%$, the peaks seen could be noise in the Auger spectra and therefore negligible.

The $\mathrm{pH}$ of each cleaner was plotted in order of decreasing copper percentages with the most copper seen on the left (most clean) and the least on the right (Figure 35). Note that the organic cleaners TCE, IPA vapor, and IPA/Cyclohexane vapor are given an artificial $\mathrm{pH}$ value of 7.0 in order to have a place on the plot. The $\mathrm{pH}$ values recorded for each of the aqueous cleaners represent measured $\mathrm{pH}$ values. As seen, the cleaners that are more effective than TCE have $\mathrm{pH}$ values from $9.5-11.5$, while those that are less effective than TCE have $\mathrm{pH}$ 's in the range of 7.3 - 8.1. A plot of pH versus copper percentage (or average effectiveness) is shown in Fig. 36. A least squares fitted line using all data points except the artificial $\mathrm{pH} 7.0$ values and the $\mathrm{pH} 11.5$ point is shown. Obviously, there is a general linear dependence shown. The trend shows that the higher the $\mathrm{pH}$, the better the cleaner for lubricants on copper.

The Auger elemental atomic percentages were averaged by element over cleaners for each lubricant, and a separate graph was made for each element seen, ordered by decreasing copper. (Figures 37-45) These graphs show the average cleaning effectiveness for each elemental constituent averaged over all the cleaners by lubricant. Cimtap stands out as leaving the most sulfur and chlorine. Cook's S697 and Cimtap leave more nitrogen than any of the other lubricants. As expected, Cook's S697 is the only lubricant to leave barium. H\&B Lard-Mineral Oil and Ivory Snow-Lanolin leave the most sodium and Ivory Snow-Lanolin leaves the most silicon. From the copper plot it can be seen that Ivory Snow-Lanolin is the easiest to clean, while Cook's S697 is the most difficult to clean in this study. The rest of the lubricants have approximately the same difficulty in cleaning.

\section{Auger Analysis Recommendations}

The top five cleaners, which all cleaned better than TCE, were Armakleen E2001A, Brulin 815GD, Micro Cleaner, Oakite NST, and Daraclean 282. Because of problems arising in subsequent processing of parts with residual sulfur and silicon (in the form of silicates), Daraclean 282 and Armakleen E2001A are not recommended.

\section{MESERAN Study Results and Discussions}

Before actual test samples were studied, SNL/NM contaminated clean aluminum panels with the above mentioned contaminants and sent them to AS-KCD, so appropriate radioactive solvents could be chosen. As mentioned previously, common practice has been to always use the radiochemical that is most sensitive (best detects) for each contaminant being tested. Three different radioactive solvents were found to be the best for these specific contaminants. Radioactive solvent BK (n-tridecane-1,13-C14 in cyclopentane) was found to be the best radioactive solvent for detecting Cook's Draw 4625, Cook's Cool 4639D, Cook's Cool S697, 3B Oil, and H\&B 50\% Lard/50\% Mineral Oil. Radioactive solvent AK $(1,1,2,2-$ tetrabromoethane-1,2-C14 in cyclopentane) was found to be the best radioactive solvent for detecting Ivory Snow/Lanolin and Boelube. Radioactive solvent AM (1,1,2,2-tetrabromoethane$1,2-\mathrm{C} 14$ in methanol) was found to be the best radioactive solvent for detecting Cimtap. 
In the process of determining final MESERAN numbers, a background test was performed prior to every test to determine the background radiation per second on the sample. This background radiation was automatically subtracted via the computer operated testing program. In addition, several clean standard measurements were made on known clean substrates of the same material as that being used in the study (in this case aluminum panels) with each of the radiochemicals being used for the evaluation. These clean standard measurements were averaged to determine the average number of radioactive counts that were obtained on a known clean surface for each of the radiochemicals. The average clean standard was then subtracted from the raw data measurement made on the sample being tested to obtain the final MESERAN number. For example, let's say that the average clean standard for a particular radiochemical is 142 radioactive counts. The raw data minus the background for the sample being tested is 189 . Therefore, the final MESERAN number would be $189-142=47$. This value would indicate that the sample is suitably clean based upon the method used at AS-KCD.

Final MESERAN numbers for Daraclean 212, Daraclean 235, Daraclean 282 and Brulin 815GD were determined by calculating the difference between the raw data and clean standards where no visual etching of substrates was observed. Clean standards are obtained by cleaning virgin aluminum panels using the precleaning process previously described. Because the MESERAN numbers can be affected by surface roughness, panels free from scratches are always chosen.

This method for determining final MESERAN numbers was not acceptable for the samples cleaned with Igepal CO-710, Oakite NST, and Micro Cleaner. These cleaners slightly etched the aluminum panels (etching not uniform) such that another method of calculating the final MESERAN numbers had to be used. After the raw data was obtained from the slightly etched panels, the panels were recleaned using a TCE ultrasonic/vapor degreasing process and retested with the MESERAN Surface Analyzer in the exact same spots as before to obtain accurate clean standard numbers. MESERAN data indicates that the numbers were always lower after cleaning with TCE than they were before (note that they were tested in the exact same spot). These clean standard numbers were then subtracted from the raw data to obtain the final MESERAN numbers.

The MESERAN data exhibits larger computed standard deviations (denoted by s) than might be expected when compared to the overall mean level of the data. This is based on the fact that the data has had a standard background value subtracted from the observed count value and the true standard deviation of the original data values should be at least the square root of the mean of the data. The subtraction does not change the standard deviation value that will be computed except when negative values are replaced with zeros. In this case, the value of $\mathbf{s}$ decreases.

There are three major characteristics to consider in the standard deviations of the MESERAN data: (1) the data is derived from counts from a radioactive source. Such data theoretically has a standard deviation equal to the square of the mean. That is, if the mean value is 100 counts, then the standard deviation is $s=10$; if the mean is $400, s=20$, (2) a data item $Z$, is computed as $\mathrm{Z}=\max (0, \mathrm{Y}-\mathrm{S})$, where $\mathrm{Y}$ is the part reading and $\mathrm{S}$ is the background standard for the day. If the Z's have any zeros, their standard deviation will be too small. In fact, if all (five) $Z$ 's are zero except one (which is equal to $m$, say), then $s=m / 5$. If all are zero, $s=0$ because the original data is less than the background, and (3) the standard deviation, $s$, will be larger than that predicted in 1, above, to account for differences from part to part and within parts. If the cleaning is only moderate, there may be islands of contamination which will increase the variability in the readings.

Table 18 shows the MESERAN data for the TCE cleaned samples. All MESERAN values shown were obtained by subtracting the clean standards from the raw data. TCE was able to sufficiently remove all of the contaminants from all of the samples. The average MESERAN number for all of the samples was 11.00 and the average standard deviation was 10.35 .

Table 19 shows the MESERAN data for the Igepal CO-710 cleaned samples. The Igepal CO-710 cleaning process appeared to slightly etch or stain the aluminum panels. Therefore, after the raw data was obtained, the panels were re-cleaned using a TCE ultrasonic cleaning/vapor 
degreasing process followed by a vacuum bake at $165^{\circ} \mathrm{F}$ for 1 hour and retested in the exact same spots to obtain clean standards. Igepal CO-710 was unable to sufficiently clean one of the Cook's Draw 4625 samples and one of the Cook's Cool 4639D samples. All of the other samples were sufficiently clean, however most were not as clean as the TCE baseline. The average MESERAN number for all of the samples was 32.78 and the average standard deviation was 24.61 .

Table 20 shows the MESERAN data for the Daraclean 212 cleaned samples. Daraclean 212 was able to sufficiently remove all of the contaminants from all of the samples. The average MESERAN number for all of the samples obtained by subtracting the clean standards from the raw data was 10.03 and the average standard deviation was 11.47. Table 21 shows the MESERAN data for the Daraclean 235 cleaned samples. Daraclean 235 was able to sufficiently remove all of the contaminants from all of the samples. The average MESERAN number for all of the samples obtained by subtracting the clean standards from the raw data was 29.90 and the average standard deviation was 14.87 .

Table 22 shows the MESERAN data for the Daraclean 282 cleaned samples. All of the samples were sufficiently clean, however several were tending towards the moderately clean level. The average MESERAN number for all of the samples obtained by subtracting the clean standards from the raw data was 35.75 and the average standard deviation was 24.66.

Table 23 shows the MESERAN data for the Brulin 815GD cleaned samples. Brulin $815 \mathrm{GD}$ was able to sufficiently remove all of the contaminants from all of the samples. The average MESERAN number for all of the samples obtained by subtracting the clean standards from the raw data was 24.78 and the average standard deviation was 13.52 .

Table 24 shows the MESERAN data for the Micro Cleaner cleaned samples. The Micro Cleaner cleaning process appeared to severely etch the aluminum panels. Therefore, after the raw data was obtained, the panels were re-cleaned using the TCE cleaning process described for Igepal CO-710 to obtain clean standards. Micro Cleaner was unable to sufficiently clean two of the 3-B Oil samples. All of the other samples were sufficiently clean, however several of them (especially the Cook's Draw 4625 samples) were tending towards the moderately clean level. The average MESERAN number for all of the samples was 37.03 and the average standard deviation was 27.26 .

Table 25 shows the MESERAN data for the Oakite NST cleaned samples. The Oakite NST cleaning process appeared to moderately etch the aluminum panels. Therefore, after the raw data was obtained, the panels were re-cleaned as before using the same TCE cleaning process described for Igepal and Microcleaner to obtain clean standards. Oakite NST was unable to sufficiently clean one of the Cook's Draw 4625 samples, one of the Cook's Cool 4639D samples, and one of the Ivory Snow/Lanolin samples. All of the other samples were sufficiently clean, however a few of them were tending towards the moderately clean level. The average MESERAN number for all of the samples was 44.45 and the average standard deviation was 51.36 .

Table 26 shows the MESERAN data for the IPA cleaned samples. IPA was able to sufficiently remove all of the contaminants from all of the samples, however one of the Cook's Draw 4625 samples was tending towards the moderately clean level and most of the samples were not as clean as the TCE baseline. The average MESERAN number for all of the samples was 33.46 and the average standard deviation was 15.62. Table 27 shows the MESERAN data for the IPA/Cyclohexane cleaned samples. IPA/Cyclohexane was unable to sufficiently clean any of the Ivory Snow/Lanolin samples, however it did remove all of the other contaminants from all of the samples. The average MESERAN number for all of the samples was 87.54 and the average standard deviation was 45.70 .

Table 28 shows a compilation of the average MESERAN numbers, average standard deviations, and the number of dirty samples for each of the cleaners tested.

Igepal CO-710, Oakite NST, and Micro Cleaner all etched the aluminum panels. Because aluminum is one of the metals used during the fabrication of switch tubes and will come into contact with the cleaner chosen, Igepal CO-710, Oakite NST, and Micro Cleaner should not be 
used. In addition, none of these aqueous cleaners were able to effectively remove all of the contaminants from all of the samples.

Only TCE, Daraclean 212, Daraclean 235, Brulin 815GD, and IPA were able to effectively remove all of the contaminants from all of the samples. All of these cleaners and the cleaning processes used appear to be acceptable for replacing TCE in the removal of the contaminants in question. However, only Daraclean 212 performed as well as or better than TCE. Brulin 815GD and Daraclean 235 were the next best cleaners. IPA was able to sufficiently remove all of the contaminants from all of the samples, however one of the samples was tending towards the moderately clean level and most of the samples were not as clean as the TCE baseline.

There is some question as to why IPA was able to remove all of the contaminants and $80 \%$ IPA/20\% Cyclohexane was unable to remove the Ivory Snow/Lanolin contaminant. The primary reason for the difference in cleaning effectiveness between IPA and $80 \%$ IPA/20\% Cyclohexane is the cleaning processes used. The IPA cleaning process consisted of ultrasonically cleaning the panels in boiling IPA $\left(190^{\circ} \mathrm{F}\right)$ for 3 minutes followed by IPA vapor degreasing for 45 seconds. The IPA/Cyclohexane cleaning process consisted of immersing the panels in boiling IPA/Cyclohexane for 3 minutes followed by IPA/Cyclohexane vapor degreasing for 45 seconds. The IPA/Cyclohexane cleaning process is not as aggressive as the IPA cleaning process. Ultrasonic cleaning is much more aggressive than boiling sump immersion. If the IPA/Cyclohexane cleaning process had used ultrasonics like the IPA cleaning process, the Ivory Snow/Lanolin contaminant would probably have been removed.

Another reason for the difference in contaminant removal between IPA and the IPA/Cyclohexane mixture could be because the Ivory Snow/Lanolin contaminant is a polar material. IPA is polar and Cyclohexane is non polar. In theory, the addition of Cyclohexane should allow the IPA/Cyclohexane mixture to do a better job of removing non polar contaminants and the MESERAN results bear that out. However, the addition of Cyclohexane to the IPA will decrease its cleaning effectiveness for polar contaminants like Ivory Snow/Lanolin.

The following observation should be noted regarding the IPA and the IPA/Cyclohexane cleaning processes. Both processes involve immersing the panels in boiling solvent for 3 minutes prior to a 45 second vapor degrease. Since the panels are immersed in the boiling solvent, they will heat up and approach the temperature of the boiling solvent. In this case, after 3 minutes the panels were probably at or very near the temperature of the boiling solvent. Therefore, when they were placed in the vapor zone for 45 seconds no (or very little) cleaning actually took place. Vapor degreasing occurs by the hot solvent vapors condensing on a cooler substrate until the substrate reaches the temperature of the solvent vapors. When the substrate reaches the same temperature as the solvent vapors no further condensation takes place. In essence, these evaluations tested ultrasonic cleaning with boiling IPA versus IPA/Cyclohexane boiling sump immersion.

Another observation should be noted regarding the IPA/Cyclohexane cleaning process. S\&K Products International Inc. performed the IPA and the IPA/Cyclohexane cleaning processes. When vapor degreasing with an IPA/Cyclohexane mixture, the azeotropic mixture (67\% Cyclohexane and 33\% IPA) should be used. However, S\&K used an 80\% IPA and 20\% Cyclohexane mixture. This mixture is not an azeotrope. In cases such as this, the mixture will initially boil at the boiling point of the lowest boiling component (Cyclohexane) until all of it is boiled off and only the higher boiling component (IPA) remains. Considering the sample size, it is fair to assume that the Cyclohexane did not completely boil off during the time the samples were cleaned. Therefore, only Cyclohexane vapors were created. As was stated previously, since the panels were already at the boiling temperature of the solvent during the boiling sump immersion step, no actual vapor degreasing took place when the panels were suspended in the vapor zone.

\section{Recommendations/MESERAN Study}

It appears from the MESERAN study that Daraclean 212 would be the best choice to replace TCE for removing the contaminants in question from switch tube assemblies. It provided the best and most consistent results. Brulin 815GD and Daraclean 235 also appear to be 
acceptable choices. IPA may be acceptable, but definitely did not perform as well as TCE. IPA/Cyclohexane may be acceptable, but it should be evaluated using the azeotropic mixture in ultrasonics followed by vapor degreasing to determine its actual effectiveness. In addition, all processes using ultrasonics followed by vapor degreasing should be performed in ultrasonic baths at temperatures cooler than the boiling solvent so that when the samples are placed in the vapor zone, vapor degreasing actually takes place.

\section{Etch Rate Study/Inductively Coupled Plasma-Atomic Emission Spectroscopy}

The aqueous alkaline cleaners that were studied as potential candidates for TCE replacement ranged in $\mathrm{pH}$ from $\approx 7.5-12$. Concern was expressed that the higher $\mathrm{pH}$ cleaners would etch some of the various metals. We have documented in a previous study (W89 Fireset Study), that preferential etching of tin-lead surfaces occurs after cleaning with a monoethanolamine (a common constituent found in alkaline aqueous cleaners) based cleaner. ${ }^{8}$ Aluminum is another metal particularly susceptible to etching. In this case study, we studied the etch rate of each of the aqueous cleaners on Aluminum 1100 using inductively coupled plasmaatomic emission spectroscopy (ICP-ES).

The Al 1100 samples (0.39")were degreased with TCE followed by a surface preparation with a non-etch solution, then deoxidized with an acid etch. After rinsing with deionized water, the coupons were transferred to polypropylene vials containing the cleaning solution. Each cleaner was tested in triplicate. Three coupons were transferred to glass vials as a control set and TCE was added to these vials. The vials containing the alternate solutions were capped and ultrasonically cleaned for 30 minutes at $135^{\circ} \mathrm{F}$. The solutions were cooled to room temperature and analyzed for Al content using ICP-ES.

The first two columns of Table 29 show the results of analysis for each cleaning solution before exposure (virgin solution) and after exposure, as parts-per-million $(\mu \mathrm{g} / \mathrm{mL})$. The quantity of $\mathrm{Al}$ etched per coupon was then calculated from the solution volume, and the etch rate was calculated as mils/minute based on a $2 \mathrm{~cm}^{2}$ surface area and 30 minutes exposure $(1 \mathrm{mil}=0.001$ inch). As shown, the Al concentrations determined in the majority of the cleaners after 30 minutes were less than 1-part-per-million. Measurable values were determined for two of the cleaners (10\% Micro Cleaner \& 10\% Oakite NST). The measurable values obtained for both these solutions were considered insignificant. These results can be considered as semiquantitative with uncertainties on the order of $100 \%(2 \mathrm{X})$.

\section{Cleaner Down-Selection Process}

Two cleaners (Brulin 815GD \& Oakite NST) were identified as the best choices for further materials compatibility evaluations, based mainly on the cleaning efficacy results. The rest of the aqueous cleaners (Daraclean 282, Armakleen E2001A, Daraclean 212, Daraclean 235, Micro Cleaner, and Igepal CO-710) were eliminated during the course of the study for various reasons. For example, Auger analysis indicated that although Daraclean 282 cleaned as well as or better than TCE, it left significant amounts of sulfur residue behind. Sulfur is considered a high risk residue (that can potentially cause electrical shorts) in the assembly of a switch tube and consequently Daraclean 282 was eliminated from consideration. Similarly, Armakleen E2001A was eliminated after significant amounts of silicates were observed. As with sulfur, silicates are unwanted residues that can affect subsequent bonding operations. Chlorine residues are also undesirable and can lead to corrosion problems under the right temperature \& humidity situation. Ironically, TCE (a solvent that has traditionally been used for many years within the DOE complex) left significant amounts of chlorine behind.

Auger results also indicated that overall, Daraclean 212 and Daraclean 235 did poorly, relative to the other cleaners, while Brulin $815 \mathrm{GD}$, Oakite NST, Micro Cleaner and Igepal CO710 performed well, without leaving unwanted residues. On the other hand, the MESERAN study indicated that Daraclean 212 was the best choice for replacing TCE with Brulin 815GD and Daraclean 235 also being acceptable choices. Contact angle measurements on OFHC Cu indicated that Micro Cleaner performed the best while Daraclean 235 performed the worst. 
Because Daraclean 235 did not do well on either the Auger analysis or the $\mathrm{Cu}$ contact angle study, it was dropped from the study. An experiment was conducted at this point to determine how well Brulin 815GD, Oakite NST and Daraclean 212 cleaned the various lubricants from aluminum 1100. Contact angle measurements on aluminum 1100 indicated that Brulin $815 \mathrm{GD}$ and Oakite NST cleaned the lubricants better than TCE, while Daraclean 212 performed poorly. Daraclean 212 was eliminated from the study because of poor performance in both the Auger study and the aluminum contact angle study.

In the Etch Rate Study, a measurable etch rate was noted on aluminum 1100 samples after ultrasonically cleaning with Micro Cleaner and Oakite NST. While this etch rate was measurable, it was considered insignificant at the time, and did not necessarily eliminate Micro Cleaner or Oakite NST from further consideration. As mentioned before, contact angle measurements on OFHC Cu indicated that Micro Cleaner cleaned as well as or better than TCE, however, severe visual etching of aluminum 6061 was noted during the MESERAN study. Moderate to severe etching was also noted during the MESERAN study after use of Oakite NST and Igepal CO-710. Micro Cleaner and Igepal CO-710 were eliminated from the study because of etching problems seen during the Etch Rate Study and because of obvious visual etching seen in the MESERAN Study. Oakite NST was also eliminated from the study after visual etching during the MESERAN Study was detected. Oakite NST, however, was not eliminated until after most of the materials compatibility studies had been performed. The IPA and IPA/Cyclohexane processes were not considered further because of flammability concerns associated with IPA and because of the expensive equipment that is necessary to house the solutions. The down-selection process left only Brulin $815 \mathrm{GD}$ without a bad mark against it.

\section{Materials Compatibility Tests}

The effect of the candidate solutions on the materials that make-up the switch tube assembly was considered next. Two different materials compatibility experiments were performed. The first experiment was an immersion test, whereby different materials (Gold, Kapton, Sn60-Pb40 Solder, Alumina, Aluminum, Copper, Kovar, Palco, Molybdenum, Niobium) were exposed for 17 hours in the candidate solutions. This experiment was conducted to determine the effect of Brulin 815GD and Oakite NST on the different materials that comprise the switch tube assembly. TCE was run as a baseline. Briefly, samples were precleaned with IPA and blown dry with filtered dry nitrogen before being immersed in the candidate solutions. Weight measurements (in triplicate) were taken before and after immersion, with a Mettler AE 260 Delta Range Balance that is sensitive to $0.1 \mathrm{mg}$. The average weight was calculated before and after being immersed and the differential was recorded. If significant weight changes are measured, this normally indicates that a reaction has taken place between the substrate and cleaner, such as etching of a metal surface or swelling of an organic material. If this occurs, the cleaner is typically not compatible with the substrate. Weight measurements (for most of the materials) after immersion indicated insignificant weight changes. One significant weight gain was noted when Kapton was immersed in TCE. The Kapton apparently absorbed the TCE and retained the TCE. A dulling of appearance of $\mathrm{Sn60-Pb40} \mathrm{was} \mathrm{noted} \mathrm{after} \mathrm{use} \mathrm{of} \mathrm{Brulin} \mathrm{815GD}$ and Oakite NST. Before immersion, the $\mathrm{Sn} 60-\mathrm{Pb} 40$ solder was bright and shiny. After immersion, one side of the Sn60-Pb40 sample looked dull and the other side looked bright and shiny. The Sn60-Pb40 samples had been placed in a vial so that one side of the sample was in contact with the solution and the other side was lying flat on the bottom of the container. It is possible that the side lying flat on the bottom of the vial was completely masked from the solution and therefore remained bright and shiny. Data can be seen in Tables 30-39. The average percent weight change for each metal by cleaner is shown in Table 45.

A second experiment was conducted, whereby the materials (Palco, Aluminum, Molybdenum, Kovar, 304L Stainless Steel, Sn60-Pb40 solder, Kapton, Alumina) were exposed to TCE, Brulin 815GD and Oakite NST for periods that would simulate an actual cleaning procedure. The samples, as before, were pre-cleaned with IPA and blown dry with filtered dry nitrogen. After inspection, the samples were weighed 3 successive times to obtain an average weight. The samples that were cleaned with Brulin 815GD and Oakite NST, were ultrasonically 
cleaned for 10 minutes (at the manufacturer's prescribed temperature; Brulin $815 \mathrm{GD}=135^{\circ} \mathrm{F}$ and Oakite NST $=120^{\circ} \mathrm{F}$ ), rinsed for 2 minutes with flowing deionized water, rinsed ultrasonically for 30-60 seconds in IPA, and blown dry with filtered dry nitrogen. The samples that were cleaned with TCE, were vapor degreased $\left(189^{\circ} \mathrm{F}\right)$ for five minutes, ultrasonically cleaned at ambient for five minutes and blown dry with filtered dry nitrogen. The results for this experiment indicate that there were no significant weight changes. Dulling of the tin-lead solder was once again noted after use of Brulin 815GD and Oakite NST. Results of the cleaning procedure study can be seen in Tables 40-44. The average percent weight change for each metal by cleaner is shown in Table 46.

\section{Summary}

As part of an Environmentally Conscious Manufacturing (ECM) program, eight aqueous alkaline cleaners and an IPA and IPA/Cyclohexane cleaning process were studied as potential replacements for TCE, for cleaning switch tube piece parts. Machining type lubricants were identified as the main contaminants. The majority of the materials that are in a switch tube assembly are metal. All aqueous cleaning processes were performed at SNL using ultrasonic cleaning. The IPA and IPA/Cyclohexane cleaning processes were performed at S\&K Products Inc.

The cleaning effectiveness of each cleaner versus TCE was determined using contact angle measurements, Auger and XPS analysis and MESERAN Surface Analysis. The candidate cleaners were narrowed down to two final cleaners (Brulin 815GD and Oakite NST) for further materials compatibility studies. Materials compatibility studies (i.e. weight gain/weight loss measurements) did not reveal any major concerns with either cleaner. Visually, none of the materials reacted with Brulin $815 \mathrm{GD}$ or Oakite NST, with the exception of the tin-lead. Dulling of tin-lead surfaces (probably due to micro etching) was apparent. A study to determine the etch rate of each of the aqueous cleaners was conducted using Inductively Coupled Plasma/Atomic Emission Spectroscopy. Measurable amounts of micro etching were noted for Oakite NST and Micro Cleaner, but the rates were considered insignificant.

Corrosion rates of some of the metals used in the switch tube were determined using thermodynamic stability references. From these sources, a limited amount of data was obtained. No concerns were raised on any of the metals that were found in these sources. No kinetic information was available.

Other factors such as waste disposal, recycling, worker safety and cost were considered in the final selection of the candidate cleaner. These factors along with cleaning efficacy, materials compatibility, etch rate, corrosion, etc., helped us select Brulin 815GD as the best choice. Brulin $815 \mathrm{GD}$ was recommended as one of the best cleaners in two out of the three cleaning efficacy studies (Auger \& MESERAN). It also performed well in the contact angle study on aluminum 1100 , it fared well in the etch rate study, there were no materials compatibility problems associated with it (other than micro etching of $\mathrm{Sn}-\mathrm{Pb}$ solder) and it did not leave any undesirable residues behind.

Brulin $815 \mathrm{GD}$ is considered a biodegradable cleaner. It contains no hazardous chemical substances at $1.0 \%$ or more listed in the NTP Annual Report on Carcinogens. It is a nonflammable cleaner that is readily recycled. It works as a splitter type cleaner whereby it has a greater affinity for the surface that it's cleaning than the contaminant itself and therefore undercuts the soil and removes it from the surface. Once cleaning has been completed, the lighter soils that are removed rise to the top of the surface and can subsequently be manually swept away with a belt skimmer while the heavier soils will settle to the bottom where they can be collected in filters. This allows one to recycle the same solution over and over again without radically depleting the alkaline source. When Brulin 815GD does eventually become spent and needs to be replaced, the Water Quality Department at SNL has given us permission to dispose of it down the drain, as long as the heavy metals have been filtered out and the $\mathrm{pH}$ is kept between 5 and 11. The measured $\mathrm{pH}$ of Brulin 815GD in concentrate form at room temperature is 11.5 . At $10 \%$ by volume, the $\mathrm{pH}$ was measured at 11.2 at room temperature and 10.4 at $135^{\circ} \mathrm{F}$. The cost of Brulin 815GD ( $\$ 12.70 /$ gallon) is almost six times less than TCE which sells for 
$\$ 74.50 /$ gallon. The fact that Brulin $815 \mathrm{GD}$ can be used more than once if desired, coupled with it being used in a $10 \%$ by volume solution, will reduce the use price even further.

Brulin 815GD will be prototyped in early 1995 at EG\&G Salem, where switch tubes are currently built. A special "lot" of switch tubes will be built via the recommended cleaning process using Brulin 815GD. This "lot" will be subjected to extensive aging and compatibility tests that include thermal cycling and humidity exposures. Concurrently, electrical and functional tests will be conducted to determine the integrity of the new process.

\section{ACKNOWLEDGEMENTS}

The authors would like to acknowledge the work of Martin Montoya of Sandia National Laboratories and Garth Christoff of Allied Signal/Kansas City Division. 


\section{References}

1. A. Savitzky and M. J. E. Golay, Smoothing and Differentiation of Data by Simplified Least Squares Procedures, in Anal. Chem., vol. 36, pp. 1627-1639, 1964.

2. J. Steinier, Y. Termonia and J. Deltour, Comments on Smoothing and Differentiation of Data Simplified Least Square Procedure, in Anal. Chem., vol. 44, pp. 1906-1909, 1972.

3. H. H. Madden, Comments on the Savitzky-Golay Convolution Methods for Least Squares Fit Smoothing and Differentiation of Digital Data, in Anal. Chem., vol. 50, pp. 13831386, 1978.

4. L. E. Davis, M. C. MacDonald, P. W. Palmberg, G. E. Riach and R. E. Weber, Handbook of Auger Electron Spectroscopy, $2^{\text {nd }}$ edition. Perkin-Elmer Corporation, Eden Prairie, Minnesota, 1978.

5. C. D. Wagner, W.M. Riggs, L. E. Davis, J. F. Moulder and G. E. Muilenberg (Editor), Handbook of X-ray Photoelectron Spectroscopy. Perkin-Elmer Corporation, Eden Prairie, Minnesota, 1979.

6. L. C. Jackson, Contaminant Cleaning for Critical Electrical Assembly Areas, (Final Report), UNCLASSIFIED, Allied Signal Inc., Kansas City Division: BDX-613-1695, February, 1978, (Available from NTIS).

7: J. L. Anderson, et. al. "Measurement and Evaluation of Surfaces and Surface Phenomena by Evaporative Rate Analyses." Journal of Paint Technology, Volume 40, Number 523, August, 1968, pp. 320-327.

8. G. J. Meier, "MC4069 Firing Set Chlorinated, Fluorinated Solvent Substitution" (Topical Report on 705914), Allied Signal Inc., Kansas City Division: KCP-613-4987, February, 1993. 
Table 1 - Contamination of Samples

\begin{tabular}{llllll}
$\begin{array}{l}\text { Analytical } \\
\text { Method } \\
\text { Used }\end{array}$ & $\begin{array}{l}\text { Substrate } \\
\text { Material }\end{array}$ & $\begin{array}{l}\text { Total \# of } \\
\text { Samples } \\
\text { Cleaned } \\
\text { per Solution } \\
\text { Volume }\end{array}$ & $\begin{array}{l}\text { Total Amt. of } \\
\text { Contamination } \\
\text { Applied }\end{array}$ & $\begin{array}{l}\text { Total Surface } \\
\text { Area Cleaned/ } / \text { Solution } \\
\text { Batch }\end{array}$ & $\begin{array}{l}\text { Volume } \\
\text { Used/Batch }\end{array}$ \\
\hline Goniometer & $\mathrm{Cu}$ & 3 each & $0.2 \mathrm{cc} / \mathrm{sample}$ & $6 \mathrm{sq}$. in. & $250 \mathrm{cc}$ \\
Goniometer & $\mathrm{Al}$ & 3 each & $0.1 \mathrm{cc} / \mathrm{sample}$ & $0.78 \mathrm{sq} . \mathrm{in}$. & $250 \mathrm{cc}$ \\
Auger & $\mathrm{Cu}$ & 1 each & $0.1 \mathrm{cc} / \mathrm{sample}$ & $0.78 \mathrm{sq} . \mathrm{in}$. & $250 \mathrm{cc}$ \\
MESERAN & $\mathrm{Al}$ & $5 \mathrm{each}$ & $0.5 \mathrm{cc} / \mathrm{sample}$ & $90 \mathrm{sq} . \mathrm{in}$. & $2500 \mathrm{cc}$
\end{tabular}


Table 2 - Candidate Cleaner pH Values

\begin{tabular}{|c|c|c|c|c|}
\hline Cleaner & Main Constituents & $\begin{array}{l}\text { pH MSDS } \\
\text { Conc. }\end{array}$ & $\begin{array}{c}\text { pH MSDS } \\
\text { at } 10 \%\end{array}$ & $\begin{array}{c}\text { pH } \\
\text { Measured at } \\
10 \%\end{array}$ \\
\hline Igepal CO-710 & $\begin{array}{c}\text { Ethylene Oxide, } \\
\text { Nonionic Surfactant }\end{array}$ & -- & $6-10$ & 7.7 \\
\hline Daraclean 212 & $\begin{array}{l}\text { Constituents } \\
\text { Proprietary }\end{array}$ & 8.5 & 8.2 & 8.1 \\
\hline Daraclean 235 & $\begin{array}{l}\text { Constituents } \\
\text { Proprietary }\end{array}$ & 7.7 & 7.1 & 7.3 \\
\hline Daraclean 282 & $\begin{array}{c}3 \text { wt\% Glycol } \\
\text { Ether/Other } \\
\text { Proprietary }\end{array}$ & $11-13$ & $10-12$ & 11.5 \\
\hline Brulin 815GD & $\begin{array}{l}\text { Sodium Silicate, } \\
\text { Sodium } \\
\text { Tripolyphosphate, } \\
\text { Amines, Other }\end{array}$ & 12.0 & 11.6 & $\begin{array}{c}11.2 \text { at } \mathrm{RT} \\
10.4 \text { at } \\
135^{\circ} \mathrm{F}\end{array}$ \\
\hline Micro Cleaner & $\begin{array}{c}\text { Sodium, } \\
\text { Triethanolammonium, } \\
\text { Ethylenediamine, } \\
\text { sulfonates, Other }\end{array}$ & 9.7 & -- & 9.6 \\
\hline Oakite NST & $\begin{array}{l}\text { Hydroxypropyl } \\
\text { ethylenediamine, } \\
\text { sulfonates/Other }\end{array}$ & 10.5 & $9.2-9.6$ & 10.7 \\
\hline $\begin{array}{l}\text { Armakleen } \\
\text { E2001A }\end{array}$ & $\begin{array}{l}\text { Constituents } \\
\text { Proprietary }\end{array}$ & 11.3 & 10.8 & 10.7 \\
\hline Isopropyl Alcohol & Reagent Grade & 7.0 & 7.0 & 7.0 \\
\hline $\begin{array}{l}80 \% \text { IPA/20\% } \\
\text { Cyclohexane }\end{array}$ & & 7.0 & 7.0 & 7.0 \\
\hline Trichloroethylene & Reagent Grade & 7.0 & 7.0 & 7.0 \\
\hline
\end{tabular}

Note: The organic cleaners TCE, IPA, and IPA/Cyclohexane are given an artificial $\mathrm{pH}$ value of 7.0. 
Table 3 - Auger Estimated Detection Limits and Measurement Errors

\begin{tabular}{ccc} 
Element & Error (\% of Reported Value) & $\begin{array}{c}\text { Detection Limits Minimum } \\
\text { Measurable (Atomic \%) }\end{array}$ \\
\hline Sulfur & $19 \%$ & $.03 \%$ \\
Chlorine & $10 \%$ & $.05 \%$ \\
Carbon & $7.3 \%$ & $.15 \%$ \\
Nitrogen & $29 \%$ & $.1 \%$ \\
Oxygen & $16 \%$ & $.05 \%$ \\
Barium & $17 \%$ & $.1 \%$ \\
Copper & $4.0 \%$ & $.08 \%$ \\
Sodium & $24 \%$ & $.08 \%$ \\
Silicon & $26 \%$ & $.5 \%$
\end{tabular}




\section{Table 4 - Contact Angle Measurements/OFHC Cu}

\section{Cleaners}

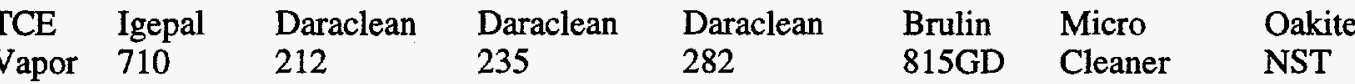

\begin{tabular}{lllllll} 
Degr. $0.5 \%$ & $10 \%$ & $20 \%$ & $10 \%$ & $10 \%$ & $10 \%$ & $10 \%$ \\
\hline
\end{tabular}

\section{Lubricant}

Cook's 4625

$\begin{array}{lllllllll} & 19.7^{\circ} & 25.0^{\circ} & 36.0^{\circ} & 46.0^{\circ} & 30.3^{\circ} & 26.7^{\circ} & 27.3^{\circ} & 26.0^{\circ} \\ \text { Std. dev. } & \pm 2.3^{\circ} & \pm 4.0^{\circ} & \pm 8.2^{\circ} & \pm 5.6^{\circ} & \pm 5.9^{\circ} & \pm 2.3^{\circ} & \pm 6.4^{\circ} & \pm 8.5^{\circ}\end{array}$

\section{Cook's 4639D}

$\begin{array}{llllllll}22.3^{\circ} & 43.3^{\circ} & 46.0^{\circ} & 40.3^{\circ} & 31.0^{\circ} & 46.7^{\circ} & 24.0^{\circ} & 33.3^{\circ}\end{array}$

$\begin{array}{llllllll}\text { Std. dev. } \quad \pm 1.2^{\circ} & \pm 2.5^{\circ} & \pm 2.3^{\circ} & \pm 16.3^{\circ} & \pm 4.6^{\circ} & \pm 10.7^{\circ} & \pm 4.0^{\circ} & \pm 8.5^{\circ}\end{array}$

\section{Cook's 5697}

$\begin{array}{lllll} & 22.3^{\circ} & 51.7^{\circ} & 26.0^{\circ} & 37.0^{\circ} \\ \text { Std. dev. } & \pm 3.8^{\circ} & \pm 3.8^{\circ} & \pm 5.3^{\circ} & \pm 0.0^{\circ}\end{array}$

$\pm 0.0^{\circ}$

$28.3^{\circ}$

$\pm 10.7^{\circ} \quad \pm 4.0^{\circ} \quad \pm 8.5^{\circ}$

3-B Oil

$\begin{array}{lrr} & 28.0^{\circ} & 35.3^{\circ} \\ \text { Std. dev. } \quad \begin{array}{r} \\ \end{array} & \pm 6.6^{\circ} \\ \text { H\&B 50 Lard/50 Mineral Oil }\end{array}$

$28.7^{\circ} 43.0^{\circ}$

Std. dev. $\quad \pm 3.1^{\circ} \quad \pm 5.6^{\circ}$

$42.0^{\circ} \quad 44.7^{\circ}$

$32.5^{\circ}$

$\pm 2.1^{\circ}$

$32.7^{\circ}$

$\pm 3.5^{\circ}$

$30.3^{\circ} \quad 16.7^{\circ}$

$30.3^{\circ}$

$\pm 8.7^{\circ}$

$\pm 6.8^{\circ}$

$\pm 1.5$

$\pm 14.0^{\circ}$

Ivory Snow/Lanolin

$\begin{array}{rrrr}25.0^{\circ} & 25.3^{\circ} & 37.0^{\circ} & 37.7^{\circ}\end{array}$

$\pm 6.4^{\circ}$

$31.0^{\circ}$

$\pm 1.7^{\circ}$

$29.3^{\circ} \quad 25.0^{\circ}$

$39.3^{\circ}$

$\pm 1.5^{\circ}$

$\pm 5.5^{\circ} \quad \pm 3.6$

$\pm 7.8^{\circ}$

\section{Cimtap}

$\begin{array}{lrrrr} & 29.0^{\circ} & 33.0^{\circ} & 66.3^{\circ} & 68.7^{\circ} \\ \text { Std. dev. } & \pm 2.0^{\circ} & \pm 6.6^{\circ} & \pm 11.9^{\circ} & \pm 11.2^{\circ}\end{array}$

$68.7^{\circ}-35.0^{\circ}$

$\pm 5.3^{\circ}$

$\begin{array}{lll}42.0^{\circ} & 28.0^{\circ} \quad 46.7^{\circ}\end{array}$

Boelube

\begin{tabular}{|c|c|c|c|c|c|c|c|c|}
\hline Std. dev. & $\begin{array}{l}25.0^{\circ} \\
\pm 1.0^{\circ}\end{array}$ & $\begin{array}{l}29.0^{\circ} \\
\pm 5.0^{\circ}\end{array}$ & $\begin{array}{r}68.3^{\circ} \\
\pm 6.1^{\circ}\end{array}$ & $\begin{array}{r}67.3^{\circ} \\
\pm 11.2^{\circ}\end{array}$ & $\begin{array}{r}44.0^{\circ} \\
\pm 9.2^{\circ}\end{array}$ & $\begin{array}{r}63.3^{\circ} \\
\pm 5.5^{\circ}\end{array}$ & $\begin{array}{l}33.3^{\circ} \\
\pm 2.5^{\circ}\end{array}$ & $\begin{array}{r}46.0^{\circ} \\
\pm 3.6^{\circ}\end{array}$ \\
\hline $\begin{array}{l}\text { Overa } \\
\text { Std. d }\end{array}$ & $\begin{array}{l}25.0^{\circ} \\
\pm 4.0^{\circ}\end{array}$ & $\begin{array}{r}35.7^{\circ} \\
\pm 10.1^{\circ}\end{array}$ & $\begin{array}{r}45.0 \\
\pm 16.2\end{array}$ & $\begin{array}{r}46.8^{\circ} \\
\pm 15.0^{\circ}\end{array}$ & $\begin{array}{l}33.0^{\circ} \\
\pm 6.4^{\circ}\end{array}$ & $\begin{array}{r}38.6^{\circ} \\
\pm 14.1^{\circ}\end{array}$ & $\begin{array}{r}26.9^{\circ} \\
\pm 13.1^{\circ}\end{array}$ & $\begin{array}{r}36.8^{\circ} \\
\pm 11.6^{\circ}\end{array}$ \\
\hline
\end{tabular}


Table 5 - Contact Angle Measurements/Aluminum 1100 Coupons

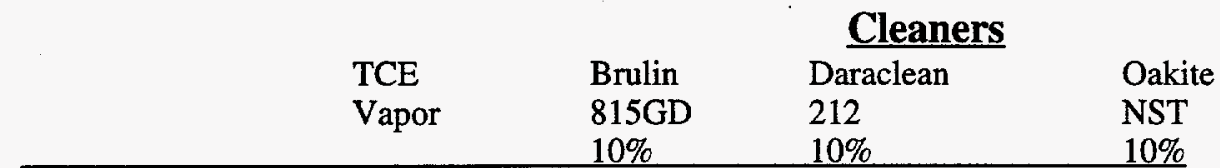

Lubricant

Cook's 4625

Std. dev.

38.8

10.2

82.2

9.3

14.0

1.5

4.1

$10 \%$

Cook's 4639D

Std. dev.

26.2

5.1

7.6

60.2

2.9

7.3

1.9

Cook's S697

Std. dev.

15.0

3.3

5.0

53.2

2.7

13.0

3.1

5.7

3-B Oil

std. dev.

17.8

5.7

7.5

47.4

4.4

7.6

1.3

1.8

H\&B 50 Lard/50 Mineral Oil

56.8

Std. dev.

13.9

1.6

61.6

4.8

6.8

1.1

8.7

1.2

47.4

6.7

9.6

std. dev.

5.0

34.0

1.0

11.0

86.6

5.5

22.6

Std. dev.

64.3

1.5

6.2

53.2

9.7

11.8

Std. dev.

38.3

OverallAvg.

Std. dev.

4.6

7.2

2.4

61.5

5.8

11.6

3.9 
Table 6 - TCE Auger Elemental Analysis

\begin{tabular}{llllllllllll} 
Sample Preparation & $\mathbf{S}$ & $\mathbf{C l}$ & $\mathbf{C}$ & $\mathbf{N}$ & $\mathbf{O}$ & $\mathbf{B a}$ & $\mathbf{C u}$ & $\mathbf{N a}$ & $\mathbf{S i}$ & $\begin{array}{c}\text { Total } \\
\text { Contam } \\
\text { inants }\end{array}$ \\
\hline \hline Clean & & & & & & & & & & \\
Clean & $3.1 \%$ & $0.2 \%$ & $42.5 \%$ & $1.0 \%$ & $9.5 \%$ & $0.0 \%$ & $43.7 \%$ & $0.0 \%$ & $0.0 \%$ & $56.3 \%$ & \\
Cook's 4625 & $2.0 \%$ & $0.1 \%$ & $58.0 \%$ & $0.6 \%$ & $7.6 \%$ & $0.0 \%$ & $31.6 \%$ & $0.0 \%$ & $0.0 \%$ & $68.4 \%$ & $62.3 \%$ \\
Cook's 4639D & $1.7 \%$ & $1.8 \%$ & $51.3 \%$ & $0.7 \%$ & $8.8 \%$ & $0.0 \%$ & $35.7 \%$ & $0.0 \%$ & $0.0 \%$ & $64.3 \%$ & \\
Cook's S697 & $0.8 \%$ & $2.2 \%$ & $61.5 \%$ & $3.2 \%$ & $5.7 \%$ & $0.1 \%$ & $26.5 \%$ & $0.0 \%$ & $0.0 \%$ & $73.5 \%$ & \\
3-B Oil & $0.6 \%$ & $2.8 \%$ & $69.0 \%$ & $5.2 \%$ & $2.5 \%$ & $1.9 \%$ & $18.0 \%$ & $0.0 \%$ & $0.0 \%$ & $82.0 \%$ & \\
H\&B Lard-Mineral Oil & $0.6 \%$ & $1.5 \%$ & $69.7 \%$ & $0.7 \%$ & $5.0 \%$ & $0.0 \%$ & $22.6 \%$ & $0.0 \%$ & $0.0 \%$ & $77.4 \%$ & \\
Ivory Snow-Lanolin & $0.5 \%$ & $1.6 \%$ & $53.7 \%$ & $0.5 \%$ & $9.2 \%$ & $0.0 \%$ & $34.5 \%$ & $0.0 \%$ & $0.0 \%$ & $65.5 \%$ & \\
Cimtap & $0.3 \%$ & $0.7 \%$ & $81.0 \%$ & $0.5 \%$ & $3.2 \%$ & $0.0 \%$ & $14.2 \%$ & $0.0 \%$ & $0.0 \%$ & $85.8 \%$ \\
Boelube & $0.6 \%$ & $11.9 \%$ & $50.4 \%$ & $6.0 \%$ & $2.2 \%$ & $0.0 \%$ & $28.8 \%$ & $0.0 \%$ & $0.0 \%$ & $71.2 \%$ & \\
& $1.0 \%$ & $1.4 \%$ & $47.0 \%$ & $0.5 \%$ & $10.4 \%$ & $0.0 \%$ & $39.5 \%$ & $0.0 \%$ & $0.0 \%$ & $60.4 \%$ & $72.5 \%$ \\
\hline
\end{tabular}

Table 7 - Igepal C0-710 Auger Elemental Analysis

\begin{tabular}{llllllllllll} 
Sample Preparation & $\mathbf{S}$ & $\mathbf{C l}$ & $\mathbf{C}$ & $\mathbf{N}$ & $\mathbf{O}$ & $\mathbf{B a}$ & $\mathbf{C u}$ & $\mathbf{N a}$ & $\begin{array}{c}\text { Si } \\
\text { Total }\end{array}$ Avg \\
& & & & & & & & & & $\begin{array}{c}\text { Contam } \\
\text { inants }\end{array}$ \\
\hline \hline Clean & $3.1 \%$ & $0.2 \%$ & $42.5 \%$ & $1.0 \%$ & $9.5 \%$ & $0.0 \%$ & $43.7 \%$ & $0.0 \%$ & $0.0 \%$ & $56.3 \%$ & \\
Clean & $2.0 \%$ & $0.1 \%$ & $58.0 \%$ & $0.6 \%$ & $7.6 \%$ & $0.0 \%$ & $31.6 \%$ & $0.0 \%$ & $0.0 \%$ & $68.4 \%$ & $62.3 \%$ \\
Cook's 4625 & $0.5 \%$ & $0.1 \%$ & $55.5 \%$ & $0.5 \%$ & $9.1 \%$ & $0.0 \%$ & $34.3 \%$ & $0.0 \%$ & $0.0 \%$ & $65.7 \%$ & \\
Cook's 4639D & $0.3 \%$ & $0.0 \%$ & $79.0 \%$ & $1.7 \%$ & $3.8 \%$ & $0.0 \%$ & $15.1 \%$ & $0.0 \%$ & $0.0 \%$ & $84.9 \%$ & \\
Cook's S697 & $0.1 \%$ & $0.3 \%$ & $78.9 \%$ & $5.3 \%$ & $2.5 \%$ & $0.0 \%$ & $12.9 \%$ & $0.0 \%$ & $0.0 \%$ & $87.1 \%$ & \\
3-B Oil & $0.5 \%$ & $0.2 \%$ & $46.5 \%$ & $0.5 \%$ & $11.4 \%$ & $0.0 \%$ & $40.9 \%$ & $0.0 \%$ & $0.0 \%$ & $59.1 \%$ & \\
H\&B Lard-Mineral Oil & $0.4 \%$ & $0.0 \%$ & $63.8 \%$ & $0.4 \%$ & $7.5 \%$ & $0.1 \%$ & $27.8 \%$ & $0.0 \%$ & $0.0 \%$ & $72.2 \%$ & \\
Ivory Snow-Lanolin & $0.5 \%$ & $0.1 \%$ & $62.1 \%$ & $0.5 \%$ & $7.6 \%$ & $0.0 \%$ & $29.1 \%$ & $0.0 \%$ & $0.0 \%$ & $70.9 \%$ & \\
Cimtap & $0.9 \%$ & $0.3 \%$ & $54.3 \%$ & $0.9 \%$ & $8.4 \%$ & $0.0 \%$ & $35.1 \%$ & $0.0 \%$ & $0.0 \%$ & $64.9 \%$ & \\
Boelube & $0.4 \%$ & $0.0 \%$ & $70.9 \%$ & $0.5 \%$ & $5.9 \%$ & $0.0 \%$ & $22.2 \%$ & $0.0 \%$ & $0.0 \%$ & $77.8 \%$ & $72.8 \%$ \\
\hline
\end{tabular}


Table 8 - Daraclean 212 Auger Elemental Analysis

\begin{tabular}{llllllllllll} 
Sample Preparation & $\mathbf{S}$ & $\mathbf{C l}$ & $\mathbf{C}$ & $\mathbf{N}$ & $\mathbf{O}$ & $\mathbf{B a}$ & $\mathbf{C u}$ & $\mathbf{N a}$ & $\begin{array}{c}\text { Si } \\
\text { Total } \\
\text { Contam } \\
\text { inants }\end{array}$ & Avg \\
\hline \hline Clean & $3.1 \%$ & $0.2 \%$ & $42.5 \%$ & $1.0 \%$ & $9.5 \%$ & $0.0 \%$ & $43.7 \%$ & $0.0 \%$ & $0.0 \%$ & $56.3 \%$ & \\
Clean & $2.0 \%$ & $0.1 \%$ & $58.0 \%$ & $0.6 \%$ & $7.6 \%$ & $0.0 \%$ & $31.6 \%$ & $0.0 \%$ & $0.0 \%$ & $68.4 \%$ & $62.3 \%$ \\
Cook's 4625 & $0.3 \%$ & $0.5 \%$ & $67.2 \%$ & $3.8 \%$ & $5.0 \%$ & $0.0 \%$ & $23.1 \%$ & $0.0 \%$ & $0.0 \%$ & $76.9 \%$ & \\
Cook's 4639D & $0.3 \%$ & $0.1 \%$ & $63.2 \%$ & $3.1 \%$ & $5.8 \%$ & $0.0 \%$ & $27.5 \%$ & $0.0 \%$ & $0.0 \%$ & $72.5 \%$ & \\
Cook's S697 & $0.2 \%$ & $0.2 \%$ & $81.7 \%$ & $3.1 \%$ & $2.1 \%$ & $0.0 \%$ & $12.8 \%$ & $0.0 \%$ & $0.0 \%$ & $87.2 \%$ & \\
3-B Oil & $0.3 \%$ & $0.1 \%$ & $68.2 \%$ & $3.1 \%$ & $4.9 \%$ & $0.0 \%$ & $23.5 \%$ & $0.0 \%$ & $0.0 \%$ & $76.5 \%$ & \\
H\&B Lard-Mineral Oil & $0.3 \%$ & $0.1 \%$ & $66.9 \%$ & $3.8 \%$ & $4.8 \%$ & $0.0 \%$ & $24.1 \%$ & $0.0 \%$ & $0.0 \%$ & $75.9 \%$ & \\
Ivory Snow-Lanolin & $0.3 \%$ & $0.1 \%$ & $67.6 \%$ & $3.8 \%$ & $4.6 \%$ & $0.0 \%$ & $23.6 \%$ & $0.0 \%$ & $0.0 \%$ & $76.4 \%$ & \\
Cimtap & $0.2 \%$ & $0.3 \%$ & $70.9 \%$ & $7.0 \%$ & $2.2 \%$ & $0.0 \%$ & $19.3 \%$ & $0.0 \%$ & $0.0 \%$ & $80.7 \%$ & \\
Boelube & $0.2 \%$ & $0.1 \%$ & $69.6 \%$ & $5.3 \%$ & $3.7 \%$ & $0.0 \%$ & $21.0 \%$ & $0.0 \%$ & $0.0 \%$ & $79.0 \%$ & $78.1 \%$ \\
\hline & & & & & & & & & &
\end{tabular}

Table 9 - Daraclean 235 Auger Elemental Analysis

\begin{tabular}{llllllllllll} 
Sample Preparation & $\mathbf{S}$ & $\mathbf{C l}$ & $\mathbf{C}$ & $\mathbf{N}$ & $\mathbf{O}$ & $\mathbf{B a}$ & $\mathbf{C u}$ & $\mathbf{N a}$ & $\mathrm{Si}$ & $\begin{array}{c}\text { Total } \\
\text { Contam } \\
\text { inants }\end{array}$ & Avg \\
\hline \hline Clean & $3.1 \%$ & $0.2 \%$ & $42.5 \%$ & $1.0 \%$ & $9.5 \%$ & $0.0 \%$ & $43.7 \%$ & $0.0 \%$ & $0.0 \%$ & $56.3 \%$ & \\
Clean & $2.0 \%$ & $0.1 \%$ & $58.0 \%$ & $0.6 \%$ & $7.6 \%$ & $0.0 \%$ & $31.6 \%$ & $0.0 \%$ & $0.0 \%$ & $68.4 \%$ & $62.3 \%$ \\
Cook's 4625 & $0.1 \%$ & $0.3 \%$ & $76.7 \%$ & $5.1 \%$ & $2.7 \%$ & $0.0 \%$ & $15.1 \%$ & $0.0 \%$ & $0.0 \%$ & $84.9 \%$ & \\
Cook's 4639D & $0.2 \%$ & $0.1 \%$ & $71.8 \%$ & $4.4 \%$ & $4.1 \%$ & $0.0 \%$ & $18.9 \%$ & $0.0 \%$ & $0.5 \%$ & $81.1 \%$ & \\
Cook's S697 & $0.1 \%$ & $0.2 \%$ & $74.4 \%$ & $5.4 \%$ & $2.9 \%$ & $0.0 \%$ & $17.0 \%$ & $0.0 \%$ & $0.0 \%$ & $83.0 \%$ & \\
3-B Oil & $0.2 \%$ & $0.1 \%$ & $64.5 \%$ & $4.8 \%$ & $4.7 \%$ & $0.0 \%$ & $25.5 \%$ & $0.0 \%$ & $0.2 \%$ & $74.5 \%$ & \\
H\&B Lard-Mineral Oil & $0.3 \%$ & $0.1 \%$ & $76.7 \%$ & $3.6 \%$ & $3.2 \%$ & $0.0 \%$ & $16.2 \%$ & $0.0 \%$ & $0.0 \%$ & $83.8 \%$ & \\
Ivory Snow-Lanolin & $0.2 \%$ & $0.1 \%$ & $71.9 \%$ & $5.0 \%$ & $3.1 \%$ & $0.0 \%$ & $19.8 \%$ & $0.0 \%$ & $0.0 \%$ & $80.2 \%$ & \\
Cimtap & $0.3 \%$ & $0.7 \%$ & $79.7 \%$ & $6.3 \%$ & $1.7 \%$ & $0.0 \%$ & $11.3 \%$ & $0.0 \%$ & $0.0 \%$ & $88.6 \%$ & \\
Boelube & $0.3 \%$ & $0.1 \%$ & $79.0 \%$ & $4.9 \%$ & $2.2 \%$ & $0.0 \%$ & $13.6 \%$ & $0.0 \%$ & $0.0 \%$ & $86.4 \%$ & $82.8 \%$ \\
\hline & & & & & & & & & &
\end{tabular}


Table 10 - Daraclean 282 Auger Elemental Analysis

\begin{tabular}{|c|c|c|c|c|c|c|c|c|c|c|c|}
\hline Sample Preparation & $\mathbf{S}$ & $\mathbf{C l}$ & $\mathbf{C}$ & $\mathbf{N}$ & $\mathbf{0}$ & $\mathbf{B a}$ & $\mathbf{C u}$ & $\mathbf{N a}$ & $\mathbf{S i}$ & $\begin{array}{c}\text { Total } \\
\text { Contam } \\
\text { inants }\end{array}$ & Avg \\
\hline$\overline{\overline{\text { Clean }}}$ & $3.1 \%$ & $0.2 \%$ & $42.5 \%$ & $1.0 \%$ & $9.5 \%$ & $0.0 \%$ & $43.7 \%$ & $0.0 \%$ & $0.0 \%$ & $56.3 \%$ & \\
\hline Clean & $2.0 \%$ & $0.1 \%$ & $58.0 \%$ & $0.6 \%$ & $7.6 \%$ & $0.0 \%$ & $31.6 \%$ & $0.0 \%$ & $0.0 \%$ & $68.4 \%$ & $62.3 \%$ \\
\hline Cook's 4625 & $4.1 \%$ & $0.4 \%$ & $61.9 \%$ & $2.2 \%$ & $4.9 \%$ & $0.0 \%$ & $25.8 \%$ & $0.0 \%$ & $0.6 \%$ & $74.2 \%$ & \\
\hline Cook's 4639D & $2.3 \%$ & $0.1 \%$ & $58.9 \%$ & $2.9 \%$ & $6.4 \%$ & $0.0 \%$ & $29.3 \%$ & $0.0 \%$ & $0.0 \%$ & $70.7 \%$ & \\
\hline Cook's S697 & $3.0 \%$ & $0.1 \%$ & $58.6 \%$ & $3.4 \%$ & $4.4 \%$ & $0.0 \%$ & $30.5 \%$ & $0.0 \%$ & $0.0 \%$ & $69.5 \%$ & \\
\hline 3-B Oil & $3.3 \%$ & $0.0 \%$ & $60.9 \%$ & $2.0 \%$ & $5.1 \%$ & $0.0 \%$ & $28.7 \%$ & $0.0 \%$ & $0.0 \%$ & $71.3 \%$ & \\
\hline H\&B Lard-Mineral Oil & $4.1 \%$ & $0.1 \%$ & $53.8 \%$ & $2.3 \%$ & $6.1 \%$ & $0.0 \%$ & $33.5 \%$ & $0.1 \%$ & $0.0 \%$ & $66.5 \%$ & \\
\hline Ivory Snow-Lanolin & $4.9 \%$ & $0.0 \%$ & $58.0 \%$ & $2.6 \%$ & $4.4 \%$ & $0.0 \%$ & $30.1 \%$ & $0.0 \%$ & $0.0 \%$ & $69.9 \%$ & \\
\hline Cimtap & $8.1 \%$ & $0.1 \%$ & $49.4 \%$ & $3.9 \%$ & $3.0 \%$ & $0.0 \%$ & $35.4 \%$ & $0.0 \%$ & $0.0 \%$ & $64.6 \%$ & \\
\hline Boelube & $4.9 \%$ & $0.0 \%$ & $56.6 \%$ & $2.5 \%$ & $5.5 \%$ & $0.0 \%$ & $30.6 \%$ & $0.0 \%$ & $0.0 \%$ & $69.4 \%$ & $69.5 \%$ \\
\hline
\end{tabular}

Table 11 - Brulin 815GD Auger Elemental Analysis

\begin{tabular}{llllllllllll} 
Sample Preparation & $\mathbf{S}$ & $\mathbf{C l}$ & $\mathbf{C}$ & $\mathbf{N}$ & $\mathbf{O}$ & $\mathbf{B a}$ & $\mathbf{C u}$ & $\mathbf{N a}$ & $\begin{array}{c}\text { Si } \\
\text { Total }\end{array}$ Avg \\
& & & & & & & & & & $\begin{array}{c}\text { Contam } \\
\text { inants }\end{array}$ \\
\hline \hline Clean & $3.1 \%$ & $0.2 \%$ & $42.5 \%$ & $1.0 \%$ & $9.5 \%$ & $0.0 \%$ & $43.7 \%$ & $0.0 \%$ & $0.0 \%$ & $56.3 \%$ & \\
Clean & $2.0 \%$ & $0.1 \%$ & $58.0 \%$ & $0.6 \%$ & $7.6 \%$ & $0.0 \%$ & $31.6 \%$ & $0.0 \%$ & $0.0 \%$ & $68.4 \%$ & $62.3 \%$ \\
Cook's 4625 & $1.3 \%$ & $0.1 \%$ & $57.4 \%$ & $1.6 \%$ & $6.8 \%$ & $0.0 \%$ & $32.1 \%$ & $0.1 \%$ & $0.5 \%$ & $67.9 \%$ & \\
Cook's 4639D & $0.5 \%$ & $0.2 \%$ & $42.6 \%$ & $2.6 \%$ & $10.3 \%$ & $0.0 \%$ & $43.8 \%$ & $0.0 \%$ & $0.0 \%$ & $56.2 \%$ & \\
Cook's S697 & $0.5 \%$ & $0.1 \%$ & $73.6 \%$ & $1.6 \%$ & $4.3 \%$ & $0.0 \%$ & $19.7 \%$ & $0.3 \%$ & $0.0 \%$ & $80.3 \%$ & \\
3-B Oil & $0.9 \%$ & $0.1 \%$ & $53.1 \%$ & $1.5 \%$ & $8.5 \%$ & $0.0 \%$ & $35.9 \%$ & $0.1 \%$ & $0.0 \%$ & $64.1 \%$ & \\
H\&B Lard-Mineral Oil & $1.1 \%$ & $0.2 \%$ & $34.6 \%$ & $1.3 \%$ & $12.8 \%$ & $0.0 \%$ & $46.8 \%$ & $0.3 \%$ & $3.0 \%$ & $53.2 \%$ & \\
Ivory Snow-Lanolin & $1.4 \%$ & $0.2 \%$ & $44.6 \%$ & $1.9 \%$ & $8.9 \%$ & $0.0 \%$ & $43.1 \%$ & $0.0 \%$ & $0.0 \%$ & $56.9 \%$ & \\
Cimtap & $1.2 \%$ & $0.3 \%$ & $46.5 \%$ & $2.4 \%$ & $8.3 \%$ & $0.0 \%$ & $39.8 \%$ & $0.0 \%$ & $1.6 \%$ & $60.2 \%$ & \\
Boelube & $0.8 \%$ & $0.2 \%$ & $51.7 \%$ & $1.3 \%$ & $9.3 \%$ & $0.0 \%$ & $36.6 \%$ & $0.2 \%$ & $0.0 \%$ & $63.4 \%$ & $62.8 \%$ \\
\hline
\end{tabular}


Table 12 - Micro Cleaner Auger Elemental Analysis

\begin{tabular}{llllllllllll} 
Sample Preparation & $\mathbf{S}$ & $\mathbf{C l}$ & $\mathbf{C}$ & $\mathbf{N}$ & $\mathbf{O}$ & $\mathbf{B a}$ & $\mathbf{C u}$ & $\mathbf{N a}$ & $\mathbf{S i}$ & $\begin{array}{c}\text { Total } \\
\text { Contam } \\
\text { inants }\end{array}$ & Avg \\
\hline \hline Clean & & & & & & & & & & & \\
Clean & $3.1 \%$ & $0.2 \%$ & $42.5 \%$ & $1.0 \%$ & $9.5 \%$ & $0.0 \%$ & $43.7 \%$ & $0.0 \%$ & $0.0 \%$ & $56.3 \%$ & \\
Cook's 4625 & $2.0 \%$ & $0.1 \%$ & $58.0 \%$ & $0.6 \%$ & $7.6 \%$ & $0.0 \%$ & $31.6 \%$ & $0.0 \%$ & $0.0 \%$ & $68.4 \%$ & $62.3 \%$ \\
Cook's 4639D & $0.8 \%$ & $0.3 \%$ & $55.8 \%$ & $2.0 \%$ & $6.4 \%$ & $0.0 \%$ & $34.5 \%$ & $0.1 \%$ & $0.0 \%$ & $65.5 \%$ & \\
Cook's S697 & $0.7 \%$ & $0.1 \%$ & $66.6 \%$ & $1.7 \%$ & $5.1 \%$ & $0.0 \%$ & $25.9 \%$ & $0.0 \%$ & $0.0 \%$ & $74.1 \%$ & \\
3-B Oil & $0.9 \%$ & $0.1 \%$ & $59.8 \%$ & $2.9 \%$ & $4.5 \%$ & $0.0 \%$ & $31.8 \%$ & $0.0 \%$ & $0.0 \%$ & $68.2 \%$ & \\
H\&B Lard-Mineral & $0.6 \%$ & $0.1 \%$ & $63.4 \%$ & $1.6 \%$ & $5.7 \%$ & $0.0 \%$ & $28.6 \%$ & $0.0 \%$ & $0.0 \%$ & $71.4 \%$ & \\
Oil & & & & & & & & & & & \\
Ivory Snow-Lanolin & $1.7 \%$ & $0.2 \%$ & $38.6 \%$ & $1.9 \%$ & $8.8 \%$ & $0.0 \%$ & $48.7 \%$ & $0.0 \%$ & $0.0 \%$ & $51.3 \%$ \\
Cimtap & $1.4 \%$ & $0.4 \%$ & $46.9 \%$ & $3.0 \%$ & $7.5 \%$ & $0.0 \%$ & $40.7 \%$ & $0.0 \%$ & $0.0 \%$ & $59.3 \%$ & \\
Boelube & $0.8 \%$ & $0.4 \%$ & $40.4 \%$ & $1.9 \%$ & $10.3 \%$ & $0.0 \%$ & $46.2 \%$ & $0.0 \%$ & $0.0 \%$ & $53.8 \%$ & $63.4 \%$ \\
\hline
\end{tabular}

Table 13 - Oakite NST Auger Elemental Analysis

\begin{tabular}{llllllllllll} 
Sample Preparation & $\mathbf{S}$ & $\mathbf{C l}$ & $\mathbf{C}$ & $\mathbf{N}$ & $\mathbf{O}$ & $\mathbf{B a}$ & $\mathbf{C u}$ & $\mathbf{N a}$ & $\begin{array}{c}\text { Si } \\
\text { Total } \\
\text { Contami } \\
\text { nants }\end{array}$ \\
\hline \hline Clean & $3.1 \%$ & $0.2 \%$ & $42.5 \%$ & $1.0 \%$ & $9.5 \%$ & $0.0 \%$ & $43.7 \%$ & $0.0 \%$ & $0.0 \%$ & $56.3 \%$ & \\
\hline Clean & $2.0 \%$ & $0.1 \%$ & $58.0 \%$ & $0.6 \%$ & $7.6 \%$ & $0.0 \%$ & $31.6 \%$ & $0.0 \%$ & $0.0 \%$ & $68.4 \%$ & $62.3 \%$ \\
Cook's 4625 & $1.2 \%$ & $0.0 \%$ & $53.6 \%$ & $1.4 \%$ & $7.9 \%$ & $0.0 \%$ & $35.9 \%$ & $0.0 \%$ & $0.0 \%$ & $64.1 \%$ & \\
Cook's 4639D & $0.5 \%$ & $0.0 \%$ & $63.9 \%$ & $1.9 \%$ & $6.0 \%$ & $0.0 \%$ & $27.5 \%$ & $0.1 \%$ & $0.0 \%$ & $72.5 \%$ & \\
Cook's S697 & $0.7 \%$ & $0.1 \%$ & $53.4 \%$ & $2.8 \%$ & $6.7 \%$ & $0.0 \%$ & $36.2 \%$ & $0.0 \%$ & $0.0 \%$ & $63.8 \%$ & \\
3-B Oil & $1.2 \%$ & $0.2 \%$ & $53.5 \%$ & $1.4 \%$ & $7.8 \%$ & $0.0 \%$ & $35.7 \%$ & $0.3 \%$ & $0.0 \%$ & $64.3 \%$ & \\
H\&B Lard-Mineral Oil & $1.6 \%$ & $0.2 \%$ & $51.8 \%$ & $1.6 \%$ & $7.8 \%$ & $0.0 \%$ & $37.0 \%$ & $0.1 \%$ & $0.0 \%$ & $63.0 \%$ & \\
Ivory Snow-Lanolin & $1.6 \%$ & $0.2 \%$ & $51.0 \%$ & $1.6 \%$ & $7.6 \%$ & $0.0 \%$ & $38.0 \%$ & $0.0 \%$ & $0.0 \%$ & $62.0 \%$ & \\
Cimtap & $1.6 \%$ & $0.1 \%$ & $53.0 \%$ & $1.5 \%$ & $7.5 \%$ & $0.0 \%$ & $36.3 \%$ & $0.0 \%$ & $0.0 \%$ & $63.7 \%$ & \\
Boelube & $1.8 \%$ & $0.2 \%$ & $54.4 \%$ & $1.6 \%$ & $7.4 \%$ & $0.0 \%$ & $34.5 \%$ & $0.1 \%$ & $0.0 \%$ & $65.5 \%$ & $64.9 \%$ \\
\hline & & & & & & & & & &
\end{tabular}




\section{Table 14 - Armakleen E2001A Auger Elemental Analysis}

\begin{tabular}{|c|c|c|c|c|c|c|c|c|c|c|c|}
\hline Sample Preparation & $\mathbf{S}$ & $\mathrm{Cl}$ & $\mathbf{C}$ & $\mathbf{N}$ & $\mathbf{0}$ & $\mathbf{B a}$ & $\mathrm{Cu}$ & $\mathbf{N a}$ & $\mathbf{S i}$ & $\begin{array}{c}\text { Total } \\
\text { Contami } \\
\text { nants }\end{array}$ & Avg \\
\hline Clean & $3.1 \%$ & $0.2 \%$ & $42.5 \%$ & $1.0 \%$ & $9.5 \%$ & $0.0 \%$ & $43.7 \%$ & $0.0 \%$ & $0.0 \%$ & $56.3 \%$ & \\
\hline Clean & $2.0 \%$ & $0.1 \%$ & $58.0 \%$ & $0.6 \%$ & $7.6 \%$ & $0.0 \%$ & $31.6 \%$ & $0.0 \%$ & $0.0 \%$ & $68.4 \%$ & $62.3 \%$ \\
\hline Cook's 4625 & $1.98 \%$ & $0.09 \%$ & $8.21 \%$ & $0.70 \%$ & $15.56 \%$ & $0.00 \%$ & $57.30 \%$ & $0.00 \%$ & $16.16 \%$ & $42.70 \%$ & \\
\hline Cook's 4639D & $1.07 \%$ & $0.02 \%$ & $38.33 \%$ & $0.88 \%$ & $11.75 \%$ & $0.00 \%$ & $38.17 \%$ & $0.00 \%$ & $9.78 \%$ & $61.83 \%$ & \\
\hline Cook's S697 & $0.37 \%$ & $0.10 \%$ & $60.18 \%$ & $2.75 \%$ & $6.64 \%$ & $0.00 \%$ & $29.95 \%$ & $0.00 \%$ & $0.00 \%$ & $70.05 \%$ & \\
\hline 3-B Oil & $2.22 \%$. & $0.02 \%$ & $21.28 \%$ & $0.44 \%$ & $13.13 \%$ & $0.00 \%$ & $49.96 \%$ & $0.00 \%$ & $12.94 \%$ & $50.04 \%$ & \\
\hline H\&B Lard-Mineral Oil & $1.42 \%$ & $0.00 \%$ & $43.26 \%$ & $0.50 \%$ & $10.75 \%$ & $0.00 \%$ & $31.89 \%$ & $0.08 \%$ & $12.09 \%$ & $68.11 \%$ & \\
\hline Ivory Snow-Lanolin & $1.17 \%$ & $0.07 \%$ & $9.00 \%$ & $0.50 \%$ & $17.99 \%$ & $0.00 \%$ & $39.40 \%$ & $0.00 \%$ & $31.89 \%$ & $60.60 \%$ & \\
\hline Cimtap & $0.70 \%$ & $0.14 \%$ & $29.36 \%$ & $0.75 \%$ & $15.14 \%$ & $0.00 \%$ & $33.62 \%$ & $0.00 \%$ & $20.30 \%$ & $66.38 \%$ & \\
\hline Boelube & $1.75 \%$ & $0.03 \%$ & $14.34 \%$ & $0.40 \%$ & $15.07 \%$ & $0.00 \%$ & $47.70 \%$ & $0.00 \%$ & $20.70 \%$ & $52.30 \%$ & $59.0 \%$ \\
\hline
\end{tabular}

\section{Table 15 - Isopropyl Alcohol Auger Elemental Analysis}

\begin{tabular}{lcccccccccc} 
Sample Preparation & $\mathbf{S}$ & $\mathbf{C l}$ & $\mathbf{C}$ & $\mathbf{N}$ & $\mathbf{O}$ & $\mathbf{B a}$ & $\mathbf{C u}$ & $\mathbf{N a}$ & $\begin{array}{c}\text { Si } \\
\begin{array}{c}\text { Total } \\
\text { Contami }\end{array}\end{array}$ \\
\hline \hline Cleants
\end{tabular}


Table 16 - Isopropyl Alcohol/Cyclohexane Auger Elemental Analysis

\begin{tabular}{|c|c|c|c|c|c|c|c|c|c|c|c|}
\hline Sample Preparation & $\mathbf{S}$ & Cl & C & $\mathbf{N}$ & $\mathbf{o}$ & $\mathbf{B a}$ & $\mathbf{C u}$ & $\mathbf{N a}$ & Si & $\begin{array}{c}\text { Total } \\
\text { Contami } \\
\text { nants }\end{array}$ & Avg \\
\hline Clean & $3.1 \%$ & $0.2 \%$ & $42.5 \%$ & $1.0 \%$ & $9.5 \%$ & $0.0 \%$ & $43.7 \%$ & $0.0 \%$ & $0.0 \%$ & $56.3 \%$ & \\
\hline Clean & $2.0 \%$ & $0.1 \%$ & $58.0 \%$ & $0.6 \%$ & $7.6 \%$ & $0.0 \%$ & $31.6 \%$ & $0.0 \%$ & $0.0 \%$ & $68.4 \%$ & $62.3 \%$ \\
\hline Cook's 4625 & $0.94 \%$ & $0.57 \%$ & $54.22 \%$ & $0.75 \%$ & $8.41 \%$ & $0.00 \%$ & $35.12 \%$ & $0.00 \%$ & $0.00 \%$ & $64.88 \%$ & \\
\hline Cook's 4639D & $0.70 \%$ & $0.24 \%$ & $64.09 \%$ & $1.74 \%$ & $6.48 \%$ & $0.00 \%$ & $26.75 \%$ & $0.00 \%$ & $0.00 \%$ & $73.25 \%$ & \\
\hline Cook's S697 & $0.08 \%$ & $0.28 \%$ & $80.57 \%$ & $8.22 \%$ & $0.93 \%$ & $0.00 \%$ & $9.92 \%$ & $0.00 \%$ & $0.00 \%$ & $90.08 \%$ & \\
\hline 3-B Oil & $0.44 \%$ & $0.14 \%$ & $68.91 \%$ & $0.62 \%$ & $5.66 \%$ & $0.00 \%$ & $24.22 \%$ & $0.00 \%$ & $0.00 \%$ & $75.78 \%$ & \\
\hline H\&B Lard-Mineral Oil & $0.84 \%$ & $0.10 \%$ & $54.65 \%$ & $0.57 \%$ & $8.33 \%$ & $0.00 \%$ & $35.33 \%$ & $0.17 \%$ & $0.00 \%$ & $64.67 \%$ & \\
\hline Ivory Snow-Lanolin & --- & --- & -- & -- & -- & -- & --- & --- & --- & -- & \\
\hline Cimtap & $1.47 \%$ & $1.31 \%$ & $56.26 \%$ & $1.22 \%$ & $7.48 \%$ & $0.00 \%$ & $31.64 \%$ & $0.62 \%$ & $0.00 \%$ & $68.36 \%$ & \\
\hline Boelube & $0.81 \%$ & $0.11 \%$ & $63.16 \%$ & $0.66 \%$ & $7.53 \%$ & $0.00 \%$ & $27.72 \%$ & $0.00 \%$ & $0.00 \%$ & $72.28 \%$ & $72.8 \%$ \\
\hline
\end{tabular}


Table 17 - Average Elemental Residue By Cleaner

\begin{tabular}{|c|c|c|c|c|c|c|c|c|c|}
\hline Cleaner & $\mathbf{S}$ & $\mathbf{C l}$ & $\mathrm{C}$ & $\mathbf{N}$ & $\mathbf{0}$ & $\mathbf{B a}$ & $\mathbf{C u}$ & $\mathbf{N a}$ & $\mathbf{S i}$ \\
\hline Armakleen E2001A & $1.33 \%$ & $0.06 \%$ & $27.99 \%$ & $0.87 \%$ & $13.26 \%$ & $0.00 \%$ & $41.00 \%$ & $0.01 \%$ & $15.48 \%$ \\
\hline Brulin 815GD & $0.94 \%$ & $0.16 \%$ & $50.52 \%$ & $1.75 \%$ & $8.64 \%$ & $0.00 \%$ & $37.22 \%$ & $0.12 \%$ & $0.64 \%$ \\
\hline Micro Cleaner & $0.96 \%$ & $0.20 \%$ & $53.13 \%$ & $2.13 \%$ & $6.94 \%$ & $0.00 \%$ & $36.62 \%$ & $0.02 \%$ & $0.00 \%$ \\
\hline Oakite NST & $1.28 \%$ & $0.13 \%$ & $54.32 \%$ & $1.71 \%$ & $7.36 \%$ & $0.00 \%$ & $35.13 \%$ & $0.06 \%$ & $0.00 \%$ \\
\hline Daraclean 282 & $4.36 \%$ & $0.10 \%$ & $57.26 \%$ & $2.75 \%$ & $4.97 \%$ & $0.00 \%$ & $30.48 \%$ & $0.02 \%$ & $0.07 \%$ \\
\hline TCE & $0.76 \%$ & $2.98 \%$ & $60.47 \%$ & $2.18 \%$ & $5.86 \%$ & $0.26 \%$ & $27.47 \%$ & -- & --- \\
\hline IPA/Cyclohexane Vapor & $0.76 \%$ & $0.39 \%$ & $63.12 \%$ & $1.97 \%$ & $6.40 \%$ & $0.00 \%$ & $27.24 \%$ & $0.11 \%$ & $0.00 \%$ \\
\hline Igepal CO-710 & $0.46 \%$ & $0.14 \%$ & $63.88 \%$ & $1.31 \%$ & $7.01 \%$ & $0.01 \%$ & $27.18 \%$ & $0.03 \%$ & -- \\
\hline Daraclean 212 & $0.26 \%$ & $0.19 \%$ & $69.41 \%$ & $4.13 \%$ & $4.14 \%$ & $0.00 \%$ & $21.87 \%$ & $0.01 \%$ & $0.00 \%$ \\
\hline Daraclean 235 & $0.21 \%$ & $0.21 \%$ & $74.34 \%$ & $4.91 \%$ & $3.06 \%$ & $0.00 \%$ & $17.17 \%$ & $0.01 \%$ & $0.08 \%$ \\
\hline IPA Vapor & $0.24 \%$ & $0.17 \%$ & $80.97 \%$ & $4.78 \%$ & $2.11 \%$ & $0.00 \%$ & $11.51 \%$ & $0.22 \%$ & $0.00 \%$ \\
\hline
\end{tabular}




\section{Table 18 - MESERAN Results}

\section{Trichloroethylene/Baseline Cleaner}

\begin{tabular}{|c|c|c|c|c|c|c|c|c|}
\hline \multirow{3}{*}{$\frac{\text { Lubricant }}{\text { Cook's } 4625}$} & \multicolumn{5}{|c|}{ Sample } & \multirow[b]{3}{*}{$=$} & \multirow{3}{*}{$\frac{\text { Ave. }}{2.20}$} & \multirow{3}{*}{$\frac{\text { Std. Dev }}{3.19}$} \\
\hline & $\frac{\# 1}{0}$ & \#2 & $\# 3$ & \#4 & $\frac{\# 5}{7}$ & & & \\
\hline & 0 & 0 & 4 & 0 & 7 & & & \\
\hline Cook's 4639D & 0 & 12 & 0 & 0 & 0 & $=$ & 2.40 & 5.37 \\
\hline Cook's S697 & 0 & 0 & 30 & 0 & 0 & $=$ & 6.00 & 13.42 \\
\hline 3-B Oil & 0 & 0 & 0 & 0 & 0 & $=$ & 0.00 & 0.00 \\
\hline$H \& B$ & 0 & 0 & 0 & 0 & 0 & $=$ & 0.00 & 0.00 \\
\hline Ivory Snow & 41 & 78 & 1 & 0 & 22 & $=$ & 28.40 & 32.47 \\
\hline Cimtap & 22 & 10 & 19 & 10 & 6 & $=$ & 13.40 & 6.77 \\
\hline Boelube & 59 & 22 & $\begin{array}{l}23 \\
\text { Ov }\end{array}$ & $\begin{array}{l}15 \\
11 \mathrm{~A}\end{array}$ & $\begin{array}{c}59 \\
\text { ages }\end{array}$ & $\begin{array}{l}= \\
=\end{array}$ & $\frac{35.60}{11.0}$ & $\frac{21.58}{10.35}$ \\
\hline
\end{tabular}

\section{LEGEND:}

MESERAN numbers less than 100 indicate good solvent cleaning effectivenenss (clean surface).

MESERAN numbers between 100 and 200 indicate moderate solvent cleaning effectiveness (islands of contamination are present).

MESERAN numbers greater than 200 indicate poor solvent cleaning effectiveness (gross contamination is present).

Notes: The MESERAN values shown were obtained by subtracting the clean standards from the raw data. 


\section{Igepal CO-710 In 0.5\% Aqueous Solution}

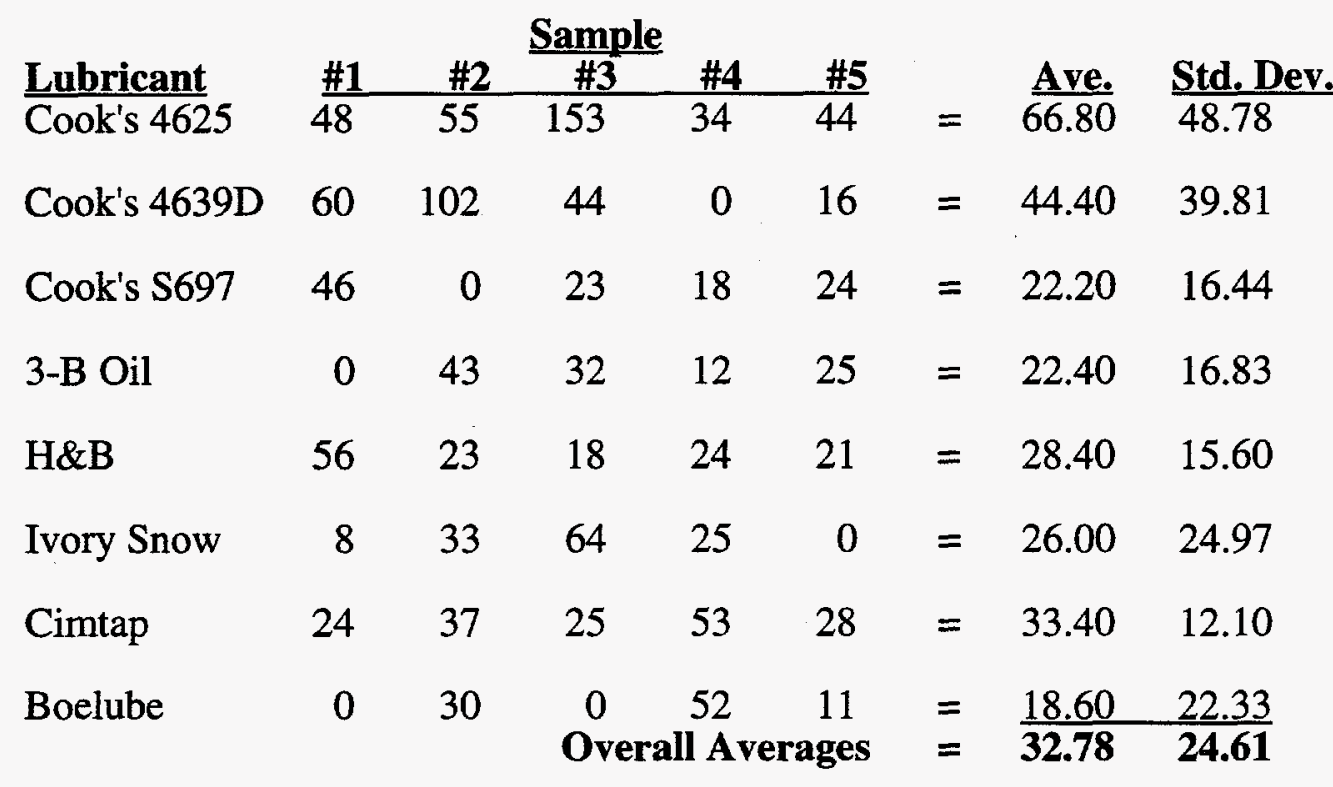

\section{LEGEND:}

MESERAN numbers less than 100 indicate good solvent cleaning effectivenenss (clean surface).

MESERAN numbers between 100 and 200 indicate moderate solvent cleaning effectiveness (islands of contamination are present).

MESERAN numbers greater than 200 indicate poor solvent cleaning effectiveness (gross contamination is present).

Notes: The MESERAN values shown were obtained by subtracting the clean standards from the raw data. The Igepal cleaning process appeared to slightly etch or stain the aluminum panels. Therefore, after the raw data was obtained, the panels were cleaned using a TCE ultrasonic cleaning/vapor degreasing process followed by a vacuum bake at $165^{\circ} \mathrm{F}$ for 1 hour and retested in the exact same spots to obtain clean standard numbers. 
Table 20 - MESERAN Results

\section{Daraclean 212 In 10\% Aqueous Solution}

\begin{tabular}{|c|c|c|c|c|c|c|c|c|}
\hline & & & Sample & & & & & \\
\hline$\frac{\text { Lubricant }}{\text { Cook's } 4625}$ & $\frac{\# 1}{0}$ & $\frac{\# 2}{0}$ & $\frac{\# 3}{0}$ & $\frac{\# 4}{0}$ & $\frac{\# 5}{0}$ & $=$ & $\frac{\text { Avg }_{\text {。 }}}{0.00}$ & $\frac{\text { Std. dev. }}{0.00}$ \\
\hline Cook's 4639D & 20 & 0 & 0 & 0 & 0 & $=$ & 4.00 & 8.94 \\
\hline Cook's S697 & 0 & 0 & 0 & 0 & 0 & $=$ & 0.00 & 0.00 \\
\hline 3-B Oil & 0 & 0 & 0 & 0 & 14 & $=$ & 2.80 & 6.26 \\
\hline$H \& B$ & 22 & 5 & 28 & 19 & 1 & $=$ & 15.00 & 11.51 \\
\hline Ivory Snow & 9 & 0 & 10 & 1 & 31 & $=$ & 10.20 & 12.48 \\
\hline Cimtap & 46 & 0 & 3 & 7 & 0 & $=$ & 11.20 & 19.66 \\
\hline Boelube & 77 & 21 & $\begin{array}{l}66 \\
\text { Overa }\end{array}$ & $\begin{array}{c}0 \\
11 \text { Ave }\end{array}$ & $\begin{array}{c}21 \\
\text { ages }\end{array}$ & $\begin{array}{l}= \\
=\end{array}$ & $\frac{37.00}{10.03}$ & $\frac{32.87}{11.47}$ \\
\hline
\end{tabular}

\section{LEGEND:}

MESERAN numbers less than 100 indicate good solvent cleaning effectivenenss (clean surface).

MESERAN numbers between 100 and 200 indicate moderate solvent cleaning effectiveness (islands of contamination are present).

MESERAN numbers greater than 200 indicate poor solvent cleaning effectiveness (gross contamination is present).

Notes: The MESERAN values shown were obtained by subtracting the clean standards from the raw data. 
Table 21 - MESERAN Results

\section{Daraclean 235 In $20 \%$ Aqueous Solution}

Sample

\begin{tabular}{|c|c|c|c|c|c|c|c|c|}
\hline Lubricant & $\# 1$ & \#2 & \#3 & \#4 & \#5 & & Ave. & Std. Dev \\
\hline Cook's 4625 & 39 & 38 & 24 & 19 & 19 & $=$ & 27.80 & 9.98 \\
\hline Cook's 4639D & 22 & 25 & 21 & 19 & 15 & $=$ & 20.40 & 3.71 \\
\hline Cook's S697 & 20 & 24 & 28 & 24 & 44 & $=$ & 28.00 & 9.38 \\
\hline 3-B Oil & 34 & 12 & 15 & 45 & 23 & $=$ & 25.80 & 13.70 \\
\hline$H \& B$ & 55 & 53 & 24 & 28 & 65 & $=$ & 45.00 & 17.99 \\
\hline Ivory Snow & 9 & 46 & 40 & 10 & 0 & $=$ & 21.00 & 20.57 \\
\hline Cimtap & 9 & 51 & 29 & 58 & 50 & $=$ & 39.40 & 20.16 \\
\hline Boelube & 15 & 61 & Ov & $\begin{array}{r}30 \\
11 \mathbf{A}\end{array}$ & $\begin{array}{l}49 \\
\text { ages }\end{array}$ & $\begin{array}{l}= \\
=\end{array}$ & $\frac{31.80}{29.90}$ & $\begin{array}{r}23.49 \\
14.87\end{array}$ \\
\hline
\end{tabular}

\section{LEGEND:}

MESERAN numbers less than 100 indicate good solvent cleaning effectivenenss (clean surface).

MESERAN numbers between 100 and 200 indicate moderate solvent cleaning effectiveness (islands of contamination are present).

MESERAN numbers greater than 200 indicate poor solvent cleaning effectiveness (gross contamination is present).

Notes: The MESERAN values shown were obtained by subtracting the clean standards from the raw data. 
Table 22 - MESERAN Results

\section{Daraclean 282 In 10\% Aqueous Solution}

\begin{tabular}{|c|c|c|c|c|c|c|c|c|}
\hline$\frac{\text { Lubricant }}{\text { Cook's } 4625}$ & $\frac{\# 1}{75}$ & $\frac{\# 2}{91}$ & $\frac{\frac{\text { Sampl }}{\# 3}}{\frac{\# 8}{58}}$ & $\frac{\# 4}{35}$ & $\frac{\# 5}{27}$ & $=$ & $\frac{\text { Ave. }}{57.00}$ & $\frac{\text { Std. Dev. }}{26.76}$ \\
\hline Cook's 4639D & 20 & 30 & 57 & 69 & 41 & $=$ & 43.40 & 19.83 \\
\hline Cook's S697 & 22 & 54 & 23 & 13 & 44 & $=$ & 31.20 & 17.08 \\
\hline 3-B Oil & 0 & 43 & 40 & 40 & 36 & $=$ & 31.80 & 17.95 \\
\hline$H \& B$ & 68 & 47 & 80 & 31 & 19 & $=$ & 61.60 & 45.05 \\
\hline Ivory Snow & 86 & 0 & 4 & 27 & 26 & $=$ & 28.60 & 34.38 \\
\hline Cimtap & 0 & 0 & 1 & 15 & 6 & $=$ & 4.40 & 6.43 \\
\hline Boelube & 15 & 0 & $\begin{array}{l}57 \\
\text { Ove }\end{array}$ & $\begin{array}{r}5 \\
\mathbf{A}\end{array}$ & $\begin{array}{c}63 \\
\text { ages }\end{array}$ & $\begin{array}{l}= \\
=\end{array}$ & $\frac{28.00}{35.75}$ & $\frac{29.78}{24.66}$ \\
\hline
\end{tabular}

\section{LEGEND:}

MESERAN numbers less than 100 indicate good solvent cleaning effectivenenss (clean surface).

MESERAN numbers between 100 and 200 indicate moderate solvent cleaning effectiveness (islands of contamination are present).

MESERAN numbers greater than 200 indicate poor solvent cleaning effectiveness (gross contamination is present).

Notes: The MESERAN values shown were obtained by subtracting the clean standards from the raw data. 
Table 23 - MESERAN Results

\section{Brulin 815GD In 10\% Aqueous Solution}

\begin{tabular}{|c|c|c|c|c|c|c|c|c|}
\hline \multirow{2}{*}{$\frac{\text { Lubricant }}{\text { Cook's } 4625}$} & & & \multirow{2}{*}{$\frac{\text { Ave. }}{40.40}$} & \multirow{2}{*}{$\frac{\text { Std. Dev. }}{23.52}$} \\
\hline & $\frac{m 1}{47}$ & $\frac{\text { t2 }}{78}$ & $\frac{\text { HI }}{22}$ & $\frac{+44}{34}$ & $\frac{H J}{21}$ & $=$ & & \\
\hline Cook's 4639D & 25 & 14 & 40 & 14 & 14 & $=$ & 21.40 & 11.44 \\
\hline Cook's S697 & 15 & 16 & 27 & 35 & 9 & $=$ & 20.40 & 10.43 \\
\hline 3-B Oil & 30 & 38 & 52 & 35 & 50 & $=$ & 41.00 & 9.59 \\
\hline $\mathrm{H} \& \mathrm{~B}$ & 31 & 12 & 27 & 36 & 23 & $=$ & 25.80 & 9.09 \\
\hline Ivory Snow & 0 & 30 & 33 & 0 & 30 & $=$ & 18.60 & 17.02 \\
\hline Cimtap & 7 & 9 & 0 & 0 & 0 & $=$ & 3.20 & 4.44 \\
\hline Boelube & 6 & 44 & $\begin{array}{c}0 \\
\text { Ove }\end{array}$ & $\begin{array}{l}39 \\
11 \mathrm{Av}\end{array}$ & $\begin{array}{c}48 \\
\text { ages }\end{array}$ & $\begin{array}{l}= \\
=\end{array}$ & $\frac{27.40}{24.78}$ & $\frac{22.60}{13.52}$ \\
\hline
\end{tabular}

\section{LEGEND:}

MESERAN numbers less than 100 indicate good solvent cleaning effectivenenss (clean surface).

MESERAN numbers between 100 and 200 indicate moderate solvent cleaning effectiveness (islands of contamination are present).

MESERAN numbers greater than 200 indicate poor solvent cleaning effectiveness (gross contamination is present).

Notes: The MESERAN values shown were obtained by subtracting the clean standards from the raw data. 
Table 24 - MESERAN Results

\section{Micro Cleaner In $10 \%$ Aqueous Solution}

\begin{tabular}{|c|c|c|c|c|c|c|c|c|}
\hline & & & Sampl & & & & & \\
\hline$\frac{\text { Lubricant }}{\text { Cook's } 4625}$ & $\frac{\# 1}{8}$ & $\frac{\# 2}{97}$ & $\frac{\# 3}{78}$ & $\frac{\# 4}{75}$ & $\frac{\# 5}{87}$ & $=$ & $\frac{\text { Ave. }}{69.00}$ & $\frac{\text { Std. dev }}{35.16}$ \\
\hline Cook's 4639D & 38 & 17 & 85 & 45 & 20 & $=$ & 41.00 & 27.29 \\
\hline Cook's S697 & 0 & 6 & 0 & 96 & 5 & $=$ & 21.40 & 41.79 \\
\hline 3-B Oil & 108 & 91 & 50 & 92 & 140 & $=$ & 96.20 & 32.55 \\
\hline$H \& B$ & 45 & 0 & 7 & 66 & 75 & $=$ & 38.60 & 33.93 \\
\hline Ivory Snow & 23 & 1 & 0 & 11 & 49 & $=$ & 16.80 & 20.25 \\
\hline Cimtap & 5 & 15 & 0 & 0 & 0 & $=$ & 4.00 & 6.52 \\
\hline Boelube & 0 & 0 & $\begin{array}{c}0 \\
\text { Over }\end{array}$ & $\begin{array}{l}0 \\
\text { Ave }\end{array}$ & $\begin{array}{l}46 \\
\text { ages }\end{array}$ & $\begin{array}{l}= \\
=\end{array}$ & $\frac{9.20}{37.03}$ & $\frac{20.57}{27.26}$ \\
\hline
\end{tabular}

\section{LEGEND:}

MESERAN numbers less than 100 indicate good solvent cleaning effectivenenss (clean surface).

MESERAN numbers between 100 and 200 indicate moderate solvent cleaning effectiveness (islands of contamination are present).

MESERAN numbers greater than 200 indicate poor solvent cleaning effectiveness (gross contamination is present).

Notes: The MESERAN values shown were obtained by subtracting the clean standards from the raw data. The Micro Clean cleaning process appeared to severely etch the aluminum panels. Therefore, after the raw data was obtained, the panels were cleaned using a TCE ultrasonic cleaning/vapor degreasing process followed by a vacuum bake at $165^{\circ} \mathrm{F}$ for 1 hour and retested in the exact same spots to obtain clean standard numbers. 
Table 25 - MESERAN Results

Oakite NST/10\%

\begin{tabular}{|c|c|c|c|c|c|c|c|c|}
\hline \multirow[b]{2}{*}{$\frac{\text { Lubricant }}{\text { Cook's } 4625}$} & \multicolumn{5}{|c|}{ Sample } & \multirow[b]{2}{*}{$=$} & \multirow[b]{2}{*}{$\frac{\text { Ave. }}{71.60}$} & \multirow[b]{2}{*}{$\frac{\text { Std. dev. }}{24.23}$} \\
\hline & 107 & $\frac{\# 2}{41}$ & $\frac{\# 3}{66}$ & $\frac{\# 4}{80}$ & $\frac{\# 5}{64}$ & & & \\
\hline Cook's 4639D & 39 & 60 & 122 & 78 & 68 & $=$ & 73.40 & 30.72 \\
\hline Cook's S697 & 0 & 53 & 27 & 51 & 5 & $=$ & 27.20 & 24.82 \\
\hline 3-B Oil & 12 & 2 & 85 & 34 & 21 & $=$ & 30.80 & 32.51 \\
\hline $\mathrm{H} \& \mathrm{~B}$ & 66 & 0 & 14 & 0 & 78 & $=$ & 31.60 & 37.56 \\
\hline Ivory Snow & 0 & 0 & 0 & 496 & 0 & $=$ & 99.20 & 221.82 \\
\hline Cimtap & 42 & 0 & 0 & 18 & 2 & $=$ & 12.40 & 18.19 \\
\hline Boelube & 0 & 0 & $\begin{array}{l}47 \\
\text { Ove }\end{array}$ & $\begin{array}{l}0 \\
11 \\
\mathbf{A v}\end{array}$ & $\begin{array}{r}0 \\
\text { ges }\end{array}$ & $\begin{array}{l}= \\
=\end{array}$ & $\frac{9.40}{44.45}$ & $\frac{21.02}{51.36}$ \\
\hline
\end{tabular}

\section{LEGEND:}

MESERAN numbers less than 100 indicate good solvent cleaning effectivenenss (clean surface).

MESERAN numbers between 100 and 200 indicate moderate solvent cleaning effectiveness (islands of contamination are present).

MESERAN numbers greater than 200 indicate poor solvent cleaning effectiveness (gross contamination is present).

Notes: The MESERAN values shown were obtained by subtracting the clean standards from the raw data. The Oakite NST cleaning process appeared to moderately etch the aluminum panels. Therefore, after the raw data was obtained, the panels were cleaned using a TCE ultrasonic cleaning/vapor degreasing process followed by a vacuum bake at $165^{\circ} \mathrm{F}$ for 1 hour and retested in the exact same spots to obtain clean standard numbers. 


\section{Table 26 - MESERAN Results}

\section{Isopropyl Alcohol Ultrasonics/Vapor Degrease/S\&K Products}

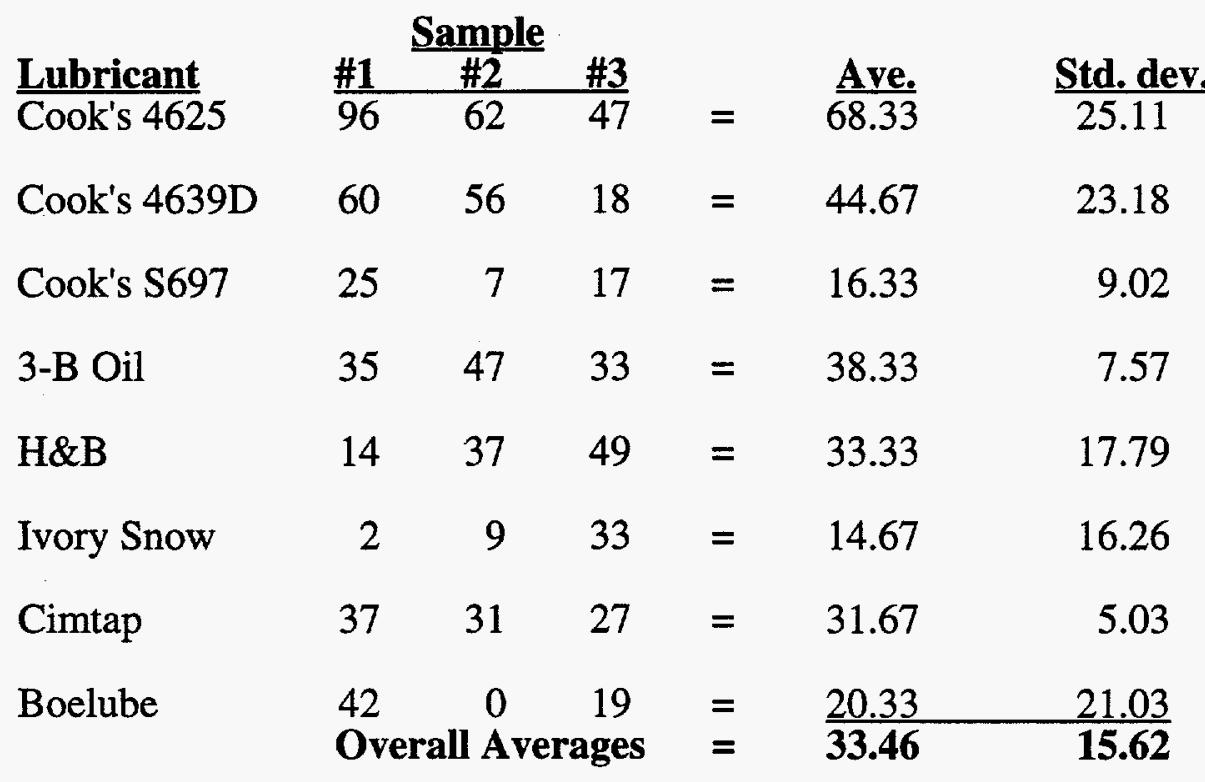

LEGEND:

MESERAN numbers less than 100 indicate good solvent cleaning effectivenenss (clean surface).

MESERAN numbers between 100 and 200 indicate moderate solvent cleaning effectiveness (islands of contamination are present).

MESERAN numbers greater than 200 indicate poor solvent cleaning effectiveness (gross contamination is present).

Notes: The MESERAN values shown were obtained by subtracting the clean standards from the raw data. 


\section{Table 27 - MESERAN Results}

\section{0\% Isopropyl Alcohol/20\% Cyclohexane Immersion/Vapor Degrease S\&K Products}

\begin{tabular}{|c|c|c|c|c|c|c|}
\hline \multirow{3}{*}{$\begin{array}{l}\text { Lubricant } \\
\text { Cook's } 4625\end{array}$} & \multicolumn{3}{|c|}{ Sample } & & \multirow{3}{*}{$\frac{\text { Ave. }}{18.33}$} & \multirow{3}{*}{$\frac{\text { Std. dev. }}{10.97}$} \\
\hline & $\frac{\# 1}{21}$ & $\# 2$ & $\frac{\# 3}{27}$ & & & \\
\hline & 22 & 6 & 27 & $=$ & & \\
\hline Cook's 4639D & 18 & 27 & 27 & $=$ & 24.00 & 5.20 \\
\hline Cook's S697 & 11 & 26 & 38 & $=$ & 25.00 & 13.53 \\
\hline 3-B Oil & 12 & 2 & 63 & $=$ & 25.67 & 32.72 \\
\hline $\mathrm{H} \& \mathrm{~B}$ & 0 & 31 & 10 & $=$ & 13.67 & 15.82 \\
\hline Ivory Snow & 271 & 692 & 755 & $=$ & 572.67 & 263.14 \\
\hline Cimtap & 29 & 0 & 0 & $=$ & 9.67 & 16.74 \\
\hline Boelube & $\begin{array}{c}7 \\
\text { Ov }\end{array}$ & $\begin{array}{r}20 \\
\text { all A }\end{array}$ & $\begin{array}{c}7 \\
\text { ges }\end{array}$ & $=$ & $\frac{11.33}{87.54}$ & $\frac{7.51}{45.70}$ \\
\hline
\end{tabular}

\section{LEGEND:}

MESERAN numbers less than 100 indicate good solvent cleaning effectivenenss (clean surface).

MESERAN numbers between 100 and 200 indicate moderate solvent cleaning effectiveness (islands of contamination are present).

MESERAN numbers greater than 200 indicate poor solvent cleaning effectiveness (gross contamination is present).

Notes: The MESERAN values shown were obtained by subtracting the clean standards from the raw data. 
Table 28

Average MESERAN Numbers and

Standard Deviations for Cleaners Tested

\begin{tabular}{llccc} 
Cleaner & $\begin{array}{l}\text { How Data } \\
\text { Was Obtained }\end{array}$ & $\begin{array}{c}\text { Average } \\
\text { Meseran \# }\end{array}$ & $\begin{array}{c}\text { \# of } \\
\text { Dirty Panels }\end{array}$ & $\begin{array}{c}\text { Ave. Std. } \\
\text { Dev. }\end{array}$ \\
\hline TCE & (raw data - clean standard) & 11.00 & 0 & 10.35 \\
Igepal 710 & (raw data - clean standard) & 32.78 & 2 & 24.61 \\
Daraclean 212 & (raw data - clean standard) & 10.03 & 0 & 11.47 \\
Daraclean 235 & (raw data - clean standard) & 29.90 & 0 & 14.87 \\
Daraclean 282 & (raw data - clean standard) & 35.75 & 1 & 24.66 \\
Brulin 815 GD & (raw data - clean standard) & 24.78 & 0 & 13.52 \\
Micro Cleaner & (raw data - clean standard) & 37.03 & 2 & 27.26 \\
Oakite NST & (raw data - clean standard) & 44.45 & 3 & 51.36 \\
IPA & (raw data - clean standard) & 33.46 & 0 & 15.62 \\
IPA/Cyclohexane & (raw data - clean standard) & 87.54 & 3 & 45.70
\end{tabular}

Table 29 - Switch Tube Etch Rate Study

Cleaner

Al Concentration

pre-clean $(\mu \mathrm{g} / \mathrm{mL})$

TCE

$0.5 \%$ Igepal 710

10\% Daraclean 212

20\% Daraclean 235

10\% Daraclean 282

$10 \%$ Brulin 815 GD

10\% Microclean

!0\% Oakite NST

$$
<1
$$

$<1$

$<1$

$<1$

$<1$

$<1$

$<1$

$<1$
30 minutes, $135^{\circ} \mathrm{F}$

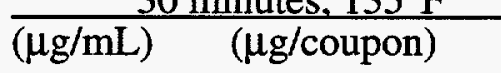

$<1$

$<20$

$<20$

$<20$

$<20$

$<20$

$<20$

3400

1000 (mil/min.)

$<5.00 \mathrm{E}-05$

$<5.00 \mathrm{E}-05$

$<5.00 \mathrm{E}-05$

$<5.00 \mathrm{E}-05$

$<5.00 \mathrm{E}-05$

$<5.00 \mathrm{E}-05$

8.00E-03

2.50E-03 
Table 30 - Immersion Tests/17 Hour Exposure

TCE Pre-Immersion Weight (gms)

Gold Sample Kapton Sample $\underline{\text { Sn/Pb Sample }}$ Alumina Sample .

\begin{tabular}{|c|c|c|c|c|c|c|c|c|c|c|}
\hline & $\# 1$ & \#2 & \#3 & $\# 1$ & $\# 2$ & \#3 & $\# 1$ & $\# 2$ & \#3 & $\# 1$ \\
\hline & 0.2793 & 0.3034 & 0.2205 & 0.0276 & 0.0292 & 0.0334 & 0.0869 & 0.0871 & 0.0904 & 17.3290 \\
\hline & 0.279 & 0.3035 & 0.2205 & 0.0276 & 0.029 & 0.0334 & 0.0869 & 0.0871 & 0.0904 & \\
\hline & 0.2793 & 0.3035 & 0.2204 & 0.0276 & 0.0291 & 0.0335 & 0.0870 & 0.0871 & 0.0903 & 17.3289 \\
\hline & 0.2973 & 0.3035 & 0.2205 & 0.0276 & 0.0291 & 0.0334 & 0.0869 & 0.0871 & 0.0904 & 17.3289 \\
\hline
\end{tabular}

TCE Post-Immersion Weight (gms)

Gold Sample $\quad \underline{\text { Kapton Sample }} \quad \underline{\mathrm{Sn} / \mathrm{Pb} \text { Sample }} \quad \underline{\text { Alumina Sample }}$

\begin{tabular}{|c|c|c|c|c|c|c|c|c|c|c|}
\hline & $\# 1$ & \#2 & \#3 & $\# 1$ & \#2 & $\# 3$ & $\# 1$ & $\# 2$ & $\# 3$ & $\# 1$ \\
\hline & $0.2 \overline{792}$ & 0.3034 & 0.2205 & 0.0290 & 0.0304 & 0.0349 & 0.0868 & 0.0871 & 0.0903 & 17.3 \\
\hline & 0.2793 & 0.3034 & 0.2205 & 0.0291 & 0.0303 & 0.0347 & 0.0869 & 0.0871 & 0.0903 & 1 \\
\hline & 0.2793 & 0.3034 & 0.2204 & 0.0291 & 0.0304 & 0.0348 & 0.0869 & 0.0871 & 0.0903 & 17 \\
\hline AVG & 0.2793 & 0.3034 & 0.2205 & 0.0291 & 0.0304 & 0.0348 & 0.0869 & 0.0871 & 0.0903 & \\
\hline & ige & 02 & 000 & 53. & 423 & 409 & -008 & 000 & -007 & 00 \\
\hline
\end{tabular}

Table 31 - Immersion Test /17 Hour Exposure

TCE Pre-Immersion Weight (gms)

$\underline{\text { Aluminum }} \quad \underline{\text { Copper }} \quad \underline{\text { Sovar }} \underline{\text { Palco }}$

\begin{tabular}{|c|c|c|c|c|c|c|c|c|c|c|c|}
\hline$\# 1$ & \#2 & $\# 3$ & $\# 1$ & \#2 & $\# 3$ & $\# 1$ & $\# 2$ & \#3 & $\# 1$ & $\# 2$ & (3 \\
\hline 4032 & .4048 & .4023 & .4195 & .5056 & .4652 & 1.0699 & 1.1430 & 1.0373 & .0470 & .0419 & .0446 \\
\hline .4032 & .40 & .402 & .415 & .5055 & .46 & 1.0699 & & 1.0373 & .0469 & .0420 & .0447 \\
\hline .4031 & .4049 & .4022 & .4195 & .5056 & .4655 & 1.0699 & 1.1430 & 1.0374 & .0470 & .0419 & .0446 \\
\hline .403 & .40 & .4023 & .419 & .5056 & .4654 & 1.0699 & 1.1430 & 1.0373 & .0470 & .0419 & .0446 \\
\hline
\end{tabular}

TCE Post-Immersion Weight (gms)

$\underline{\text { Aluminum }} \quad \underline{\text { Copper }} \quad \underline{\text { Kovar }} \quad \underline{\text { Palco }}$

$\begin{array}{cccccccccccc}\# 1 & \# 2 & \# 3 & \# 1 & \# 2 & \# 3 & \# 1 & \# 2 & \# 3 & \# 1 & \# 2 & \# 3 \\ .4013 & .4048 & .4023 & .4195 & .5056 & .4654 & 1.0700 & 1.1430 & 1.0373 & .0469 & .0419 & .0447 \\ .4031 & .4048 & .4022 & .4195 & .5056 & .4655 & 1.0700 & 1.1430 & 1.0373 & .0470 & .0419 & .0448 \\ .4032 & .4048 & .4022 & .4195 & .5055 & .4655 & 1.0700 & 1.1430 & 1.0373 & .0470 & .0418 & .0448 \\ .4031 & .4048 & .4022 & .4195 & .5056 & .4655 & 1.0700 & 1.1430 & 1.0373 & .0470 & .0419 & .0448\end{array}$

\% Change

$\begin{array}{llllllllllll}-0.01 & -0.02 & -0.01 & 0.02 & 0.00 & 0.01 & 0.01 & 0.00 & 0.00 & 0.00 & -0.16 & 0.30\end{array}$ 
Table 32 - Immersion Test /17 Hour Exposure

TCE Pre-Immersion Weight (gms)

\begin{tabular}{|c|c|c|c|c|c|}
\hline \multicolumn{3}{|c|}{ Molybdenum } & \multicolumn{3}{|c|}{ Niobium } \\
\hline$\# 1$ & $\# 2$ & \#3 & $\# 1$ & $\# 2$ & $\# 3$ \\
\hline 0.3962 & 0.3870 & 0.5063 & 0.1329 & 0.1329 & 0.1341 \\
\hline 0.3962 & 0.3870 & 0.5061 & 0.1329 & 0.1329 & 0.1341 \\
\hline 0.3962 & 0.3869 & 0.5062 & 0.1329 & 0.1329 & 0.1341 \\
\hline 0.3962 & 0.3870 & 0.5062 & 0.1329 & 0.1329 & 0.1341 \\
\hline
\end{tabular}

TCE Post Immersion Weight (gms)

Molybdenum

\begin{tabular}{|c|c|c|c|c|c|}
\hline \multicolumn{3}{|c|}{ Molybdenum } & \multicolumn{3}{|c|}{ Niobium } \\
\hline \#1 & \#2 & \#3 & $\# 1$ & $\# 2$ & $\# 3$ \\
\hline $0 . \overline{3962}$ & 0.3870 & 0.5062 & 0.1329 & 0.1329 & 0.1341 \\
\hline 0.3962 & 0.3870 & 0.5063 & 0.1329 & 0.1330 & 0.1341 \\
\hline 0.3962 & 0.3869 & 0.5062 & 0.1328 & 0.1330 & 0.1341 \\
\hline AVG 0.3962 & 0.3870 & 0.5062 & 0.1329 & 0.1330 & 0.1341 \\
\hline Chang & & & & & \\
\hline 0.00 & 0.00 & 0.01 & -0.03 & 0.05 & 0.00 \\
\hline
\end{tabular}

Table 33 - Immersion Test /17 Hour Exposure

Brulin 815GD Pre-Immersion Weight (grams)

$\underline{\mathrm{Sn} / \mathrm{Pb} \text { Solder Samples }}$

Kapton Samples

Alumina Sample

$\begin{array}{ccccccc}\# 1 & \# 2 & \# 3 & \# 1 & \# 2 & \# 3 & \# 1 \\ 0.0942 & 0.0901 & 0.0834 & 0.0303 & 0.0293 & 0.0273 & 17.3031 \\ 0.0941 & 0.0901 & 0.0834 & 0.0303 & 0.0293 & 0.0273 & 17.3031 \\ 0.0942 & 0.0900 & 0.0835 & 0.0302 & 0.0292 & 0.0273 & 17.3031 \\ 0.0942 & 0.0901 & 0.0834 & 0.0303 & 0.0293 & 0.0273 & 17.3031\end{array}$

Brulin 815GD Post-Immersion Weight (grams)

$\underline{\mathrm{Sn} / \mathrm{Pb} \text { Solder Samples }}$

$\begin{array}{ccccccc}\# 1 & \# 2 & \# 3 & \# 1 & \# 2 & \# 3 & \# 1 \\ 0.0942 & 0.0900 & 0.0834 & 0.0306 & 0.0296 & 0.0277 & 17.3029 \\ 0.0941 & 0.0899 & 0.0835 & 0.0301 & 0.0297 & 0.0276 & 17.3029 \\ 0.0943 & 0.0899 & 0.0835 & 0.0306 & 0.0296 & 0.0276 & 17.3029 \\ 0.0942 & 0.0899 & 0.0835 & 0.0306 & 0.0296 & 0.0276 & 17.3029\end{array}$

AVG 0.0942

\% Change
0.04
$-0.15+0.04$
$+1.21$
$+1.25$
$+1.22$
$-0.0012$ 
Table 34 - Immersion Test /17 Hour Exposure

Brulin 815GD Pre-Immersion Weight (gms)

Aluminum Samples

Gold Samples

$\begin{array}{cccccc}\# 1 & \# 2 & \# 3 & \# 1 & \# 2 & \# 3 \\ 0.4023 & 0.4028 & 0.4023 & 0.2385 & 0.2361 & 0.2622 \\ 0.4023 & 0.4028 & 0.4022 & 0.2384 & 0.2361 & 0.2622 \\ 0.4023 & 0.4028 & 0.4023 & 0.2385 & 0.2361 & 0.2622 \\ \text { AVG } 0.4023 & 0.4028 & 0.4023 & 0.2385 & 0.2361 & 0.2622\end{array}$

\section{Brulin 815GD Post-Immersion Weight (gms)}

\begin{tabular}{|c|c|c|c|c|c|}
\hline \multicolumn{3}{|c|}{ Aluminum Samples } & \multicolumn{3}{|c|}{ Gold Samples } \\
\hline$\# 1$ & \#2 & \#3 & \#1 & $\# 2$ & $\# 3$ \\
\hline 0.4023 & 0.4028 & 0.4028 & 0.2385 & 0.2361 & 0.2622 \\
\hline 0.4024 & 0.4028 & 0.4028 & 0.2385 & 0.2361 & 0.2621 \\
\hline 0.4024 & 0.4028 & 0.4029 & 0.2385 & 0.2361 & 0.2622 \\
\hline AVG 0.4024 & 0.4028 & 0.4028 & 0.2385 & 0.2361 & 0.2622 \\
\hline$\frac{\text { \% Change }}{0.00}$ & & & & & \\
\hline 0.02 & 0.00 & 0.14 & 0.01 & 0.00 & -0.01 \\
\hline
\end{tabular}

Table 35

Brulin 815GD Pre-Immersion Weight (gms)

Aluminum Samples Copper Samples $\quad \underline{\text { Kovar Samples }} \quad \underline{\text { Palco Samples }}$

\begin{tabular}{|c|c|c|c|c|c|c|c|c|c|c|c|}
\hline$\# 1$ & \#2 & $\# 3$ & $\# 1$ & $\# 2$ & $\# 3$ & $\# 1$ & $\# 2$ & \#3 & $\# 1$ & \#2 & $\# 3$ \\
\hline 4038 & .4023 & .4026 & .5024 & .4903 & .4326 & 1.5167 & 1.2605 & 1.0545 & .0493 & .0430 & .0465 \\
\hline 4038 & .4022 & .4025 & .5025 & .4905 & .4326 & 1.5167 & 1.2605 & 1.0547 & .0492 & .0431 & .0466 \\
\hline 4038 & .4023 & .4025 & .5025 & .4905 & . 4326 & 1.5166 & 1.2605 & 1.0547 & .0493 & .0431 & 0465 \\
\hline 4038 & .4023 & .4025 & .5025 & .4904 & .4326 & 1.5167 & 1.2605 & 1.0546 & .0493 & .0431 & 0465 \\
\hline
\end{tabular}

Brulin 815GD Post-Immersion Weight (gms)

Aluminum Samples Copper Samples $\quad \underline{\text { Kovar Samples }} \quad$ Palco Samples

$\begin{array}{cccccccccccc}\# 1 & \# 2 & \# 3 & \# 1 & \# 2 & \# 3 & \# 1 & \# 2 & \# 3 & \# 1 & \# 2 & \# 3 \\ .4038 & .4022 & .4025 & .5023 & .4903 & .4325 & 1.5167 & 1.2605 & 1.0547 & .0492 & .0432 & .0466 \\ .4039 & .4023 & .4025 & .5022 & .4903 & .4324 & 1.5166 & 1.2605 & 1.0548 & .0492 & .0432 & .0466 \\ .4038 & .4022 & .4026 & .5023 & .4903 & .4325 & 1.5166 & 1.2605 & 1.0547 & .0493 & .0431 & .0466 \\ .4038 & .4022 & .4025 & .5023 & .4903 & .4325 & 1.5166 & 1.2605 & 1.0547 & .0492 & .0432 & .0466\end{array}$

\% Change
$0.01-0.0$
$\begin{array}{llll}0.00 & -0.04 & -0.03 & -0.03\end{array}$
$0.00 \quad 0.00$
$\begin{array}{ll}0.01 & -0.07\end{array}$
0.23
0.14 
Table 36 - Immersion Test /17 Hour Exposure

Brulin 815GD Pre-Immersion Weight (gms)

Molybdenum

Niobium

\begin{tabular}{|c|c|c|c|c|c|}
\hline$\# 1$ & $\# 2$ & $\# 3$ & \#1 & \#2 & $\# 3$ \\
\hline $0 . \overline{3272}$ & 0.4628 & 0.3966 & 0.1406 & 0.1392 & 0.1398 \\
\hline 0.3273 & 0.4628 & 0.3968 & 0.1406 & 0.1392 & 0.1398 \\
\hline 0.3273 & 0.4628 & 0.3968 & 0.1405 & 0.1393 & 0.1398 \\
\hline G 0.3273 & 0.4628 & 0.3967 & 0.1406 & 0.1392 & 0.1398 \\
\hline
\end{tabular}

Brulin 815GD Post-Immersion Weight (gms)

\begin{tabular}{|c|c|c|c|c|c|}
\hline \multicolumn{3}{|c|}{ Molybdenum } & \multicolumn{3}{|c|}{ Niobium } \\
\hline$\# 1$ & $\# 2$ & \#3 & $\# 1$ & \#2 & \#3 \\
\hline $0 . \overline{3271}$ & 0.4626 & 0.3966 & 0.1404 & 0.1393 & 0.1399 \\
\hline 0.3271 & 0.4626 & 0.3966 & 0.1404 & 0.1392 & 0.1399 \\
\hline 0.3271 & 0.4626 & 0.3966 & 0.1405 & 0.1392 & 0.1399 \\
\hline AVG 0.3271 & 0.4626 & 0.3966 & 0.1404 & 0.1392 & 0.1399 \\
\hline $\begin{array}{c}\text { Change } \\
-0.05\end{array}$ & -0.04 & -0.03 & -0.09 & 0.00 & 0.07 \\
\hline
\end{tabular}

Table 37

Oakite NST Pre-Immersion Weight (grams)

$\underline{\mathrm{Sn} / \mathrm{Pb} \text { Solder Samples } \quad \text { Kapton Samples } \quad \text { Alumina Sample }}$

$\begin{array}{ccccccc}\# 1 & \# 2 & \# 3 & \# 1 & \# 2 & \# 3 & \# 1 \\ 0.0857 & 0.0878 & 0.0901 & 0.0284 & 0.0289 & 0.0278 & 17.2873 \\ 0.0858 & 0.0878 & 0.0902 & 0.0286 & 0.0289 & 0.0279 & 17.2872 \\ 0.0857 & 0.0879 & 0.0901 & 0.0285 & 0.0289 & 0.0278 & 17.2871 \\ 0.0857 & 0.0878 & 0.0901 & 0.0285 & 0.0289 & 0.0278 & 17.2872\end{array}$

Oakite NST Post-Immersion Weight (grams)

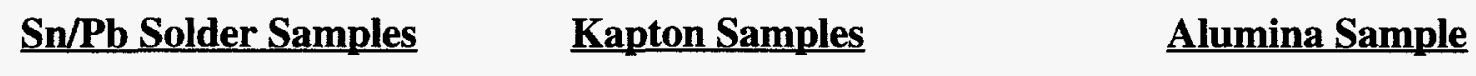

$\begin{array}{ccccccc}\# 1 & \# 2 & \# 3 & \# 1 & \# 2 & \# 3 & \# 1 \\ 0.0856 & 0.0878 & 0.0900 & 0.0291 & 0.0294 & 0.0284 & 17.2871 \\ 0.0856 & 0.0877 & 0.0900 & 0.0290 & 0.0293 & 0.0284 & 17.2869 \\ 0.0856 & 0.0877 & 0.0899 & 0.0290 & 0.0294 & 0.0284 & 17.2869 \\ 0.0856 & 0.0877 & 0.0900 & 0.0290 & 0.0294 & 0.0284 & 17.2870\end{array}$

\% Change

$\begin{array}{lllllll}-0.16 & -0.11 & -0.18 & +1.87 & +1.61 & +2.04 & -0.0010\end{array}$


Table 38- Immersion Test /17 Hour Exposure

Oakite NST Pre-Immersion Weight (gms)

Copper

Gold

Molybdenum

\begin{tabular}{|c|c|c|c|c|c|c|c|c|}
\hline$\# 1$ & $\# 2$ & \#3 & $\# 1$ & $\# 2$ & $\# 3$ & $\# 1$ & $\# 2$ & $\# 3$ \\
\hline 0.4427 & 0.4894 & 0.5933 & 0.2834 & 0.5201 & 0.2164 & 0.1544 & 0.1954 & $\overline{0.29} 83$ \\
\hline 0.4427 & 0.4893 & 0.5933 & 0.2835 & 0.5201 & 0.2164 & 0.1544 & 0.1954 & 0.2893 \\
\hline 0.4427 & 0.4893 & 0.5933 & 0.2835 & 0.5201 & 0.2164 & 0.1544 & 0.1954 & 0.2893 \\
\hline 0.4427 & 0.4893 & 0.5933 & 0.2835 & 0.5201 & 0.2164 & 0.1544 & 0.1954 & 0.2893 \\
\hline
\end{tabular}

Oakite NST Post Immersion Weight (gms)

Copper

Gold

Molybdenum

$\begin{array}{ccccccccc}\# 1 & \# 2 & \# 3 & \# 1 & \# 2 & \# 3 & \# 1 & \# 2 & \# 3 \\ 0.4427 & 0.4893 & 0.5933 & 0.2835 & 0.5201 & 0.2165 & 0.1543 & 0.1953 & 0.2981 \\ 0.4427 & 0.4892 & 0.5933 & 0.2835 & 0.5201 & 0.2164 & 0.1542 & 0.1953 & 0.2982 \\ 0.4427 & 0.4892 & 0.5933 & 0.2835 & 0.5202 & 0.2164 & 0.1542 & 0.1953 & 0.2982 \\ \text { AVG } 0.4427 & 0.4892 & 0.5933 & 0.2835 & 0.5201 & 0.2164 & 0.1542 & 0.1953 & 0.2982 \\ & & & & & & & & \\ \begin{array}{c}\text { \% Change } \\ 0.00\end{array} & -0.02 & 0.00 & 0.01 & 0.01 & 0.02 & -0.11 & -0.05 & -0.04\end{array}$

Table 39 - Immersion Test /17 Hour Exposure

Oakite NST Pre-Immersion Weight (gms)

\begin{tabular}{|c|c|c|c|c|c|}
\hline \multicolumn{3}{|c|}{ Niobium } & \multicolumn{3}{|c|}{ Palco } \\
\hline$\# 1$ & \#2 & \#3 & $\# 1$ & $\# 2$ & \#3 \\
\hline 0.1451 & 0.1459 & 0.1442 & 0.0425 & 0.0340 & 0.0396 \\
\hline 0.1450 & 0.1459 & 0.1442 & 0.0424 & 0.0341 & 0.0396 \\
\hline 0.1450 & 0.1459 & 0.1443 & 0.0424 & 0.0341 & 0.0396 \\
\hline 0.1450 & 0.1459 & 0.1442 & 0.0424 & 0.0341 & 0.0396 \\
\hline
\end{tabular}

Oakite NST Post - Immersion Weight (gms)

Niobium

$$
\# 1
$$

0.1450

0.1450

0.1450

AVG 0.1450

\% Change

Palco

$\begin{array}{ccccc}\# 2 & \# 3 & \# 1 & \# 2 & \# 3 \\ 0.1458 & 0.1443 & 0.0425 & 0.0341 & 0.0395 \\ 0.1459 & 0.1443 & 0.0425 & 0.0341 & 0.0396 \\ 0.1459 & 0.1443 & 0.0425 & 0.0341 & 0.0396 \\ 0.1459 & 0.1443 & 0.0425 & 0.0341 & 0.0396\end{array}$
$\begin{array}{ll}-0.02 & 0.05\end{array}$
0.16
$-0.02$
0.10
$-0.08$

0.05 
Table 40 - Clean Test

Trichloroethylene Pre-Clean Weight (grams)

\begin{tabular}{|c|c|c|c|c|c|c|c|c|c|c|}
\hline \multicolumn{3}{|c|}{ Palco Wire } & \multicolumn{3}{|c|}{ Aluminum Slugs } & \multirow{2}{*}{$\begin{array}{r}\text { Moly } \\
\# 1\end{array}$} & \multirow{2}{*}{$\begin{array}{c}\text { Kovar } \\
\# 1\end{array}$} & \multicolumn{3}{|c|}{ 304L } \\
\hline$\# 1$ & $\# 2$ & \#3 & Smal & Medium & Large & & & $\# 1$ & $\# 2$ & $\# 3$ \\
\hline 104 & 0.1054 & 0.1065 & 1.2840 & 1.0813 & 1.9109 & 2.4621 & 1.8607 & 1.6843 & 1.6317 & 1.7358 \\
\hline & & 0.10 & 1.28 & 1.08 & 1.9 & & 1.8 & & & \\
\hline 0. & 0.1055 & 0.1066 & 1.2839 & 1.0813 & 1.9109 & 2.4 & 1.8 & 1.68 & 1.6 & 1.7358 \\
\hline 0.10 & 0.1055 & 0.1066 & 1.2840 & 1.0813 & 1.9109 & 2.4621 & 1.8608 & 1.6843 & 1.6317 & 1.7358 \\
\hline
\end{tabular}

Trichloroethylene Post-Clean Weight (grams)

\begin{tabular}{|c|c|c|c|c|c|c|c|c|c|c|}
\hline \multicolumn{3}{|c|}{ Palco Wire } & \multicolumn{3}{|c|}{ Aluminum Slugs } & \multirow{2}{*}{$\begin{array}{r}\text { Moly } \\
\# 1\end{array}$} & \multirow{2}{*}{ Kovar } & \multicolumn{3}{|c|}{$\underline{304 L}$} \\
\hline \#1 & \#2 & \#3 & Small & Medium & Large & & & $\# 1$ & $\# 2$ & \#3 \\
\hline $0 . \overline{1046}$ & 0.1054 & 0.1067 & 1.2839 & 1.0812 & 1.9109 & 2.4618 & 1.8608 & 1.6843 & 1.6318 & 1.7357 \\
\hline 0.1046 & 0.1055 & 0.1066 & 1.2839 & 1.0812 & 1.9108 & 2.4618 & 1.8608 & 1.6843 & 1.6317 & 1.7358 \\
\hline 0.1046 & 0.1055 & 0.1066 & 1.2840 & 1.0812 & 1.9108 & 2.4617 & 1.8608 & 1.6843 & 1.6317 & 1.7358 \\
\hline AVG 0.1046 & 0.1055 & 0.1066 & 1.2839 & 1.0812 & 1.9108 & 2.4618 & 1.8608 & 1.6843 & 1.6317 & 1.7358 \\
\hline Chat & & & & & & & & & & \\
\hline 0 & 0.00 & 0.00 & -0.01 & -0.01 & -0.01 & -0.01 & 0.00 & 0.00 & 0.00 & 0.00 \\
\hline
\end{tabular}

Table 41- Clean Test

Brulin 815GD Pre-clean Weight (grams)

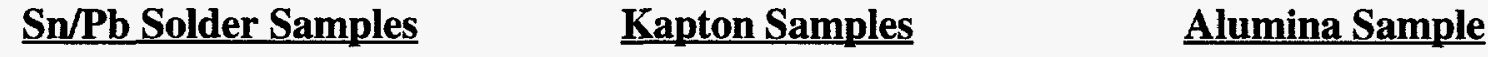

\begin{tabular}{ccccccc}
$\# 1$ & $\# 2$ & $\# 3$ & $\# 1$ & $\# 2$ & $\# 3$ & $\# 1$ \\
\hline 0.0906 & 0.0904 & 0.0865 & 0.0264 & 0.0294 & 0.0276 & 17.2795 \\
0.0906 & 0.0904 & 0.0865 & 0.0264 & 0.0294 & 0.0276 & 17.2795 \\
0.0906 & 0.0904 & 0.0865 & 0.0264 & 0.0293 & 0.0276 & 17.2795 \\
AVG 0.0906 & 0.0904 & 0.0865 & 0.0264 & 0.0293 & 0.0276 & 17.2795
\end{tabular}

\section{Brulin 815GD Post-Clean Weight (grams)}

$\underline{\mathrm{Sn} / \mathrm{Pb} \text { Solder Samples }}$

$\begin{array}{ccccccc}\# 1 & \# 2 & \# 3 & \# 1 & \# 2 & \# 3 & \# 1 \\ 0.0878 & 0.0884 & 0.0848 & 0.0266 & 0.0296 & 0.0279 & 17.2780 \\ 0.0877 & 0.0882 & 0.0848 & 0.0266 & 0.0296 & 0.0279 & 17.2870 \\ 0.0878 & 0.0881 & 0.0848 & 0.0265 & 0.0296 & 0.0279 & 17.2780 \\ 0.0878 & 0.0882 & 0.0848 & 0.0266 & 0.0296 & 0.0279 & 17.2780\end{array}$

AVG 0.0878

\% Change

$-3.13$
$-2.40$

$-1.97$

$+0.63$

$+0.79$

$+1.09$

$-0.01$ 
Table 42- Clean Test

\section{Brulin 815GD Pre-Clean Weight (grams)}

\begin{tabular}{|c|c|c|c|c|c|c|c|c|c|c|}
\hline \multicolumn{2}{|c|}{ Palco Wire } & \multicolumn{4}{|c|}{ Aluminum Slugs } & Moly & $\underline{\text { Kovar }}$ & \multicolumn{3}{|c|}{ Stainless } \\
\hline$\# 1$ & $\# 2$ & $\# 3$ & Small & Medium & Large & \#1 & $\# 1$ & $\# 1$ & $\# 2$ & \#3 \\
\hline 0.099 & 0.1016 & 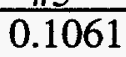 & 0.6131 & 0.6323 & 1.2074 & 2.5135 & 8077 & 1.7798 & 983 & 1.72 \\
\hline 0.0 & 0.1 & & & & 1.2 & 2.5 & & 1.' & & \\
\hline & 0.1 & & 0.6131 & & 1.20 & & 1.8079 & 1.7798 & 83 & 1.72 \\
\hline 0.0993 & 0.1016 & 0.1061 & 0.6131 & 0.6323 & 1.2074 & 2.5135 & 1.8078 & 1.7798 & 1.6983 & 1.7213 \\
\hline
\end{tabular}

Brulin 815GD Post-Clean Weight (grams)

\begin{tabular}{|c|c|c|c|c|c|c|c|c|c|c|}
\hline \multicolumn{2}{|c|}{ Palco Wires } & \multicolumn{4}{|c|}{ Aluminum Slugs } & Moly & Kovar & \multicolumn{3}{|c|}{ Stainless } \\
\hline$\# 1$ & $\# 2$ & $\# 3$ & Small & Medium & Large & \#1 & \#1 & \#1 & $\# 2$ & \#3 \\
\hline 0.0992 & 0.1016 & 0.1061 & 0.6122 & 0.6322 & 1.2071 & 2.5131 & 1.8078 & 1.7799 & 1.6983 & 1.7214 \\
\hline 0.0992 & 0.1016 & 0.1061 & 0.6122 & 0.6320 & 1.2071 & 2.5131 & 1.8079 & 1.7799 & 1.6983 & 1.7213 \\
\hline 0.0992 & 0.1016 & 0.1061 & 0.6122 & 0.6322 & 1.2071 & 2.5131 & 1.8079 & 1.7798 & 1.6983 & 1.7214 \\
\hline 0.0992 & 0.1016 & 0.1061 & 0.6122 & 0.6321 & 1.2071 & 2.5131 & 1.8079 & 1.7799 & 1.6983 & 1.7214 \\
\hline $\mathrm{Ch}$ & & & & & & & & & & \\
\hline & 0.03 & 0.03 & -0.15 & -0.03 & -0.03 & -0.02 & 0.00 & 0.00 & 0.00 & 0.00 \\
\hline
\end{tabular}

Table 43 - Clean Test

Oakite NST Pre-Clean Weight (grams)

\section{Sn/Pb Solder Samples}

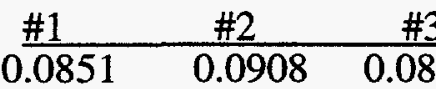

0.0852

0.0852

0.0908

0.0908

AVG

0.0908

0.0839

0.0839

0.0839

Kapton Samples

Alumina Samples

\section{Oakite NST Post-Clean Weight (grams)}

Sn/Pb Solder Samples

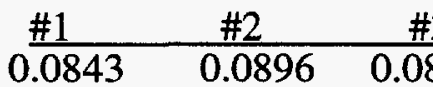

0.0843

0.0844

AVG $\quad 0.0844$

0.0896

0.0896

0.0830

0.0831

0.0830

\% Change

$-0.94$

$-1.32 \quad-1.07$

$+0.80$

$+0.050$

$+0.47$

$-0.01$

Alumina Samples

17.2684

17.2684

17.2683

17.2684 
Table 44 - Clean Test

Oakite NST Pre-Clean Weight (grams)

\begin{tabular}{|c|c|c|c|c|c|c|c|c|c|c|}
\hline \multicolumn{2}{|c|}{ Palco Wires } & \multicolumn{4}{|c|}{ Aluminum Slugs } & Moly & Koval & \multicolumn{3}{|c|}{ 304L } \\
\hline$\# 1$ & $\# 2$ & $\# 3$ & Small & Medium & Lar & \#1 & \#1 & $\# 1$ & \#2 & \#3 \\
\hline 0.109 & 0.0973 & 0.1014 & 0.75 & 0.6712 & 0.6034 & 2.3165 & 1.7760 & 1.6961 & 1.6997 & 1.6835 \\
\hline 0.10 & 0.0973 & 0.10 & 0.7546 & 0.67 & 0.60 & 2.3166 & 1.7761 & 1.6962 & 1.6998 & 1.6835 \\
\hline & 0.0973 & 0.10 & 0.7 & 0.6 & 0.6 & & 1.7761 & 1.6962 & 1.6998 & 1.6835 \\
\hline 0.1093 & 0.0973 & 0.1015 & 0.7546 & 0.6712 & 0.6034 & 2.3166 & 1.7761 & 1.6962 & 1.6998 & 1.6835 \\
\hline
\end{tabular}

Oakite NST Post-Clean (grams)

$\underline{\text { Palco Wires }}$

$\begin{array}{ccc}\# 1 & \# 2 \\ 0.1093 & 0.0973 & 0.10\end{array}$

$\begin{array}{lll}0.1093 & 0.0973\end{array}$

\begin{tabular}{ll}
0.1093 & 0.0973 \\
\hline
\end{tabular}

AVG 0.1093

0.0973

0.1015

0.1015

0.1015

\% Change

0.00

0.00

0.00

$-0.04$

$-0.06$

$-0.04$

$-0.0043 \quad 0.00$

$0.00-0.01$

0.00 
Table 45 - Average \% wt. Change - Immersion Test

Substrate

Gold

Kapton

$\mathrm{Sn} / \mathrm{Pb}$

Alumina

Aluminum

Copper

Kovar

Palco

Molybdenum

Niobium

\section{Trichloroethylene}

$-0.01$

4.54

$-0.05$

0.00

$-0.01$

0.01

0.00

0.05

0.00

0.01

\section{Brulin 815GD}

0.00

1.23

$-0.02$

$-0.00$

0.05

$-0.03$

0.00

0.10

$-0.04$

$-0.01$
Oakite NST

0.01

1.84

$-0.15$

0.00

$-0.01$

---

0.06

$-0.07$

0.00

Table 46 - Average \% Weight Change - Cleaning Test

Substrate

Palco

Aluminum

Molybdenum

Kovar

$304 \mathrm{~L}$

$\mathrm{Sn} / \mathrm{Pb}$

Kapton

Alumina
Trichloroethylene 0.00

$-0.01$

0.00

0.00

0.00

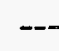

$\cdots$

$--$
Brulin 815GD

$-0.01$

$-0.07$

$-0.02$

0.00

0.00

$-2.50$

0.84

$-0.01$
Oakite NST

0.00

$-0.05$

0.00

0.00

0.00

$-1.11$

0.44

$-0.01$ 
Igepal C0-710

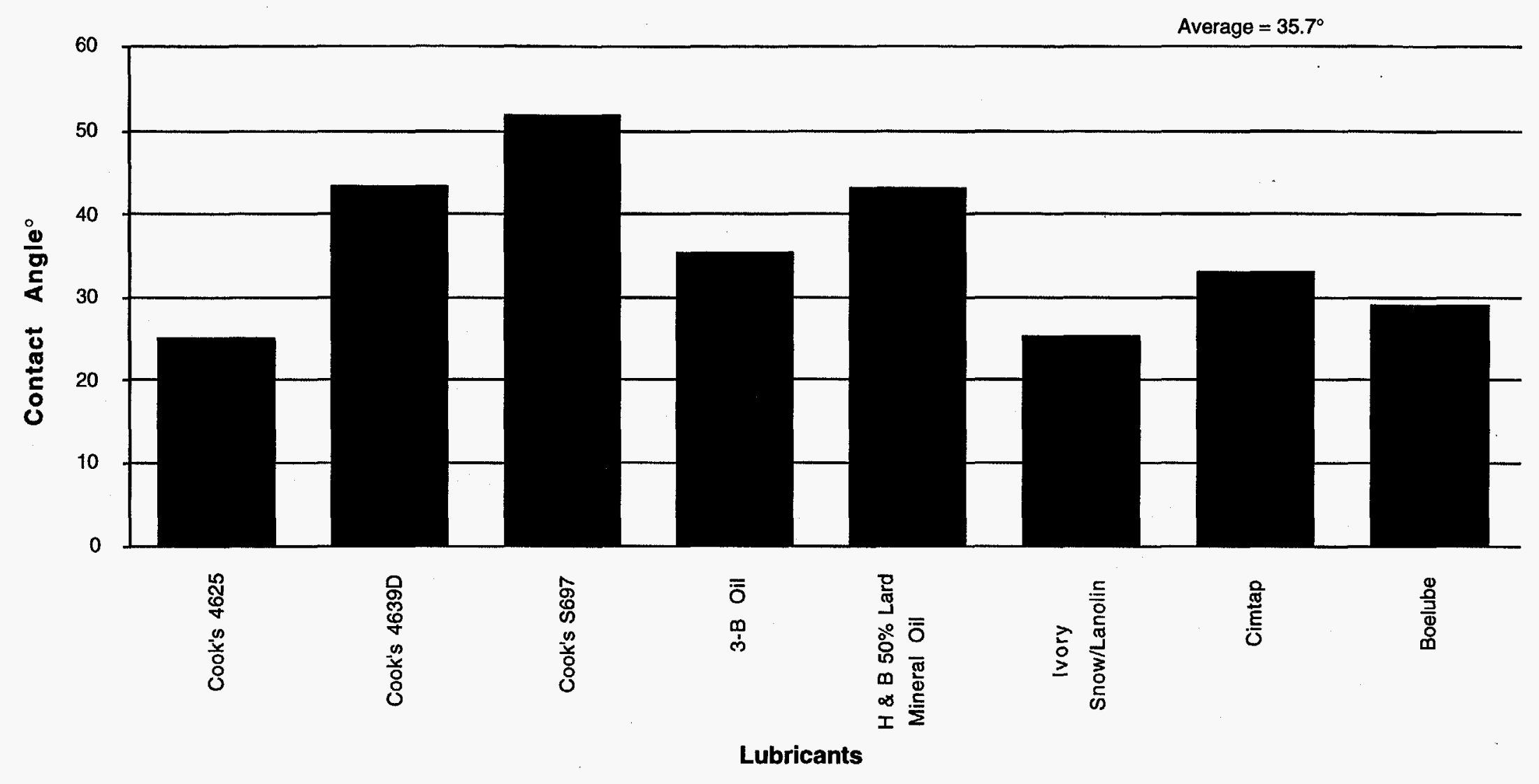

Figure 1 - Contact Angle Measurements For

Igepal CO-710 


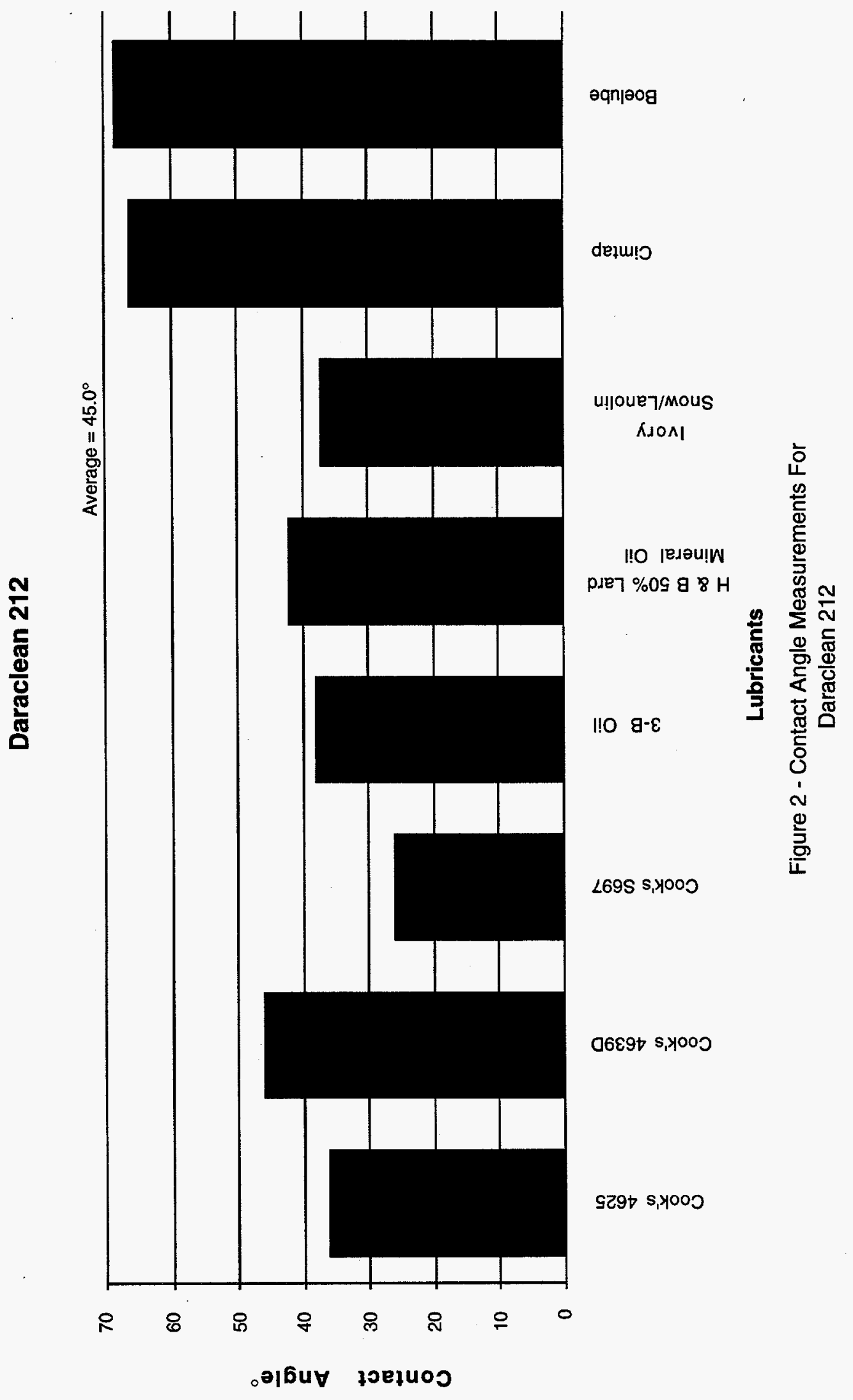

8
15
0
0
0
0 
Daraclean 235

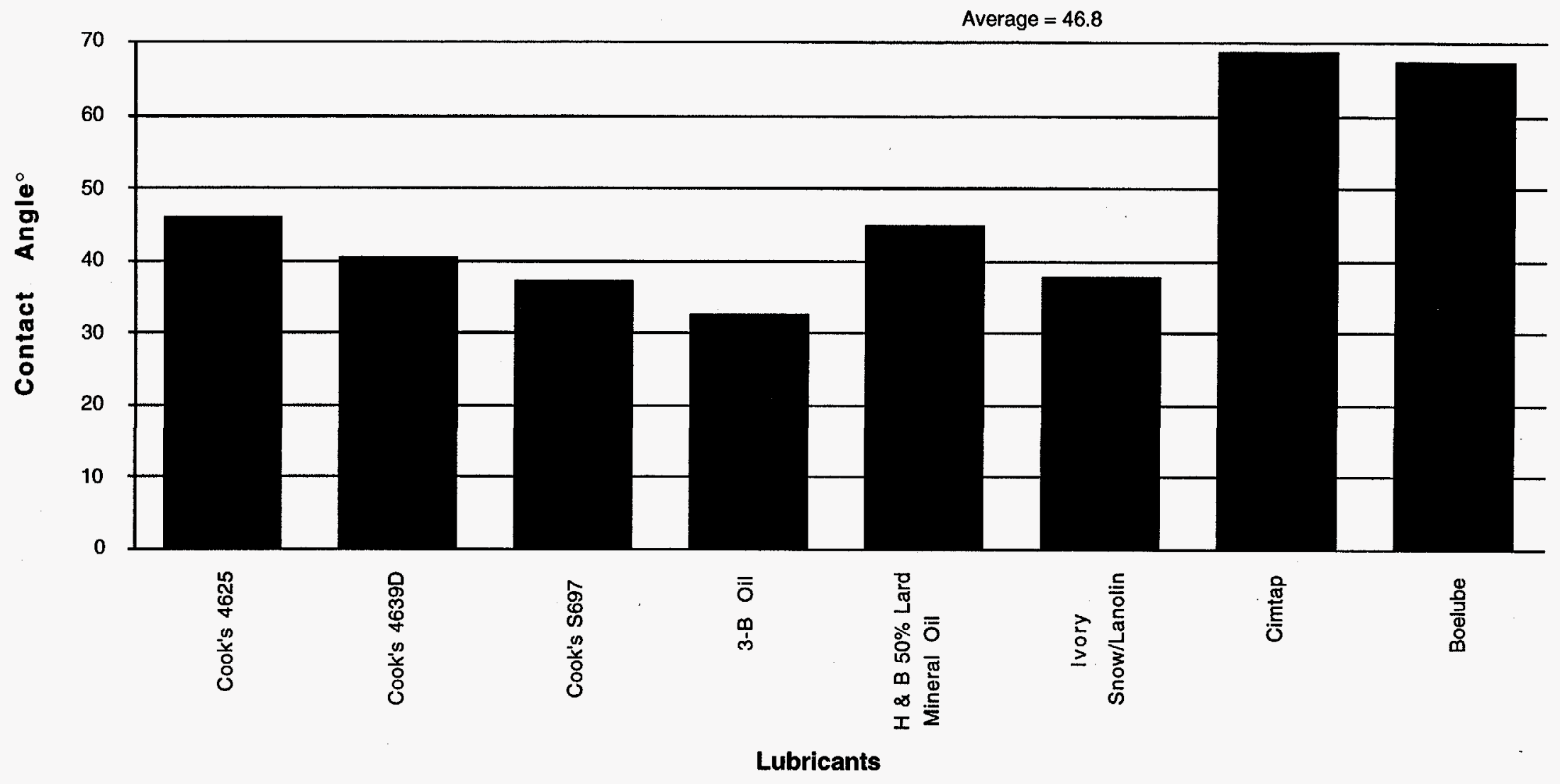

Figure 3 - Contact Angle Measurements For

Daraclean 235 
Daraclean 282

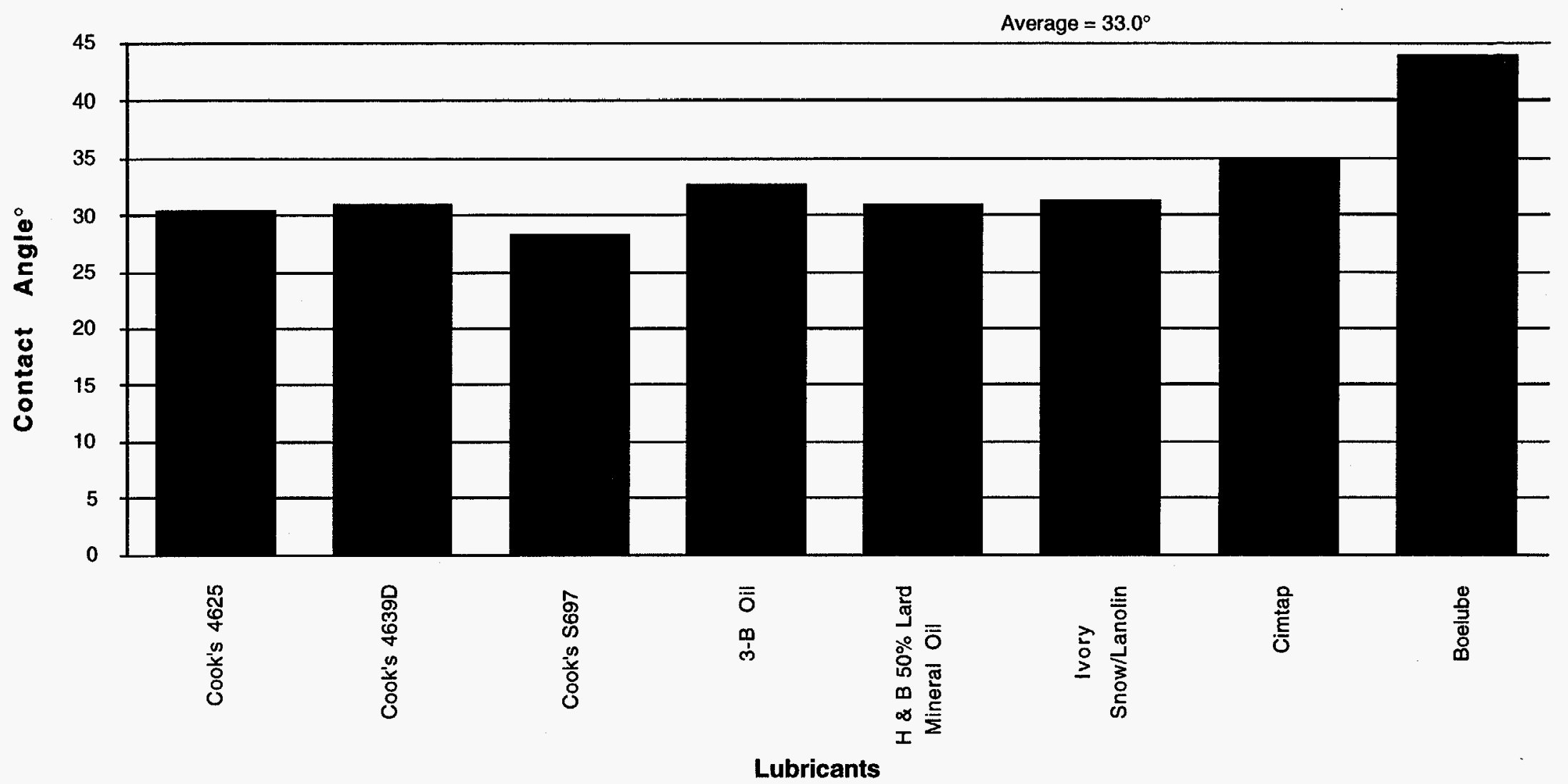

Figure 4 - Contact Angle Measurements For

Daraclean 282 


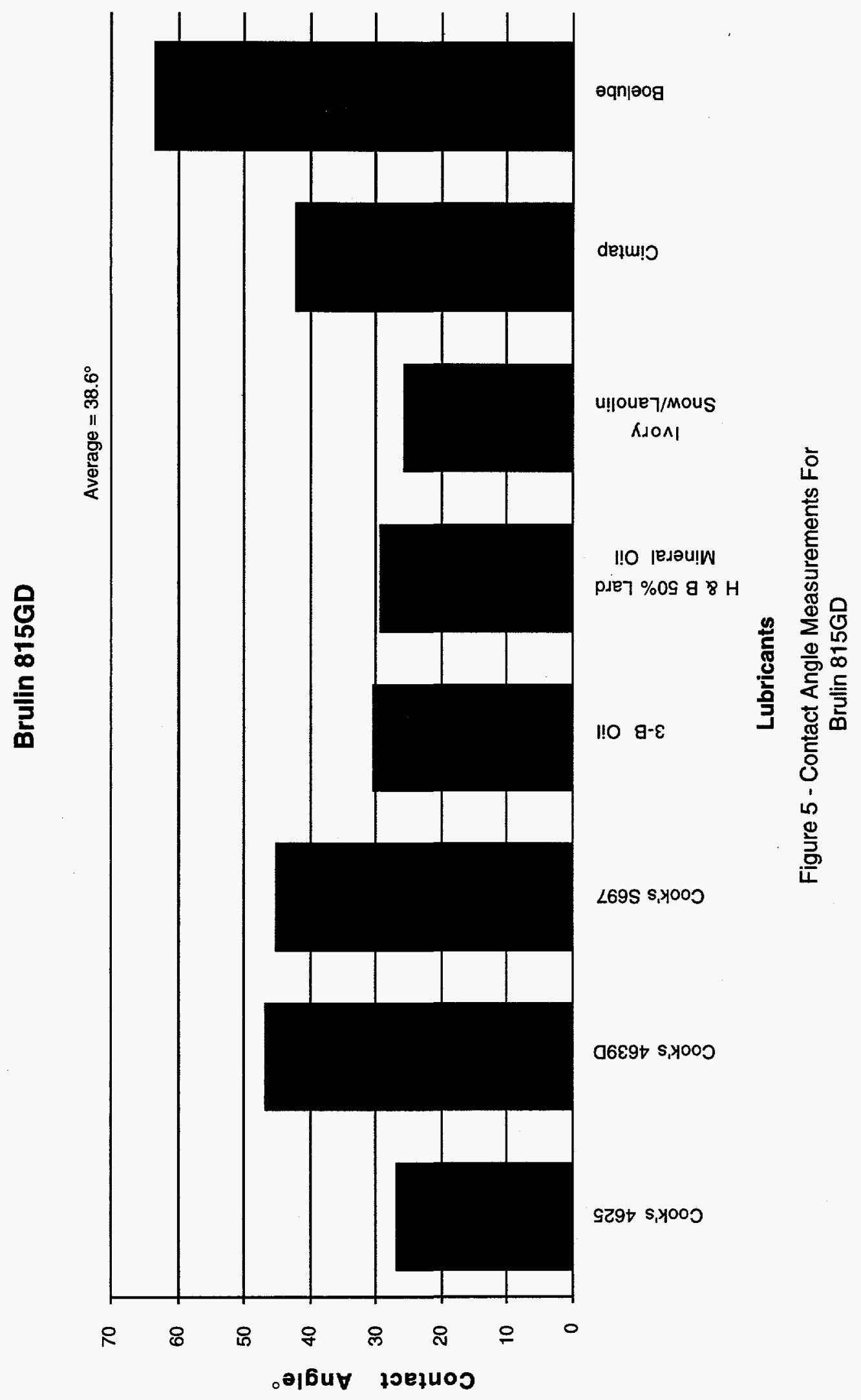

98
8
8
8
0 


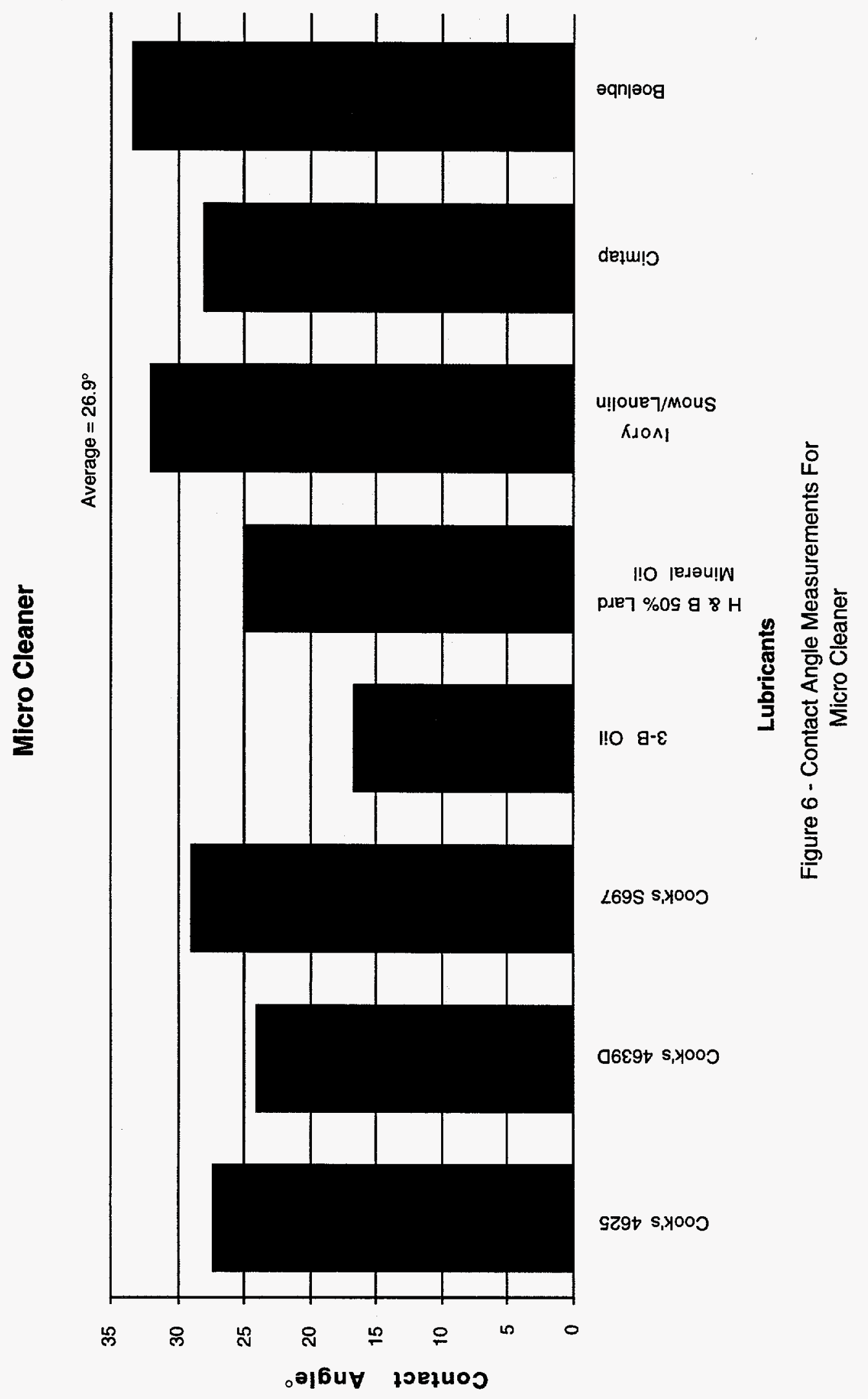

芯 


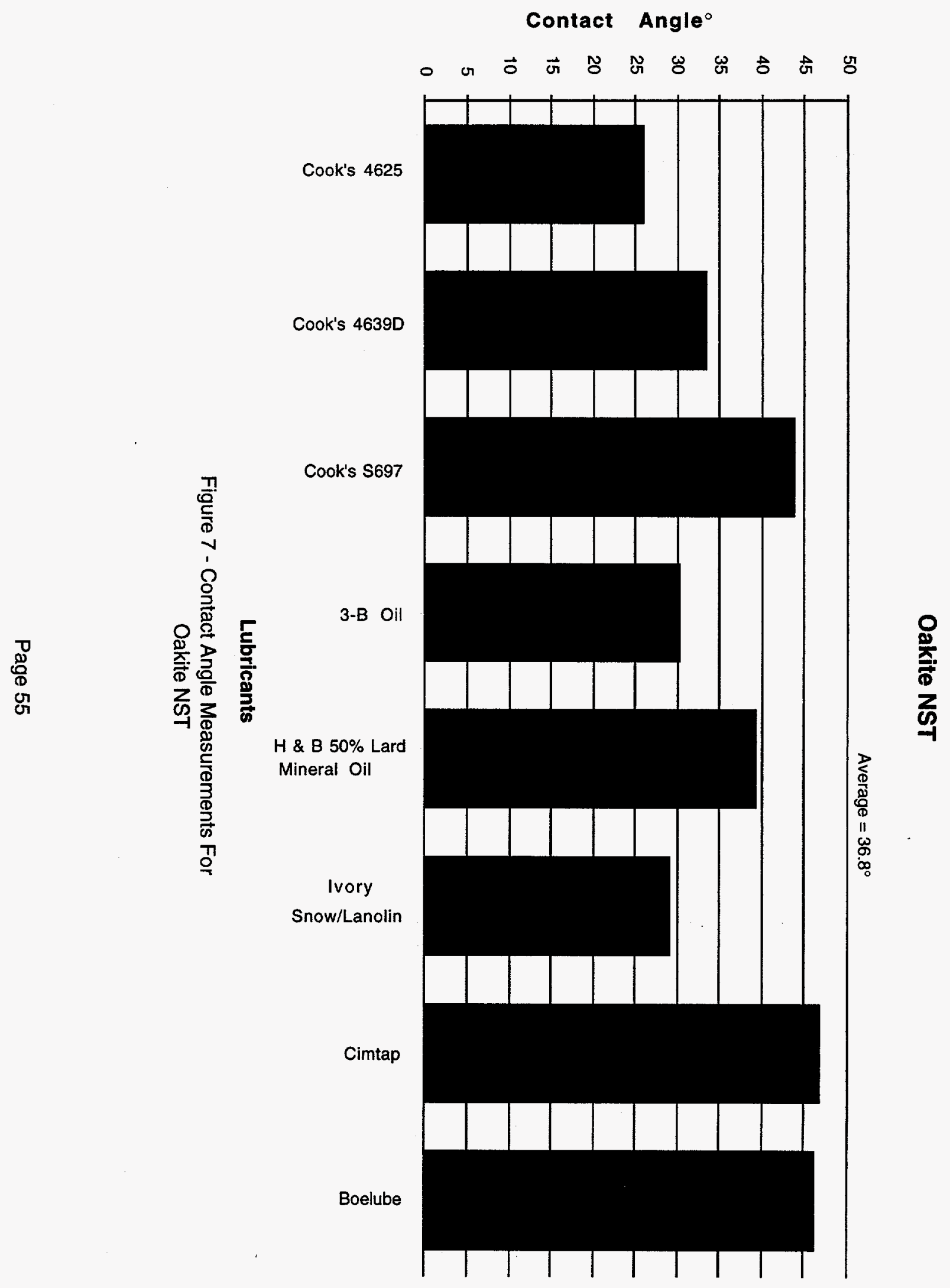




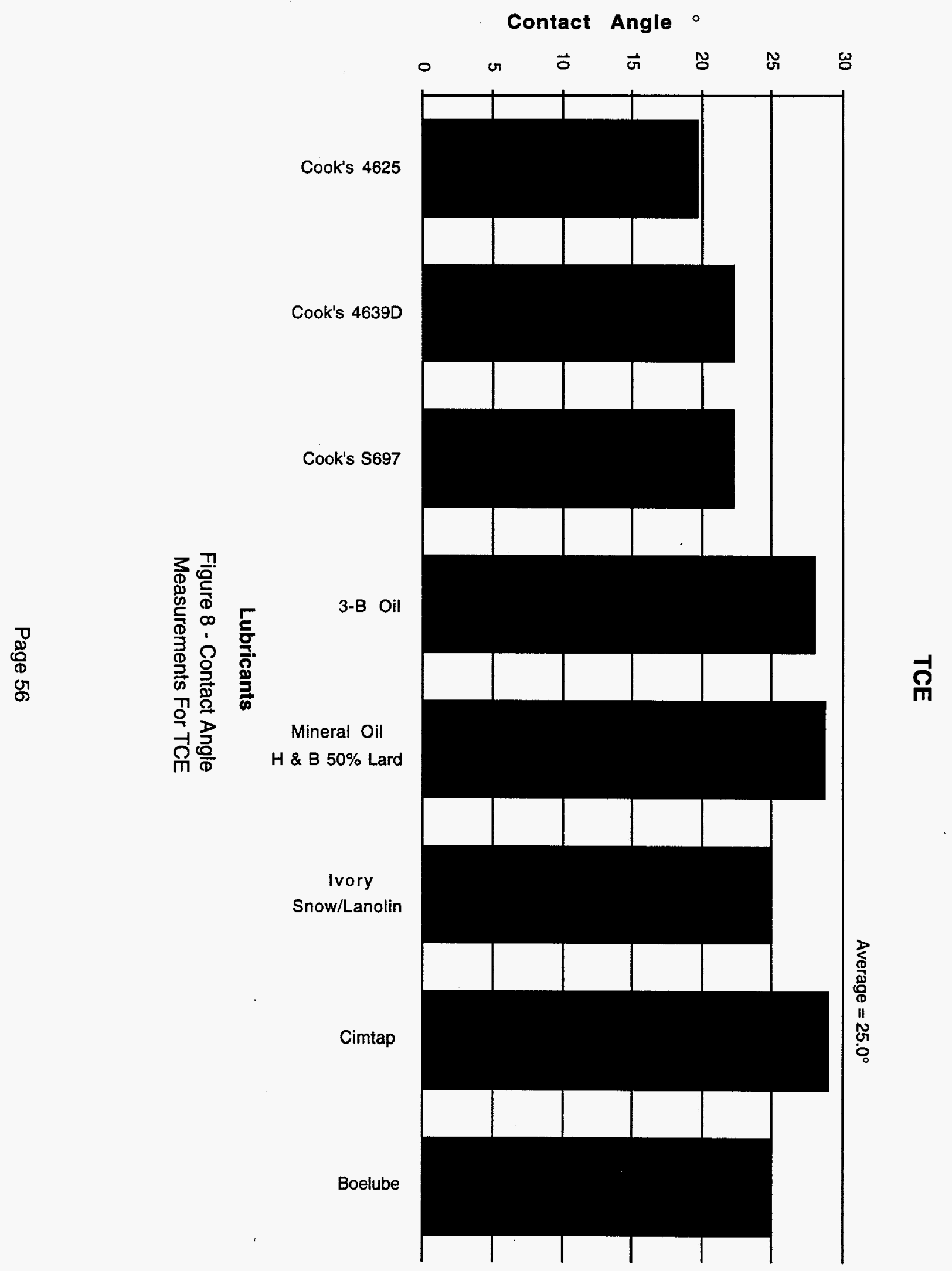




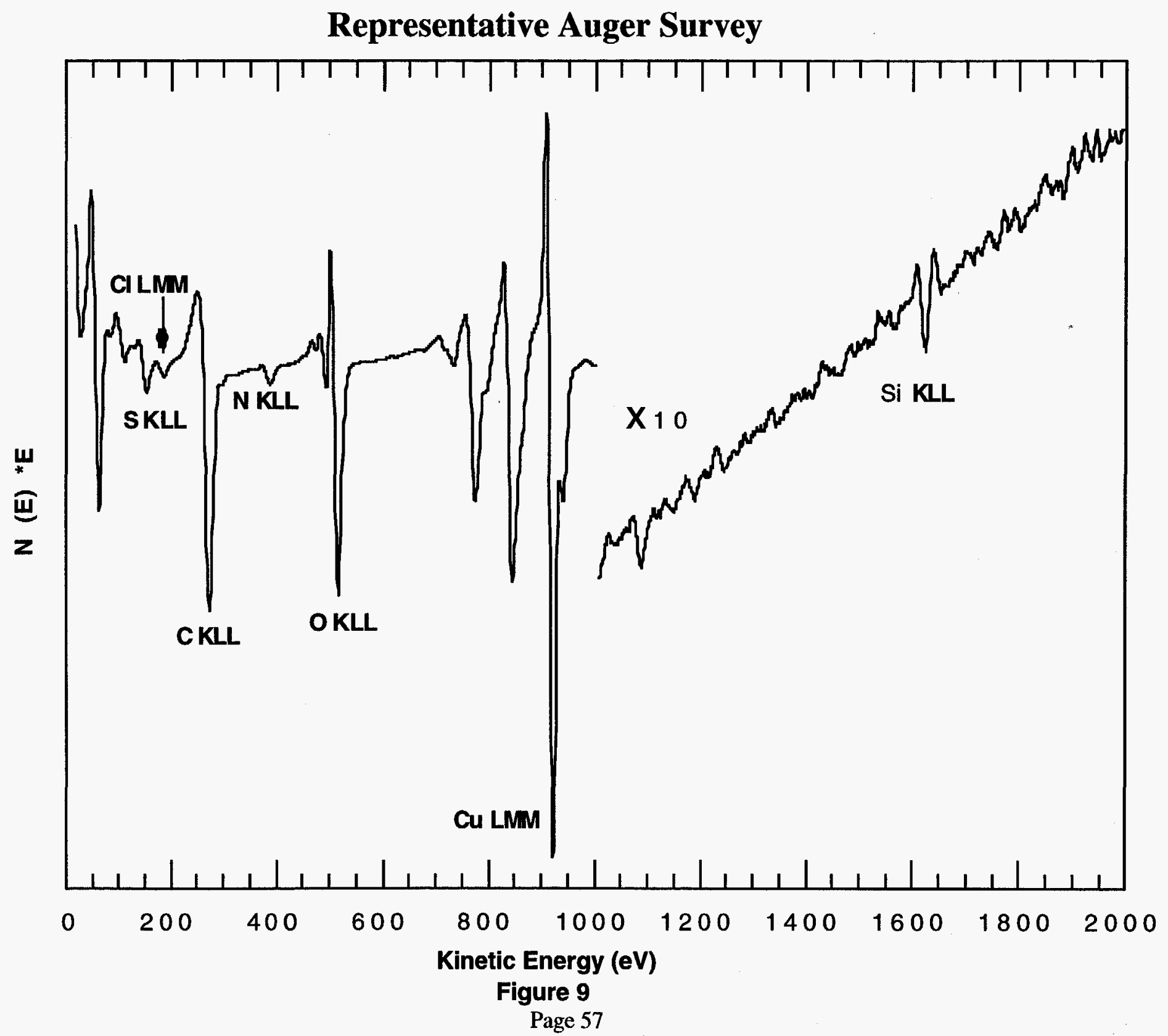




\section{Clean \\ 2 Cook's 4625 \\ 3 Cook's 4639D \\ 4 Cook's 5697 \\ 5 3-B Oil \\ 6 H\&B 50 Lard 50 Mineral Oil \\ 7 Ivory Snow/ Lanolin \\ 8 Cimtap \\ 9 Boelube}

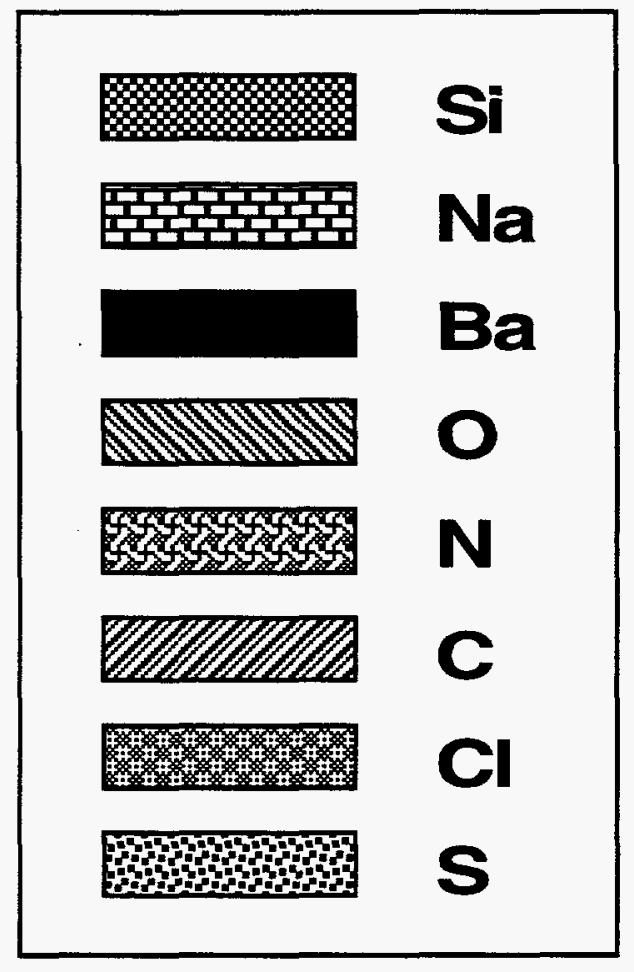

Figure 10 - LEGEND 


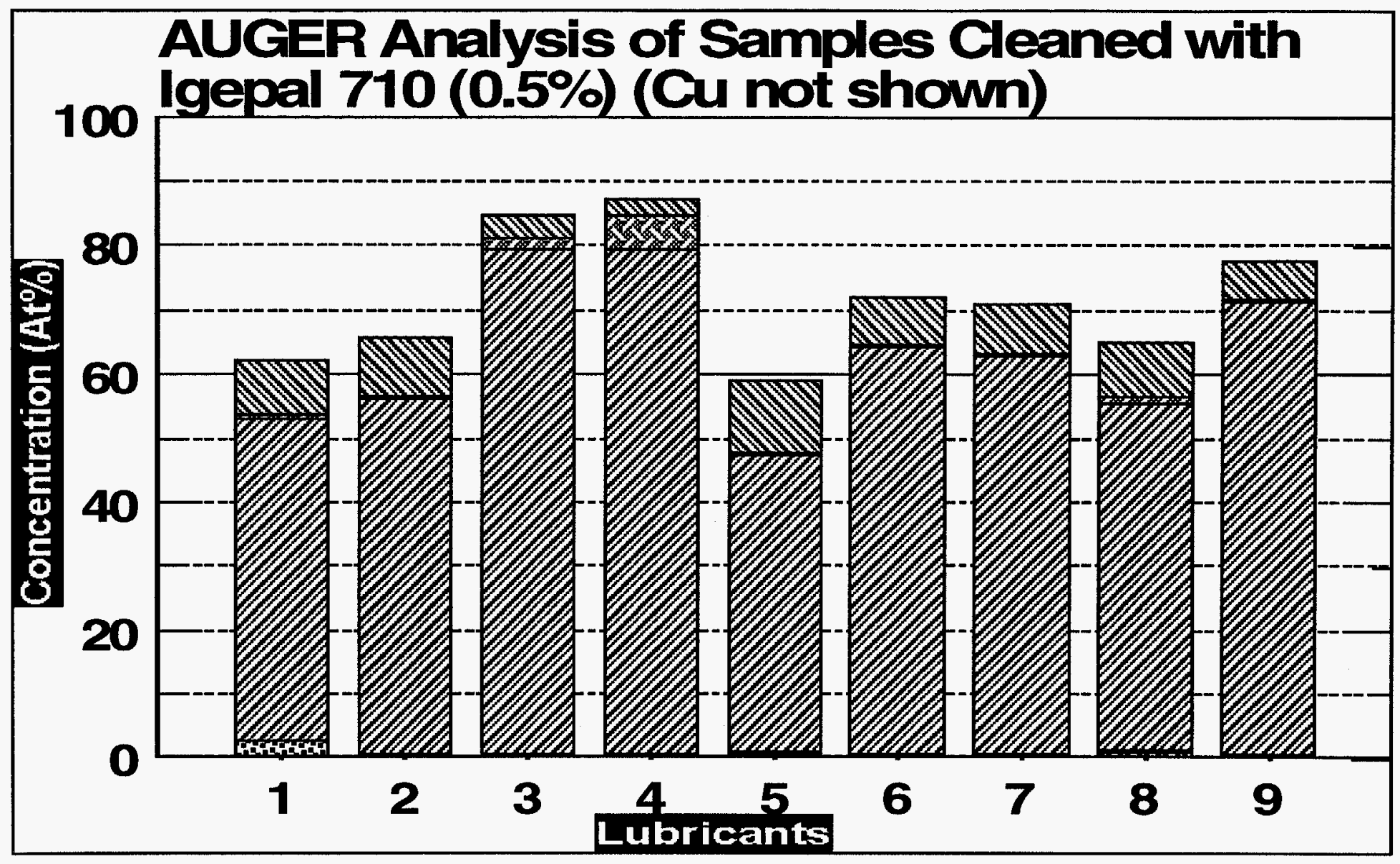

Figure 11 - Auger Analysis For Igepal C0-710

Page 59 


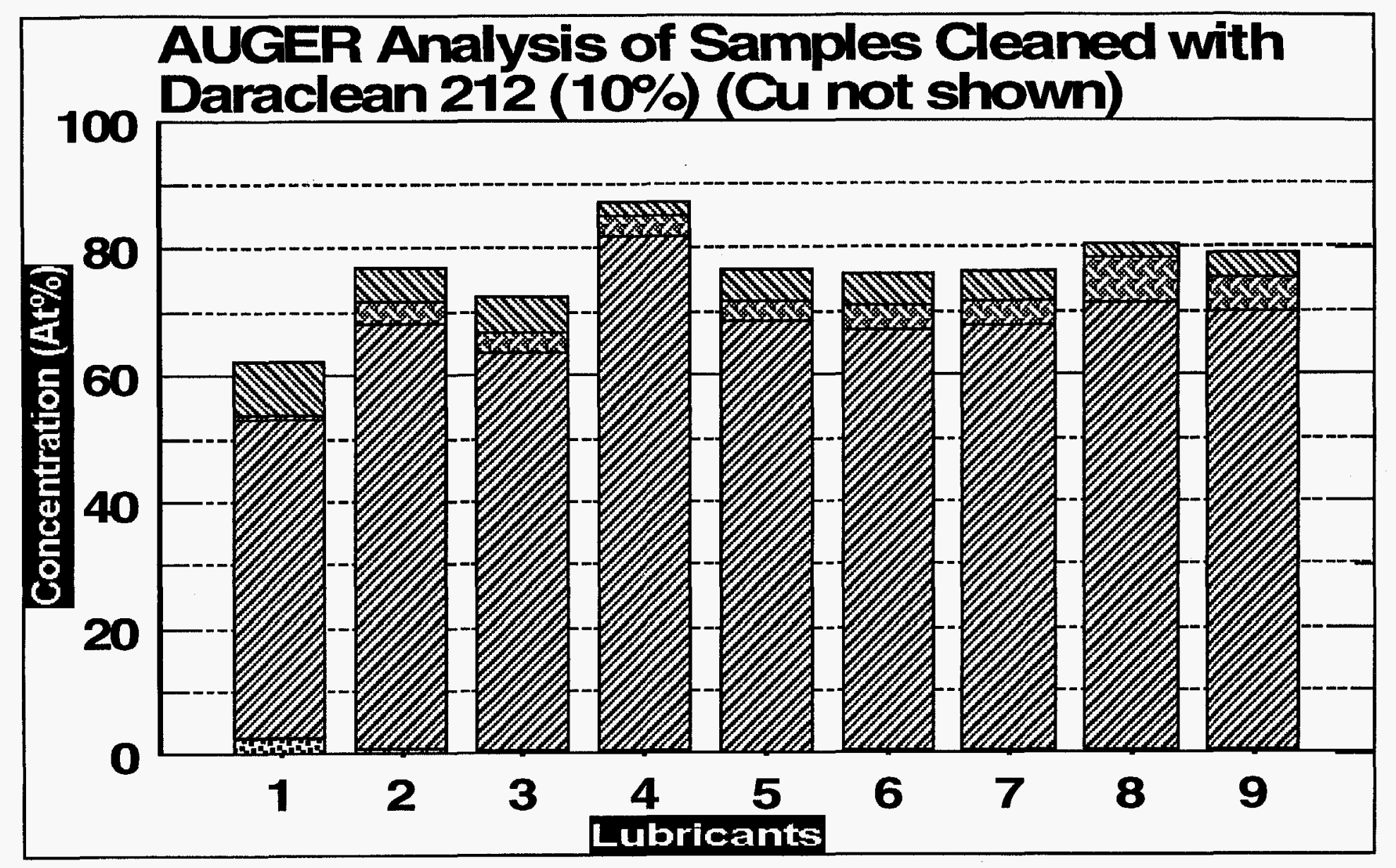

Figure 12 - Auger Analysis For Daraclean 212

Page 60 


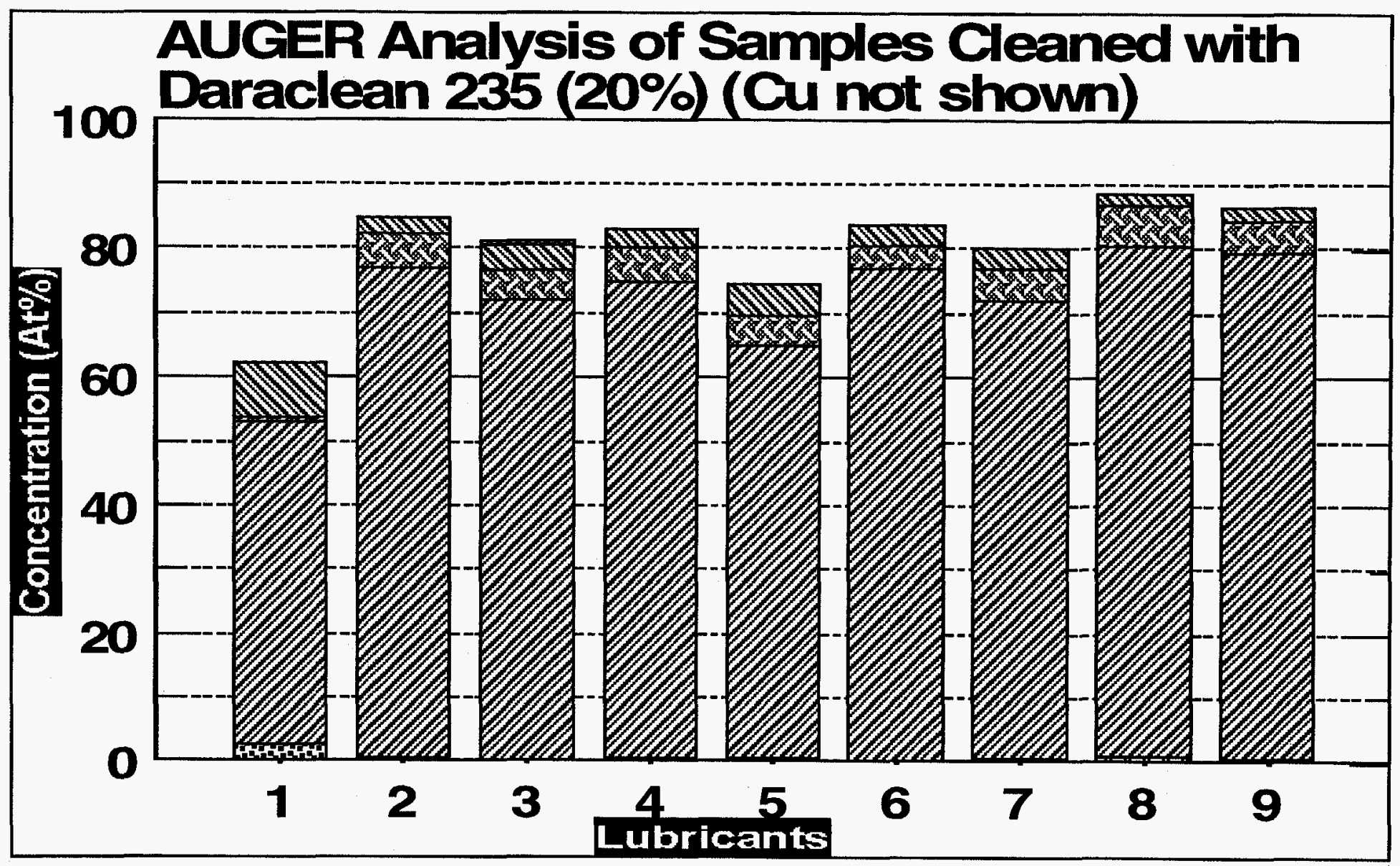

Figure 13 - Auger Analysis For Daraclean 235 


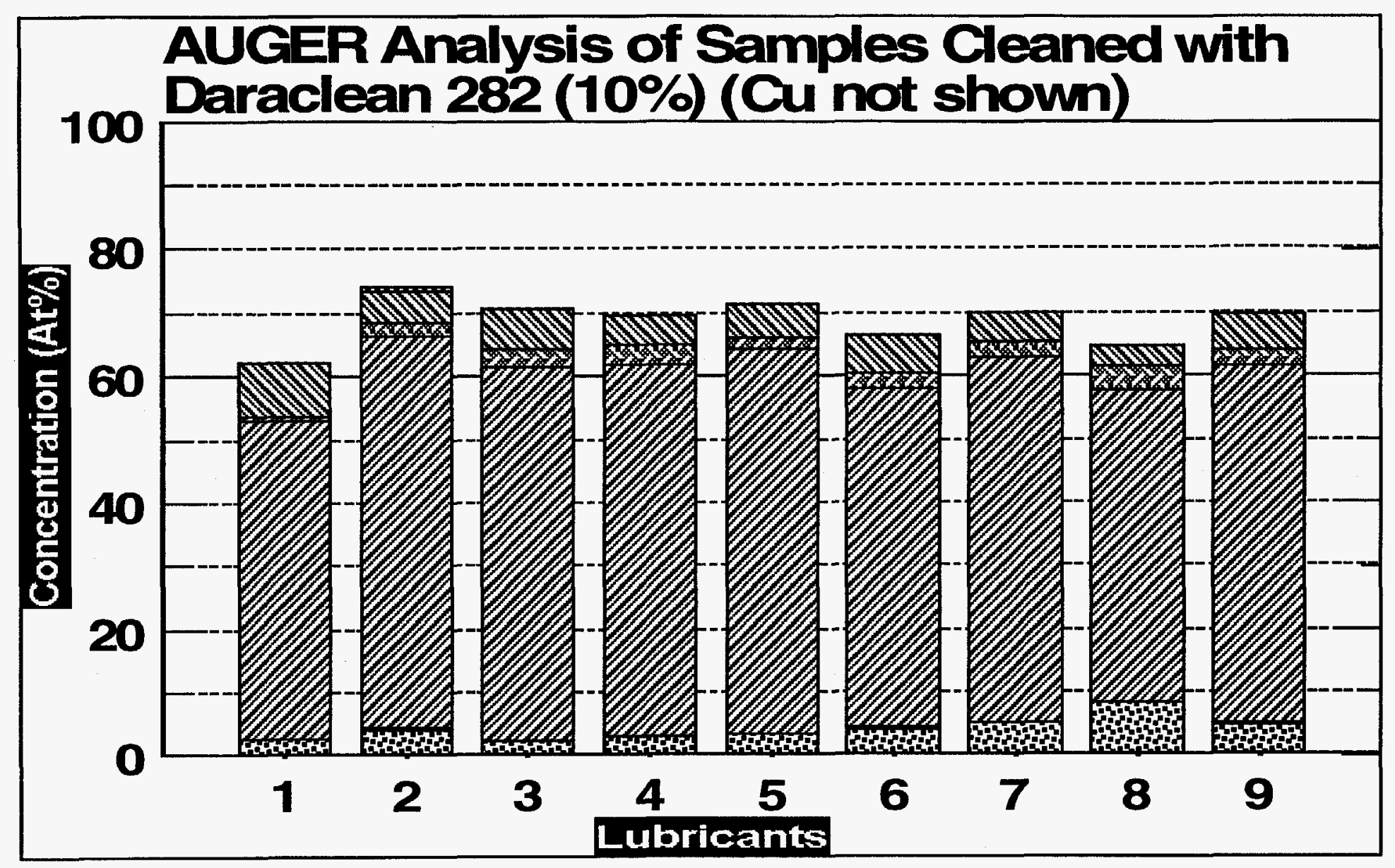

Figure 14 - Auger Analysis For Daraclean 282

Page 62 


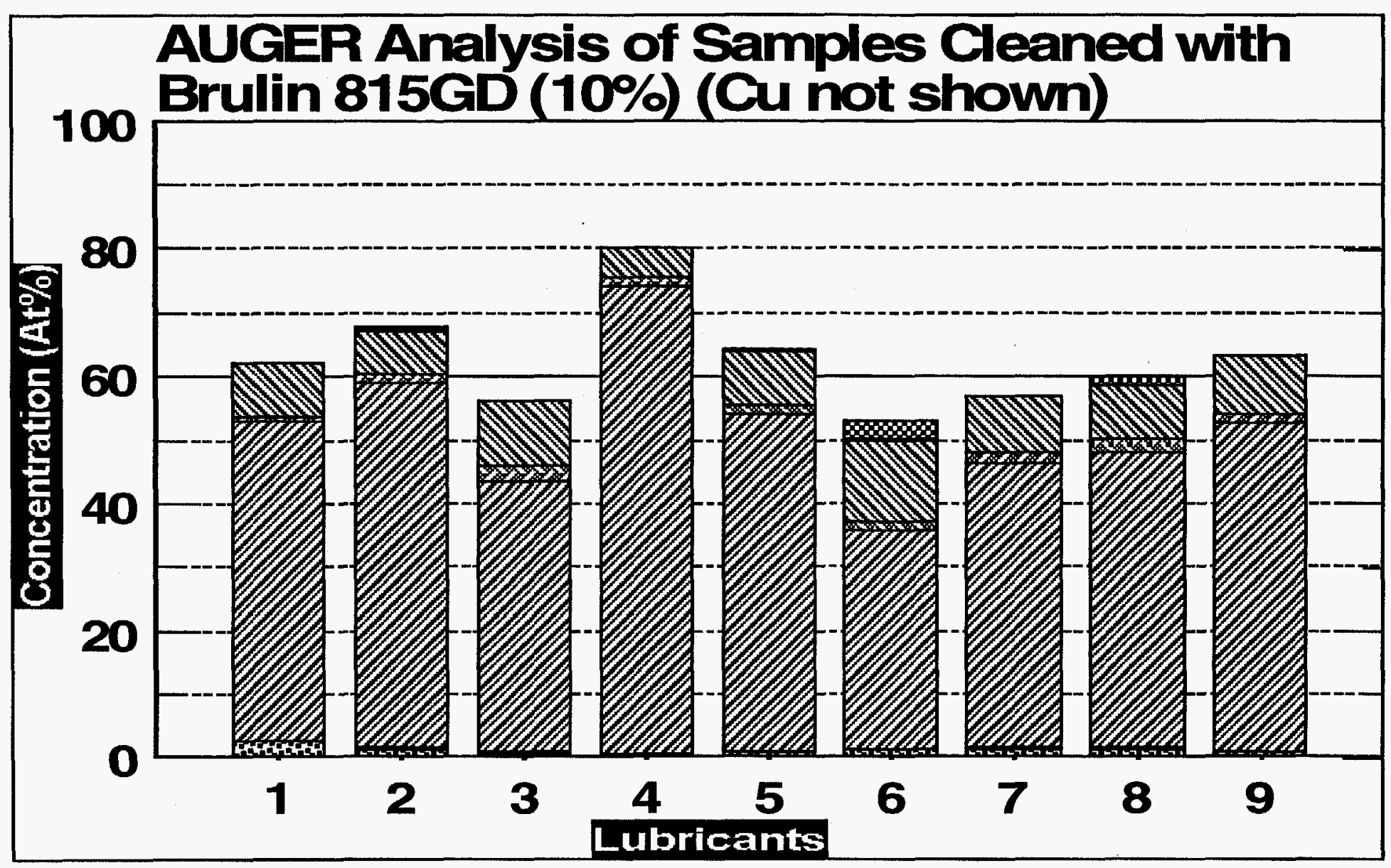

Figure 15 - Auger Analysis For Brulin 815GD

Page 63 


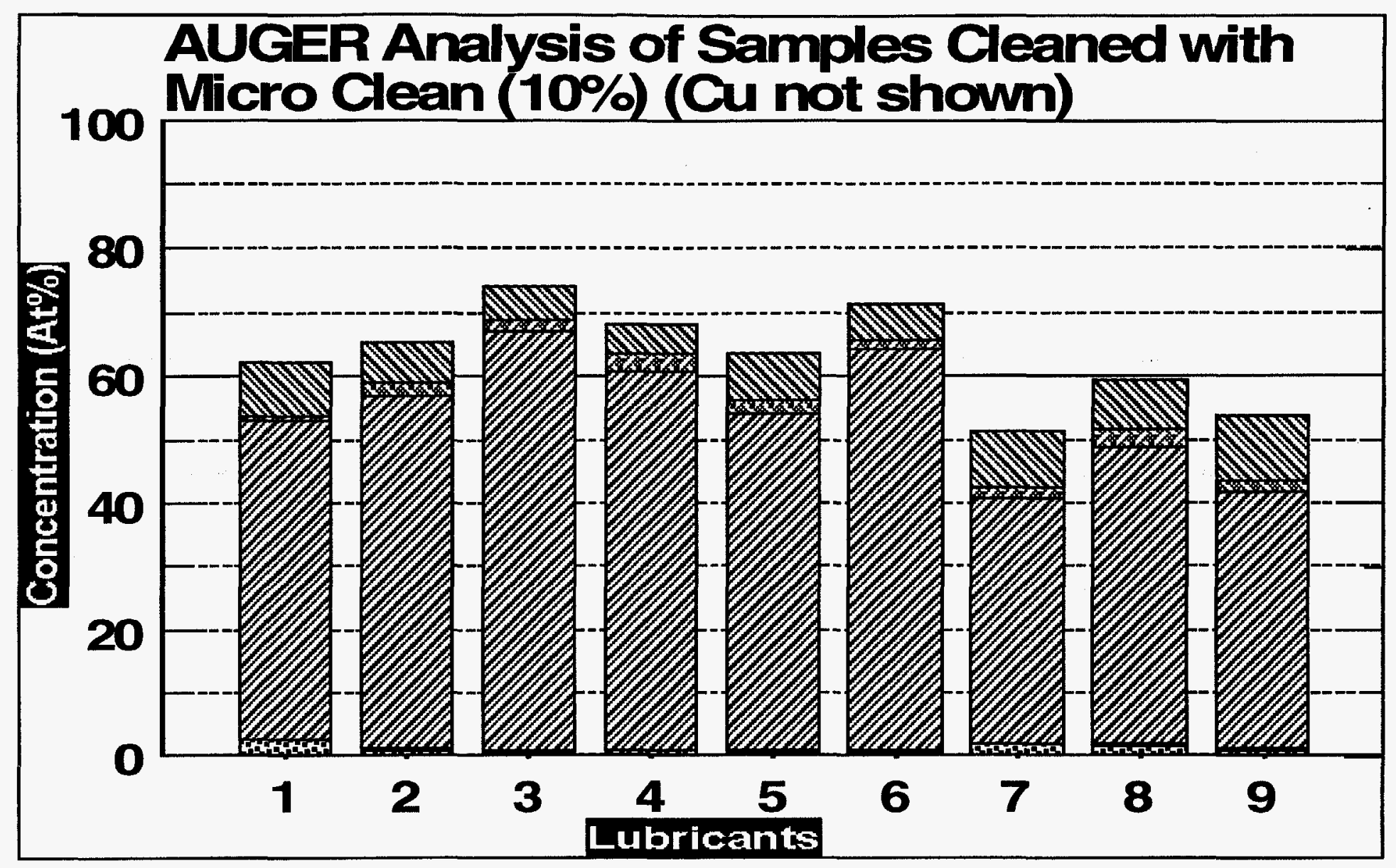

Figure 16 - Auger Analysis For Micro Cleaner

Page 64 


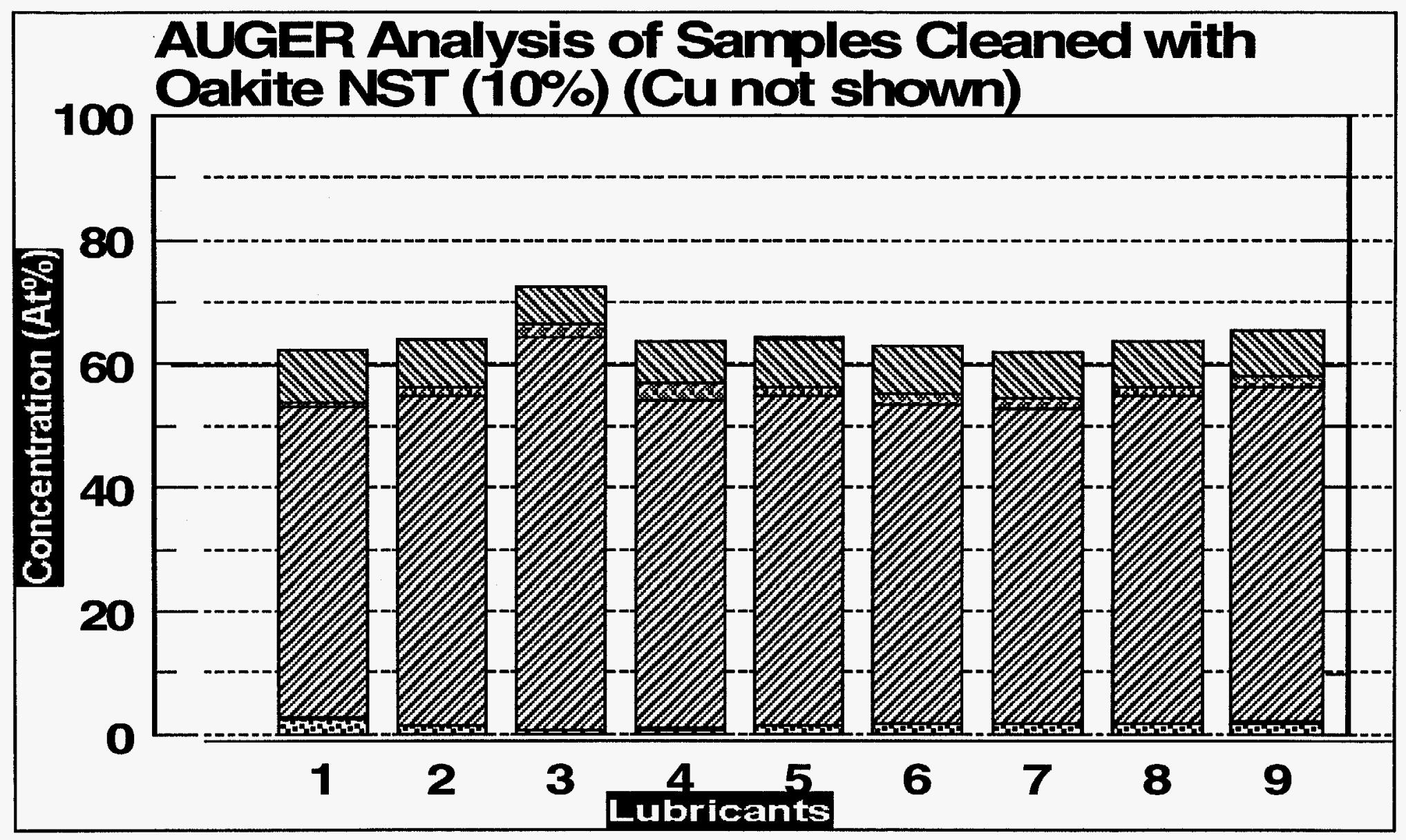

Figure 17 - Auger Analysis For Oakite NST

Page 65 


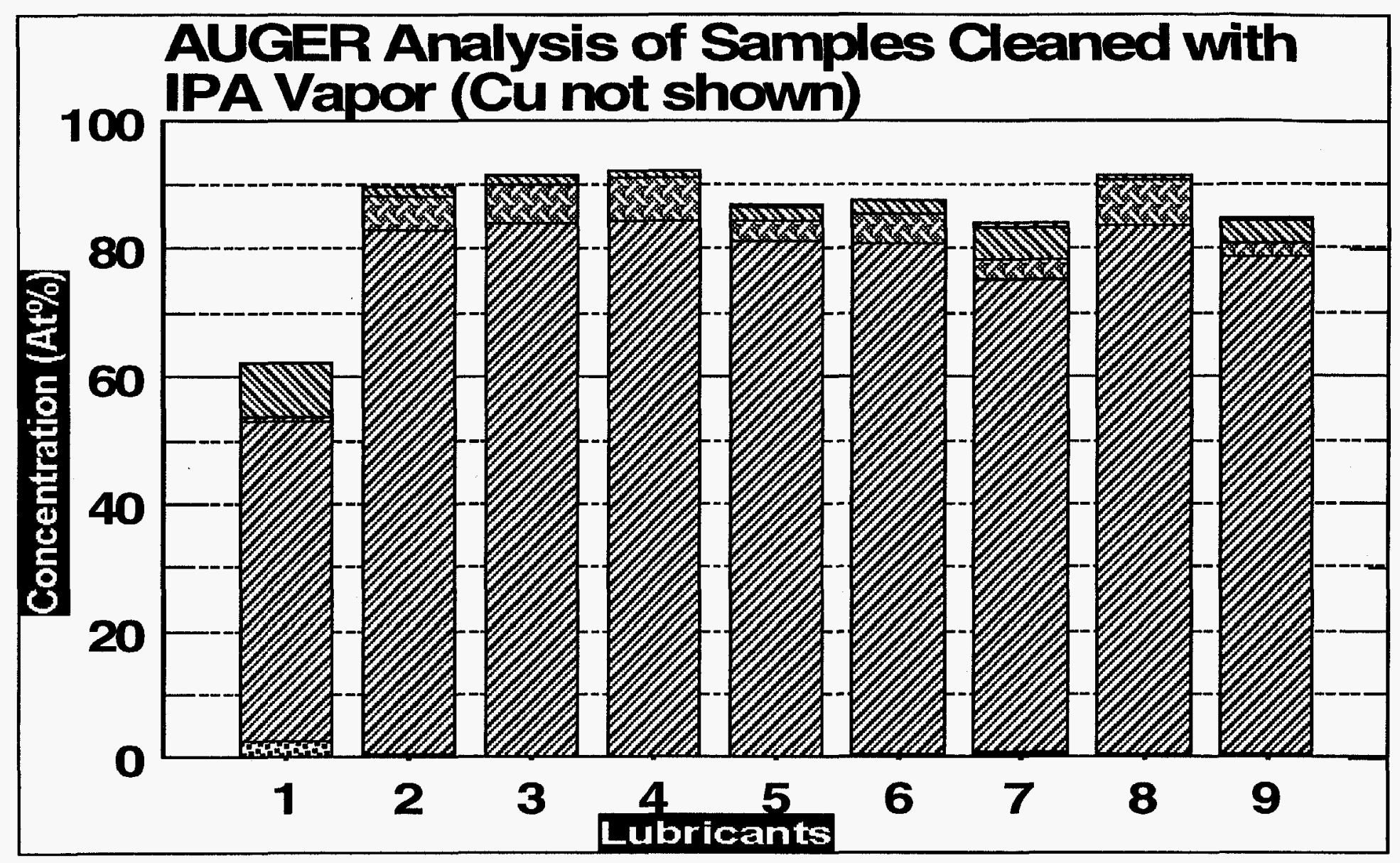

Figure 18 - Auger Analysis For IPA

Page 66 


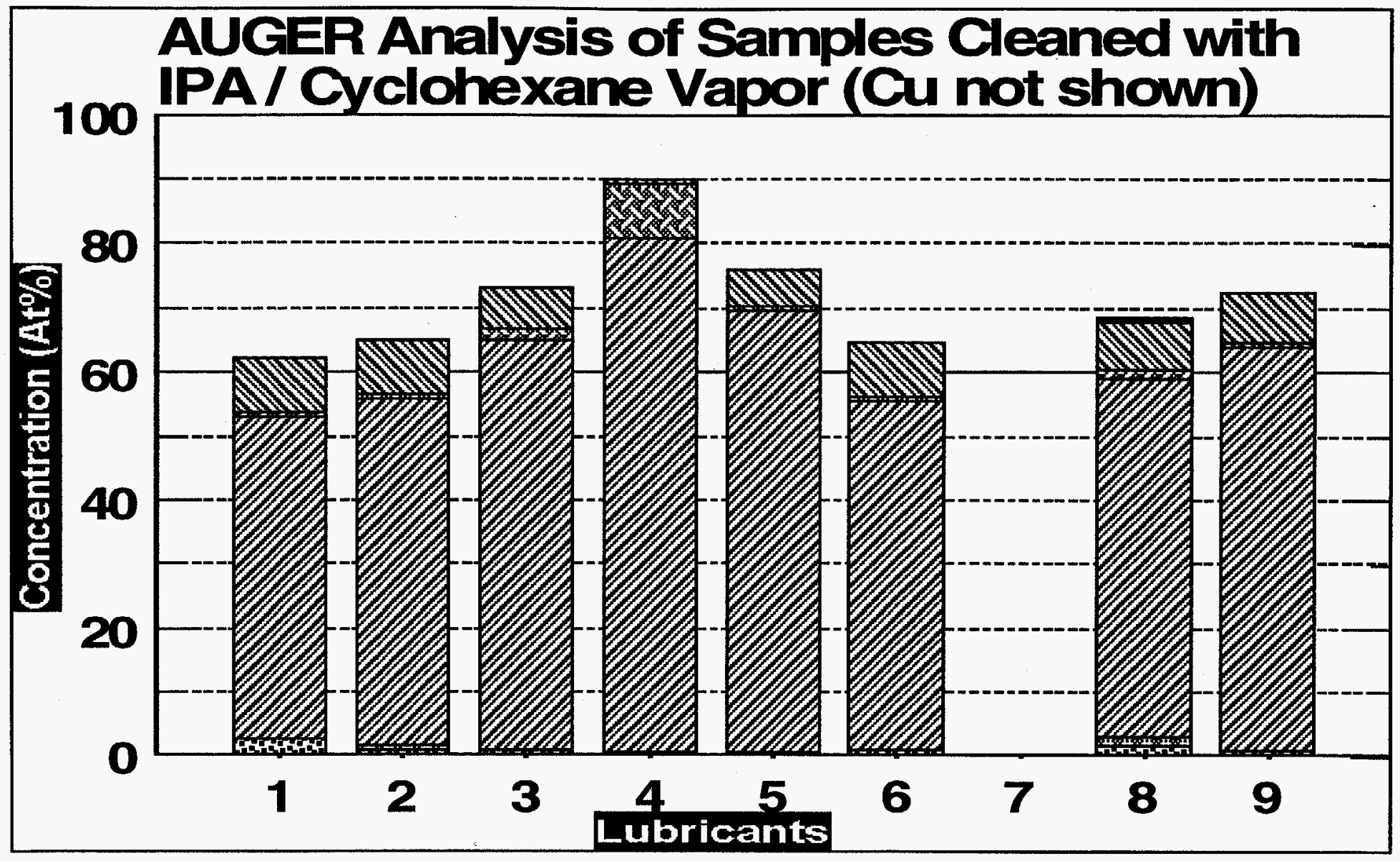

Figure 19 - Auger Analysis For IPA/Cyclohexane Page 67 


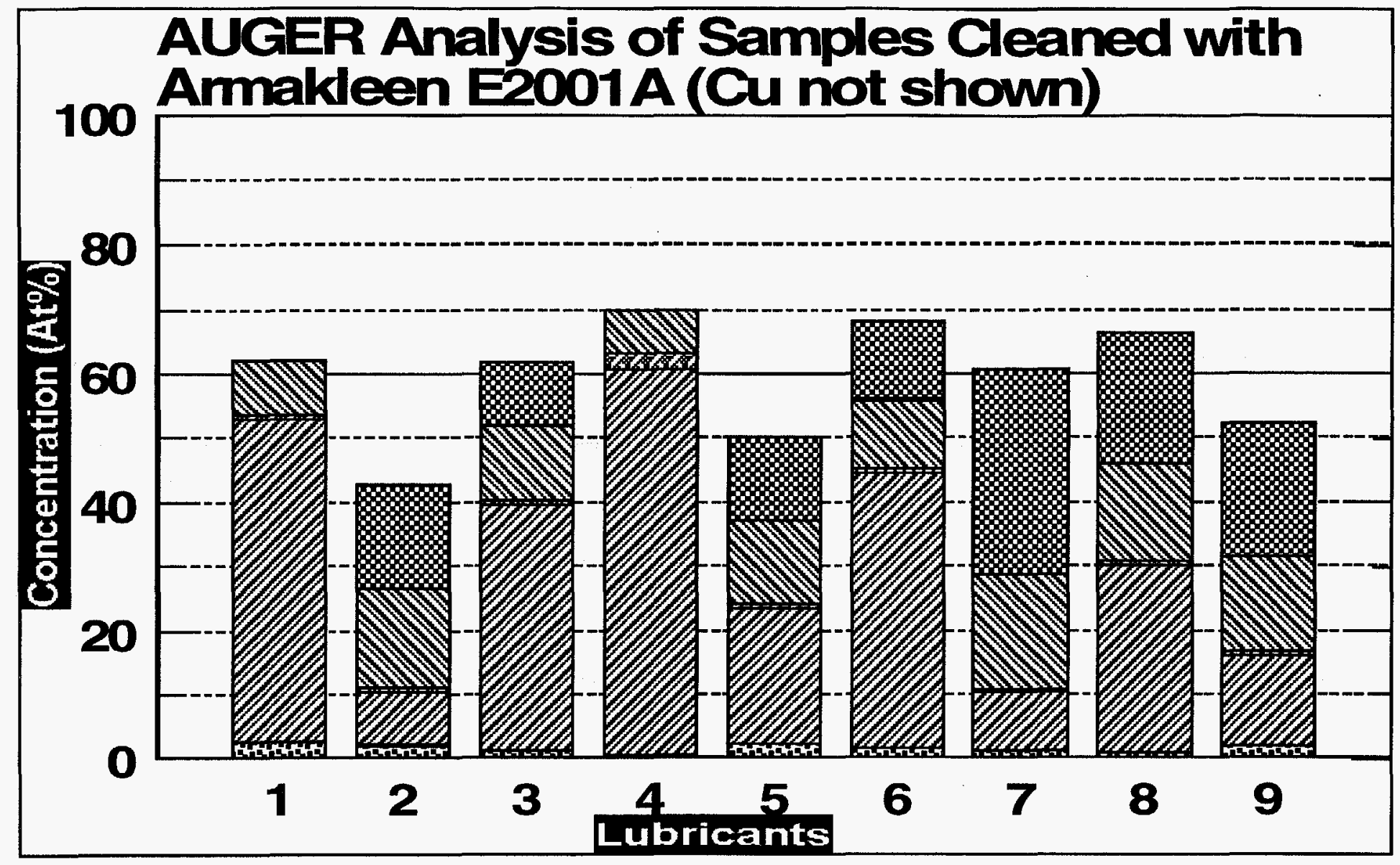

Figure 20 - Auger Analysis For Armakleen E-2001A

Page 68 


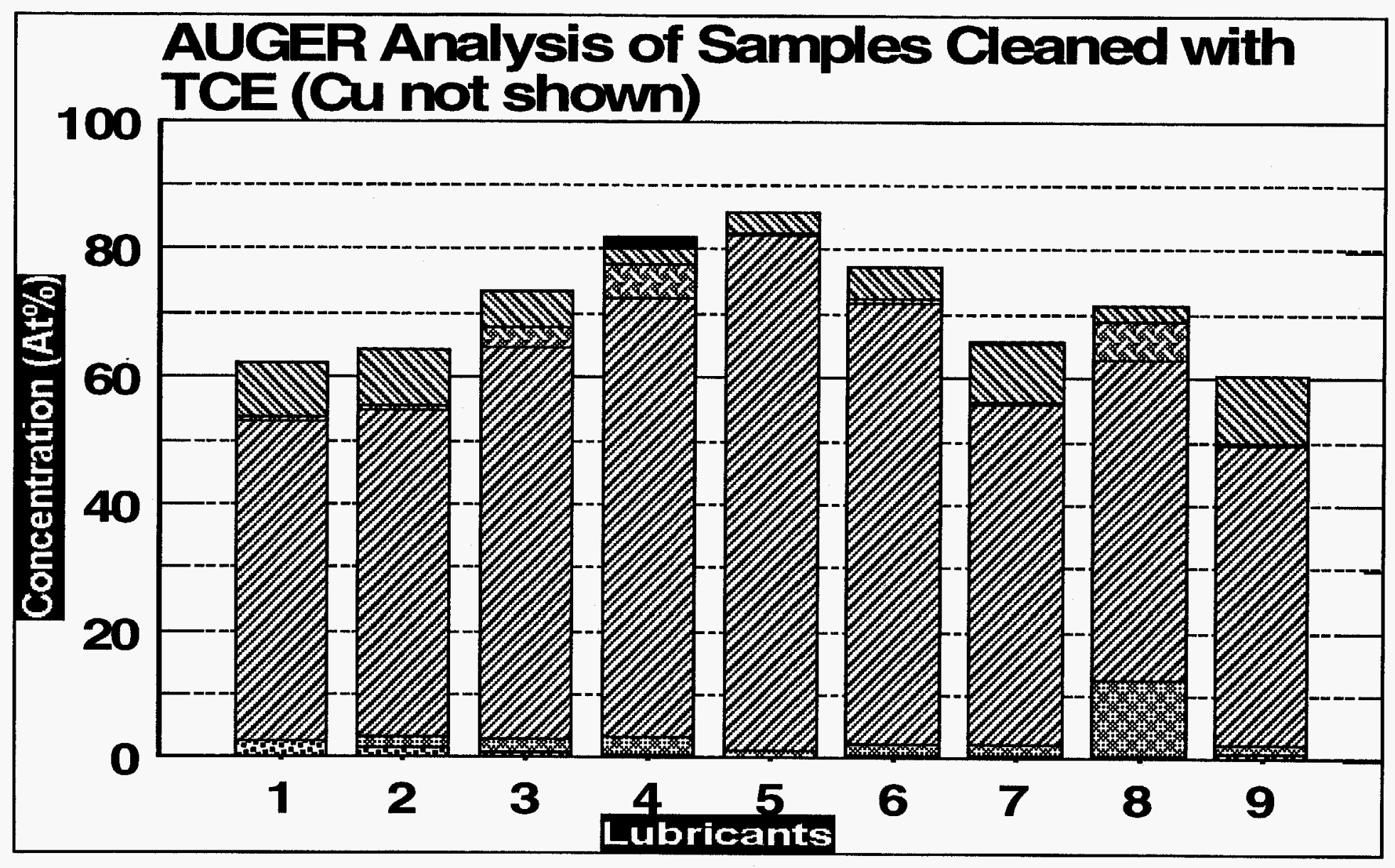

Figure 21 - Auger Analysis For TCE

Page 69 


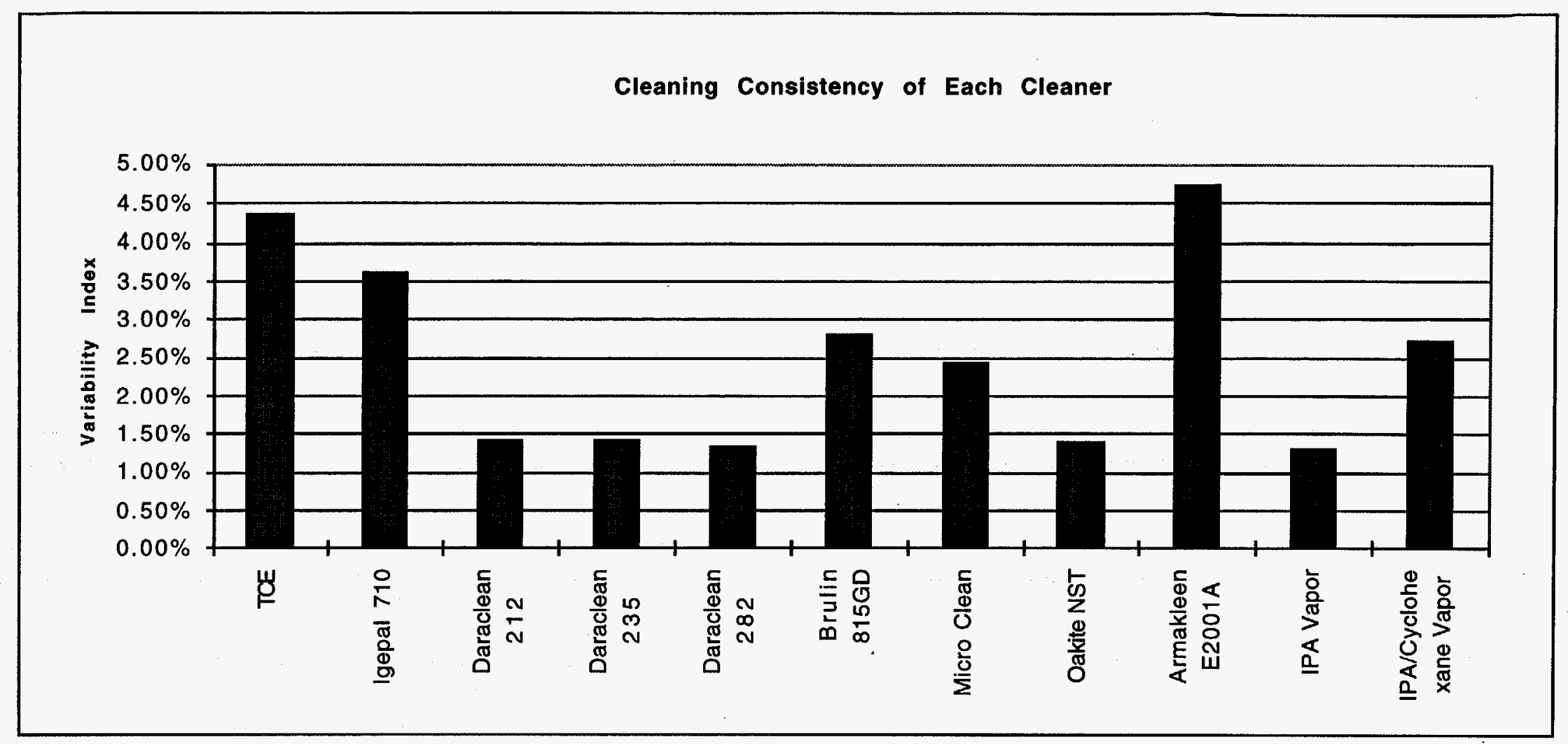

Figure 22 - Cleaning Consistency of Each Cleaner

Page 70 
Auger Survery of a Representative Sample

Cleaned With Armakleen E2001A

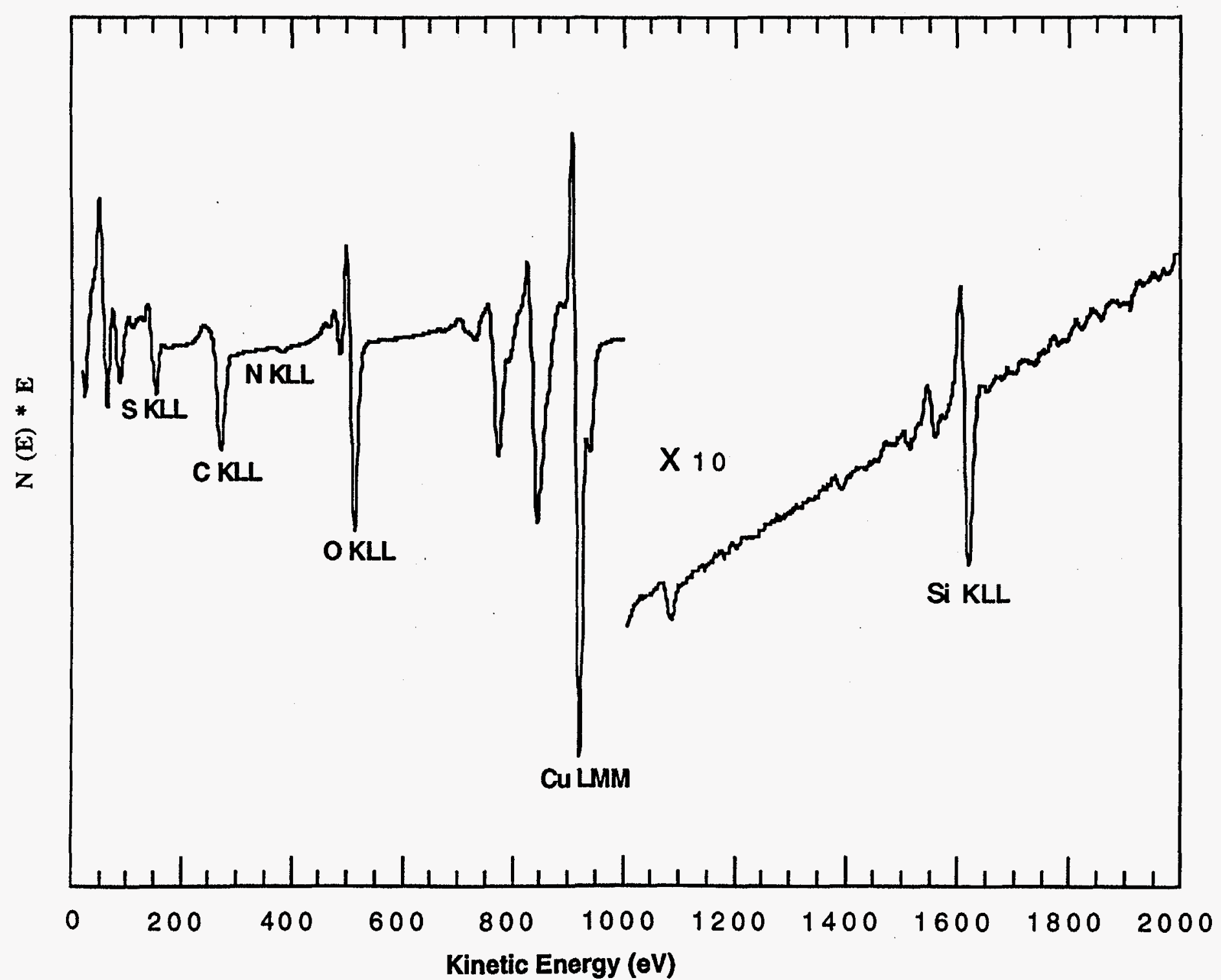

Figure 23

Page 71 
Representative Sample Cleaned With

Armakleen E2001A

XPS Oxygen 1s Region

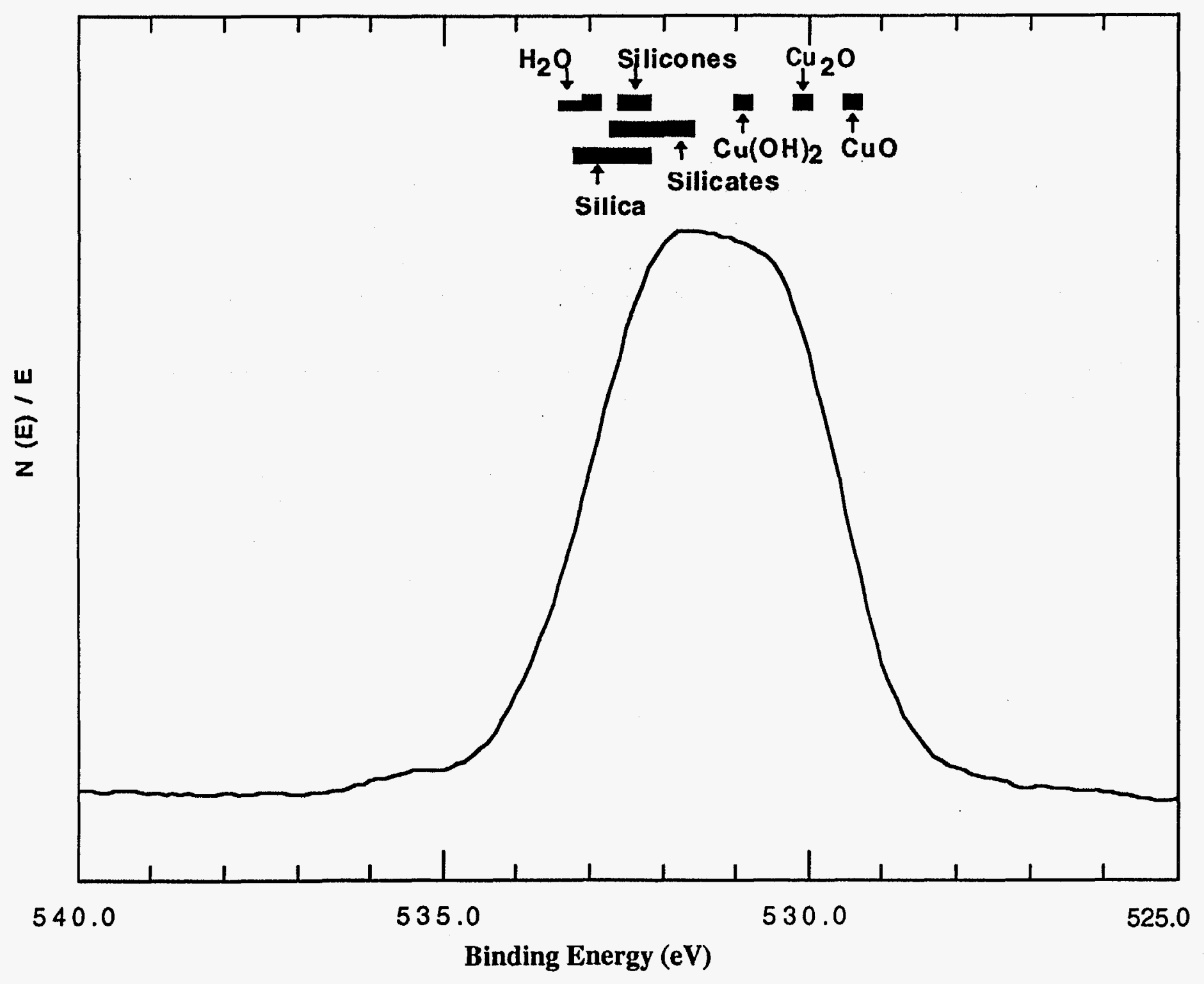

Figure 24

Page 72 
Representative Sample Cleaned With

Armakleen E2001A

XPS Silicon 2p Region

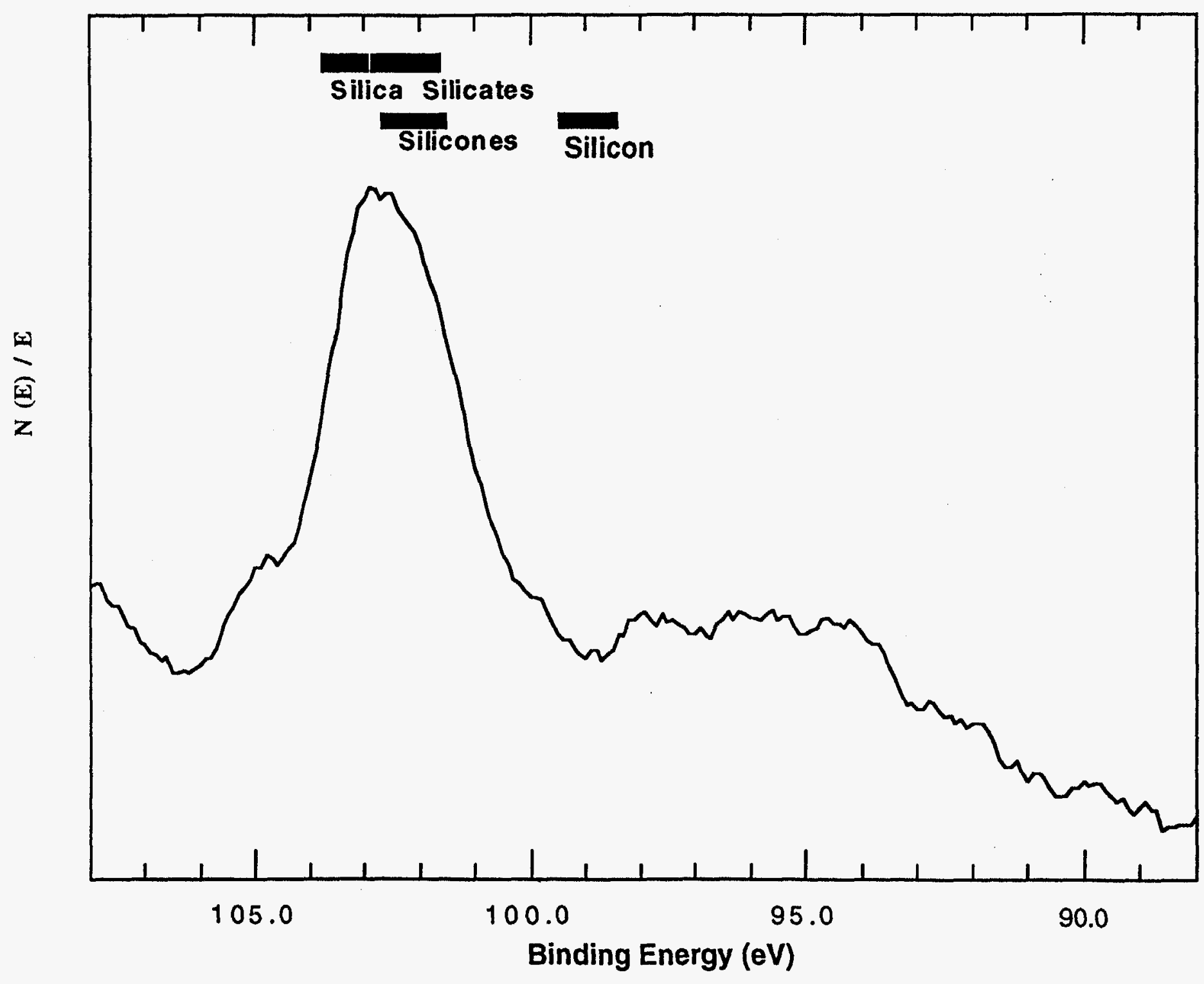

Figure 25

Page 73 


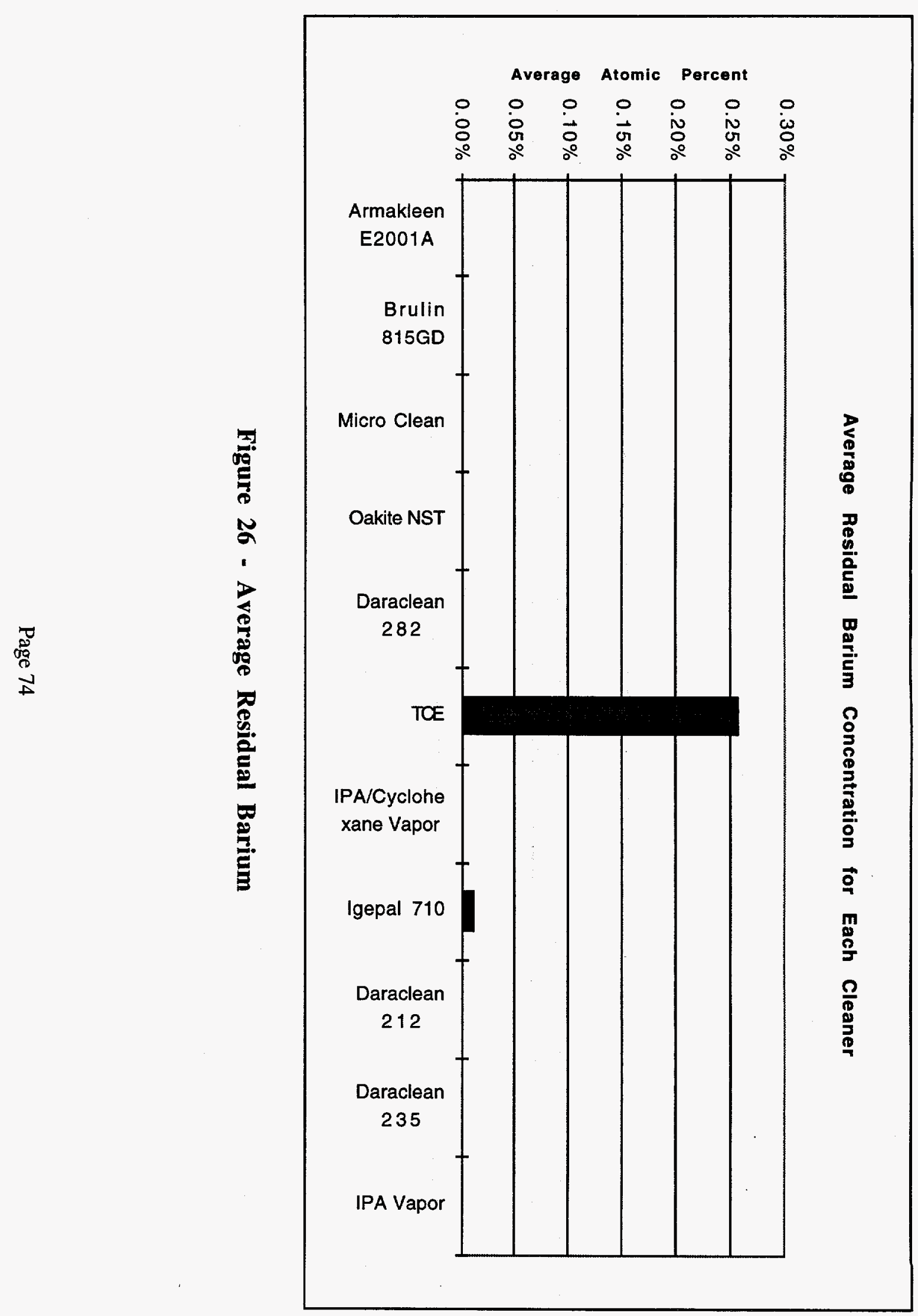




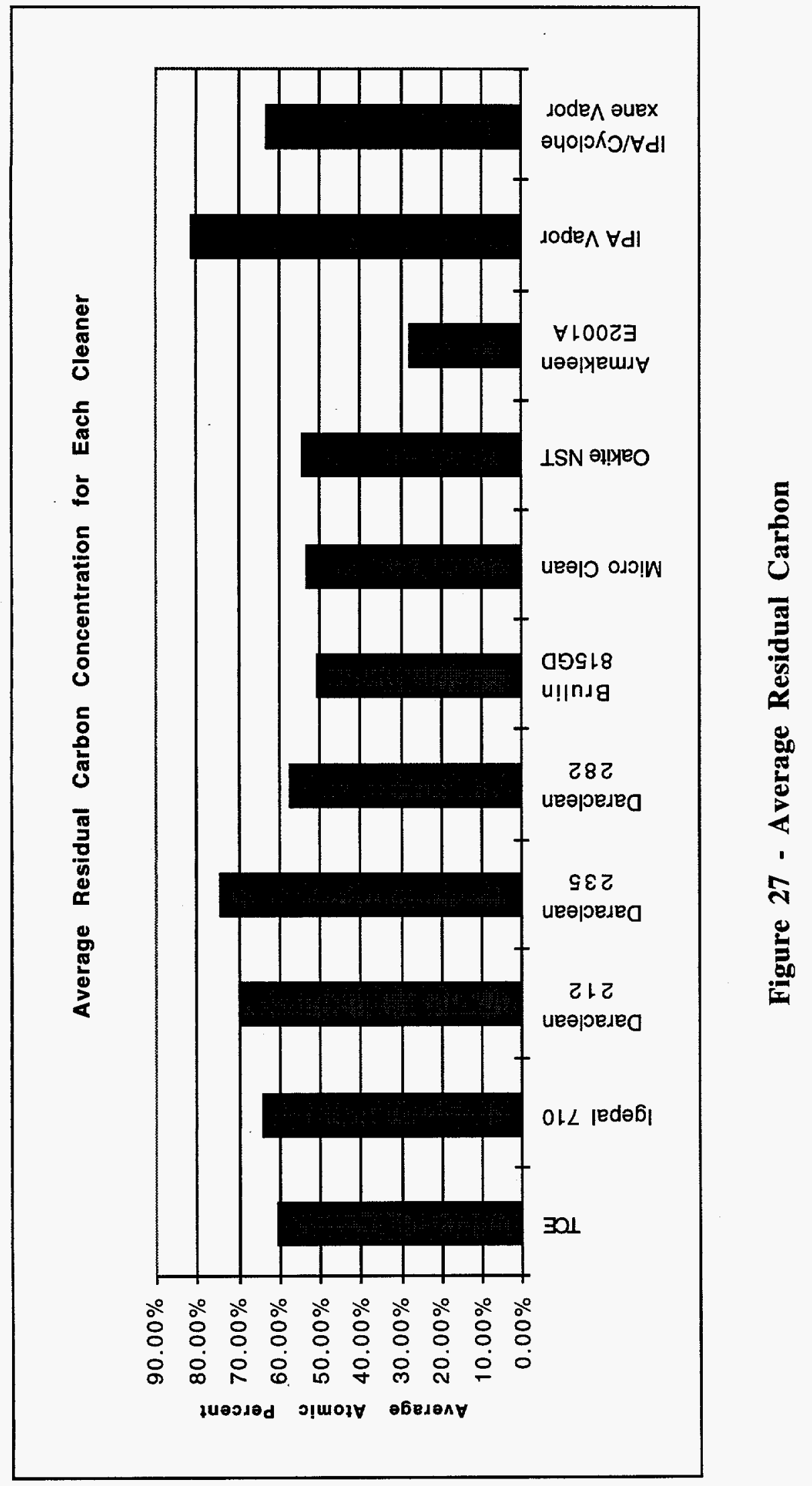

$\frac{2}{2}$ 


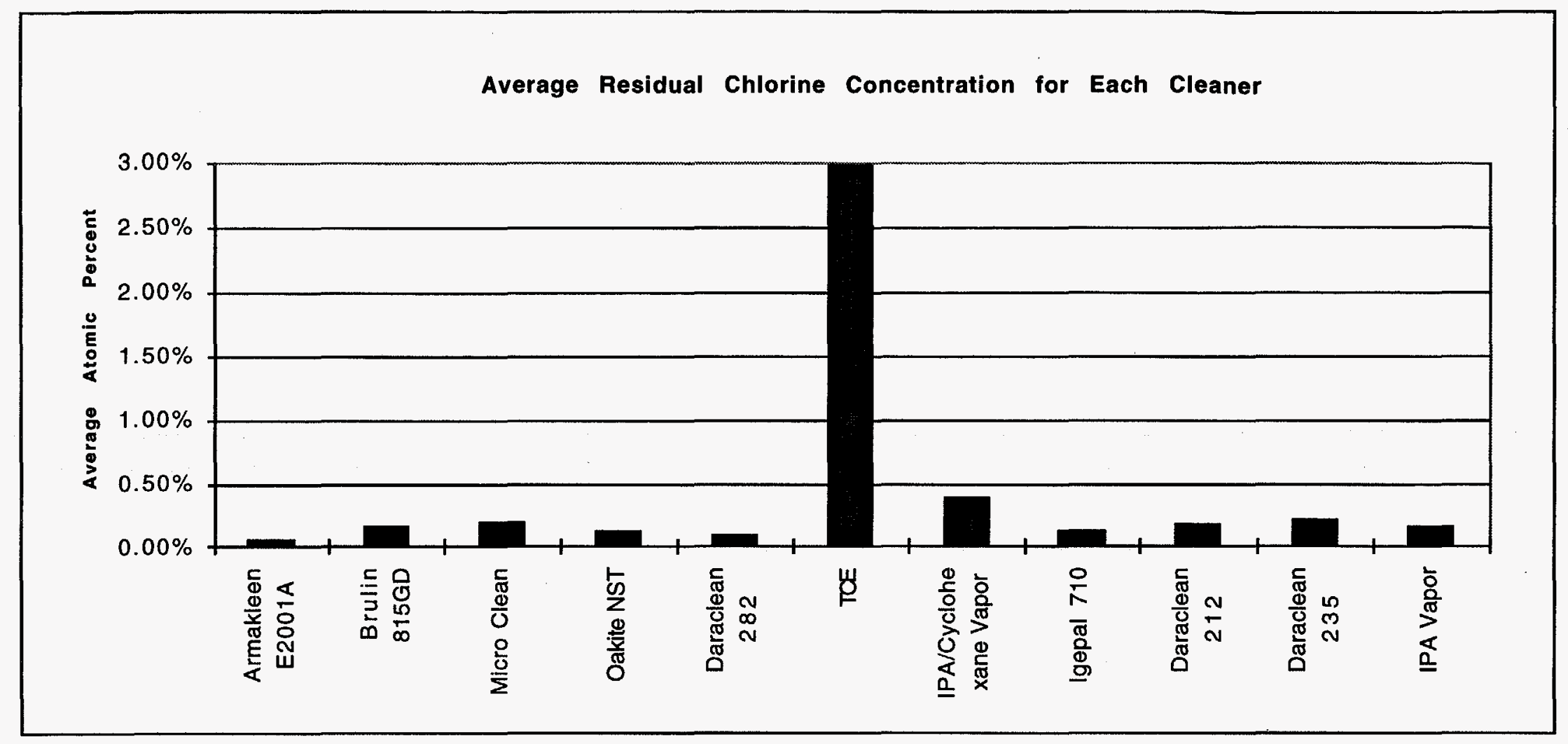

Figure 28 - Average Residual Chlorine 


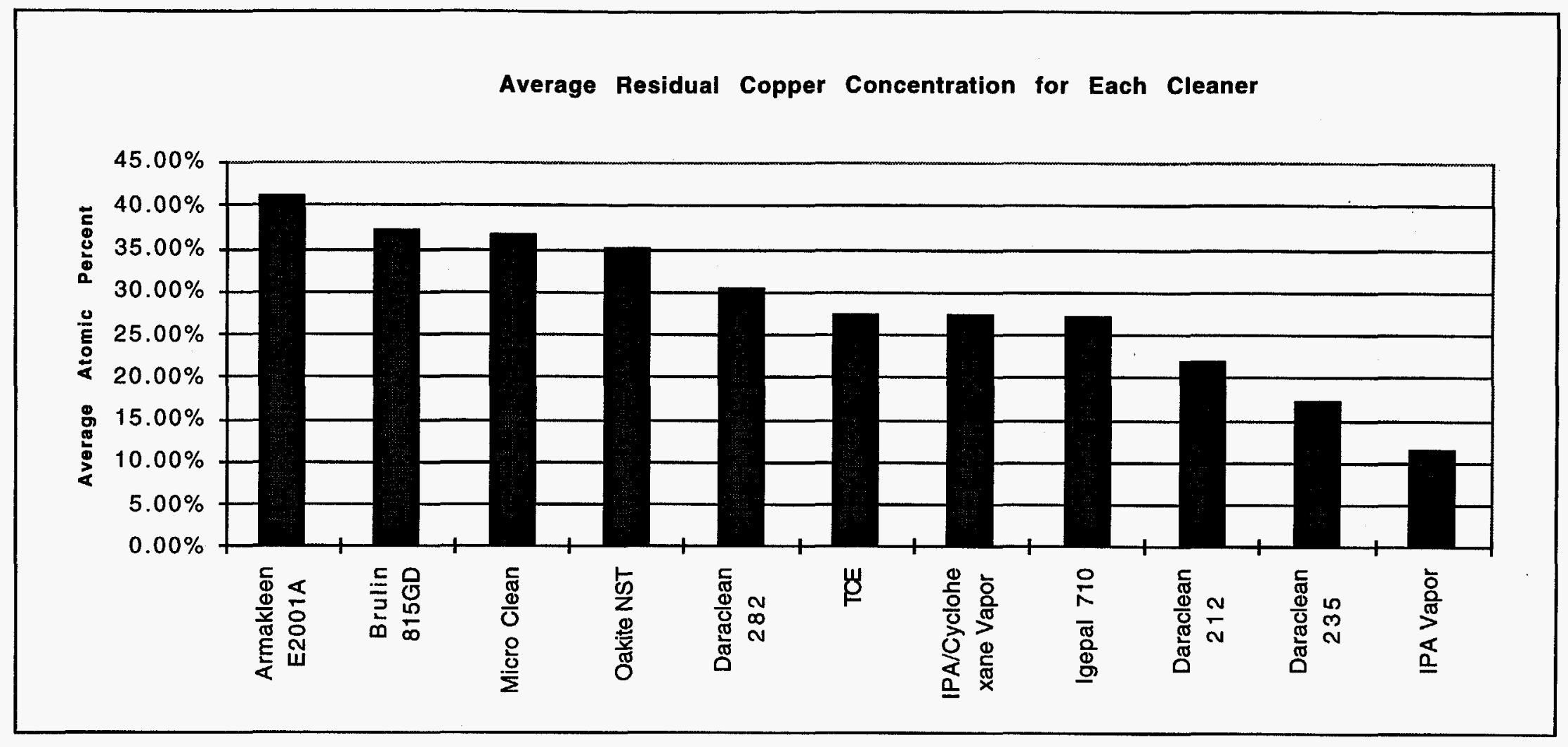

Figure 29 - Average Residual Copper 


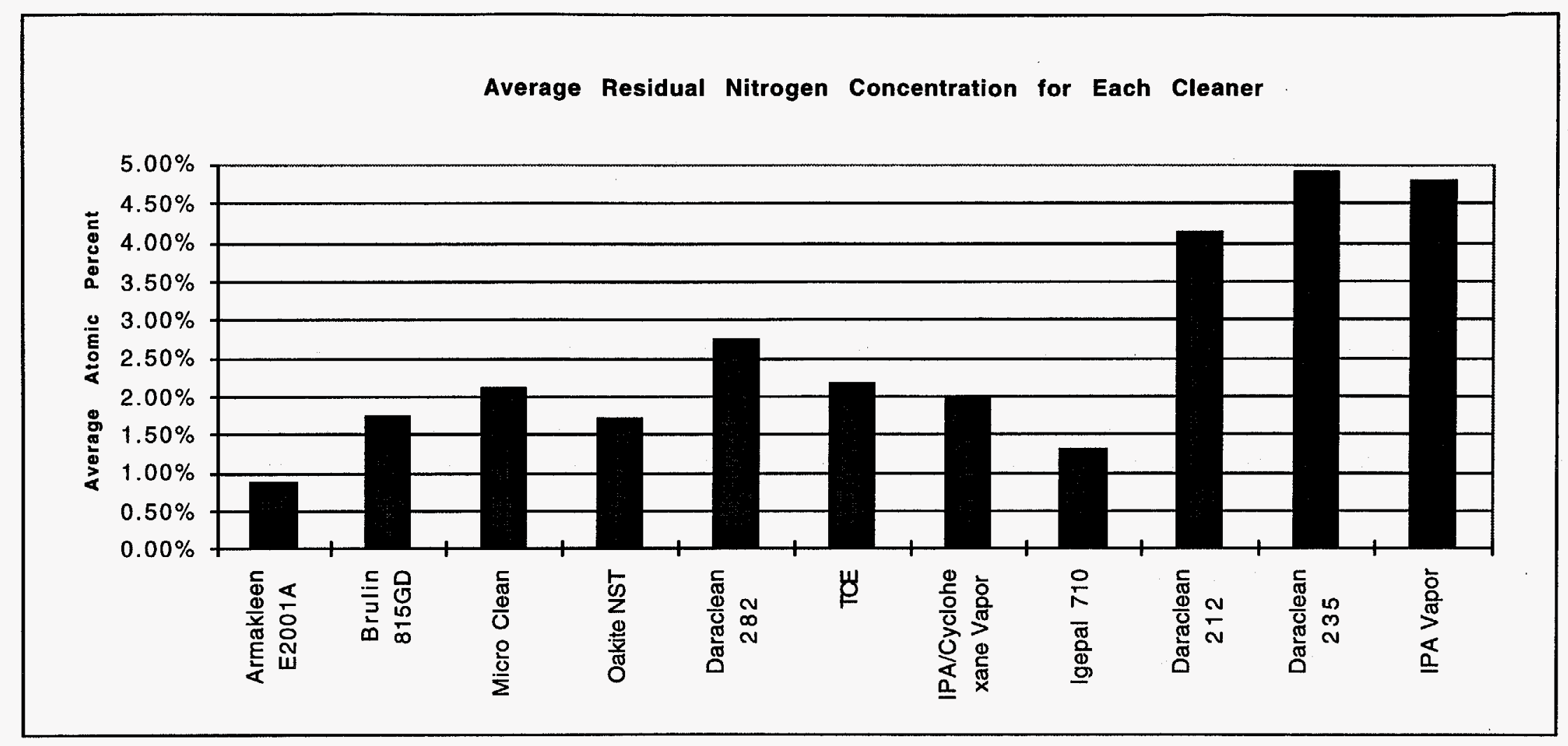

Figure 30 - Average Residual Nitrogen 


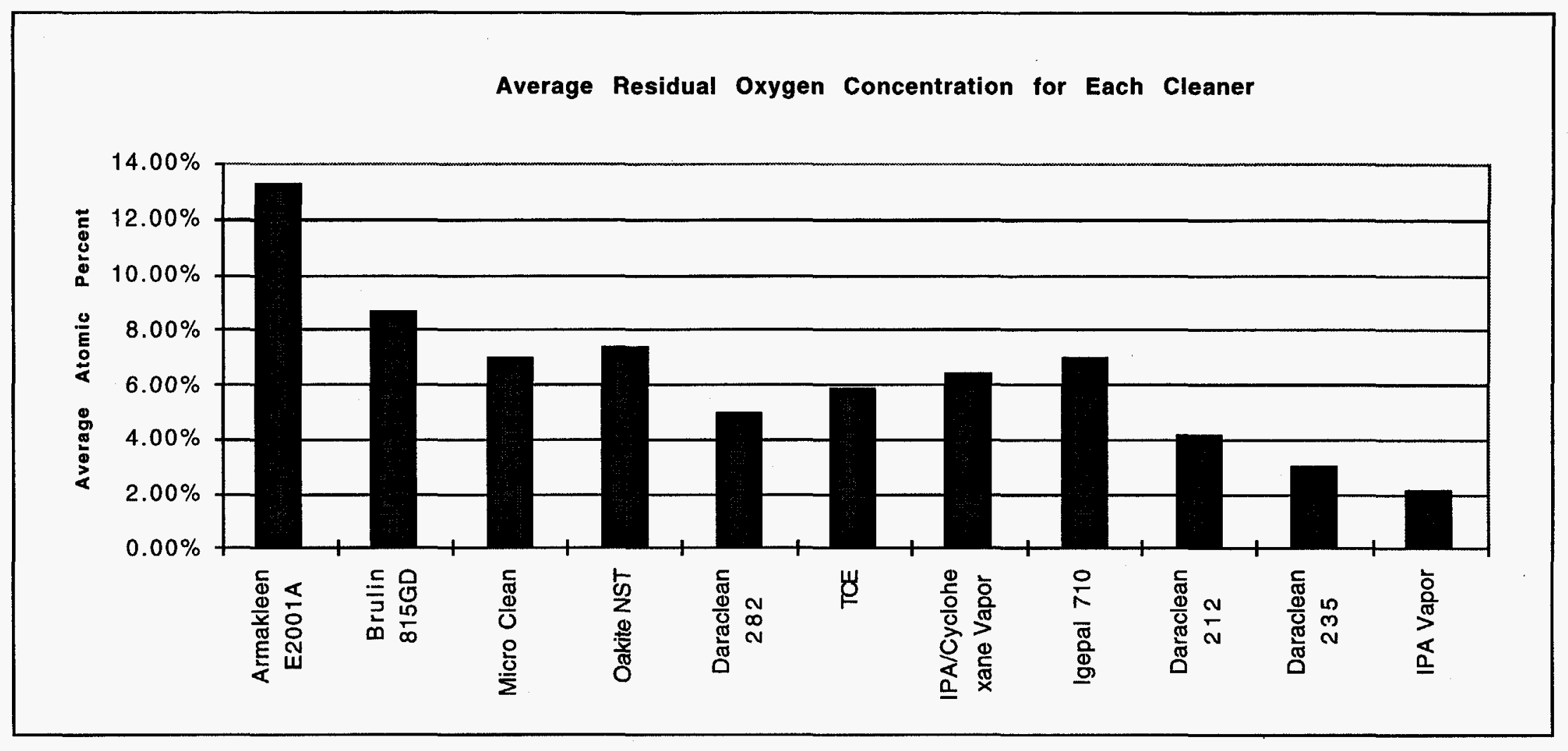

Figur 31 - Average Residual Oxygen 


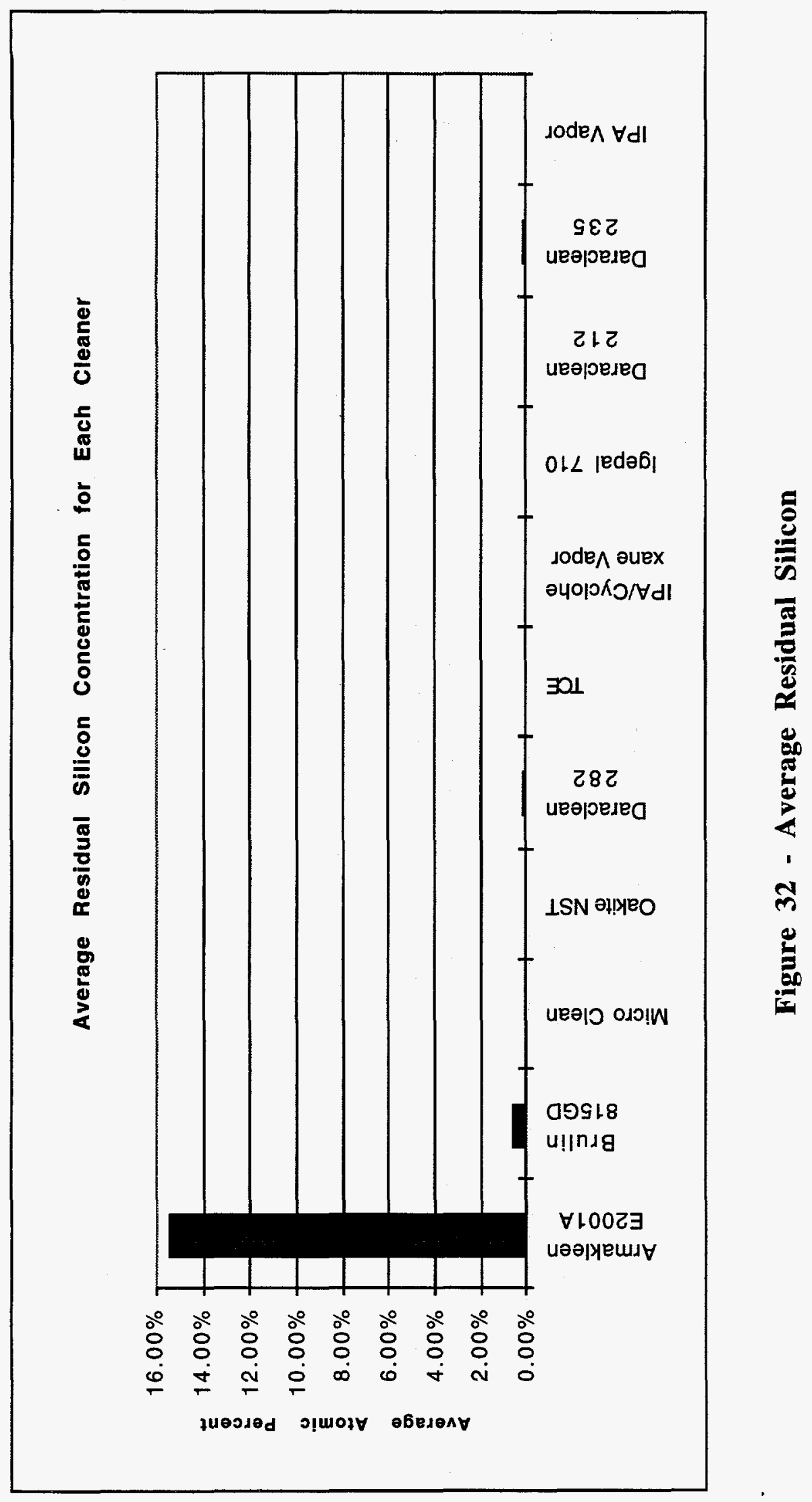




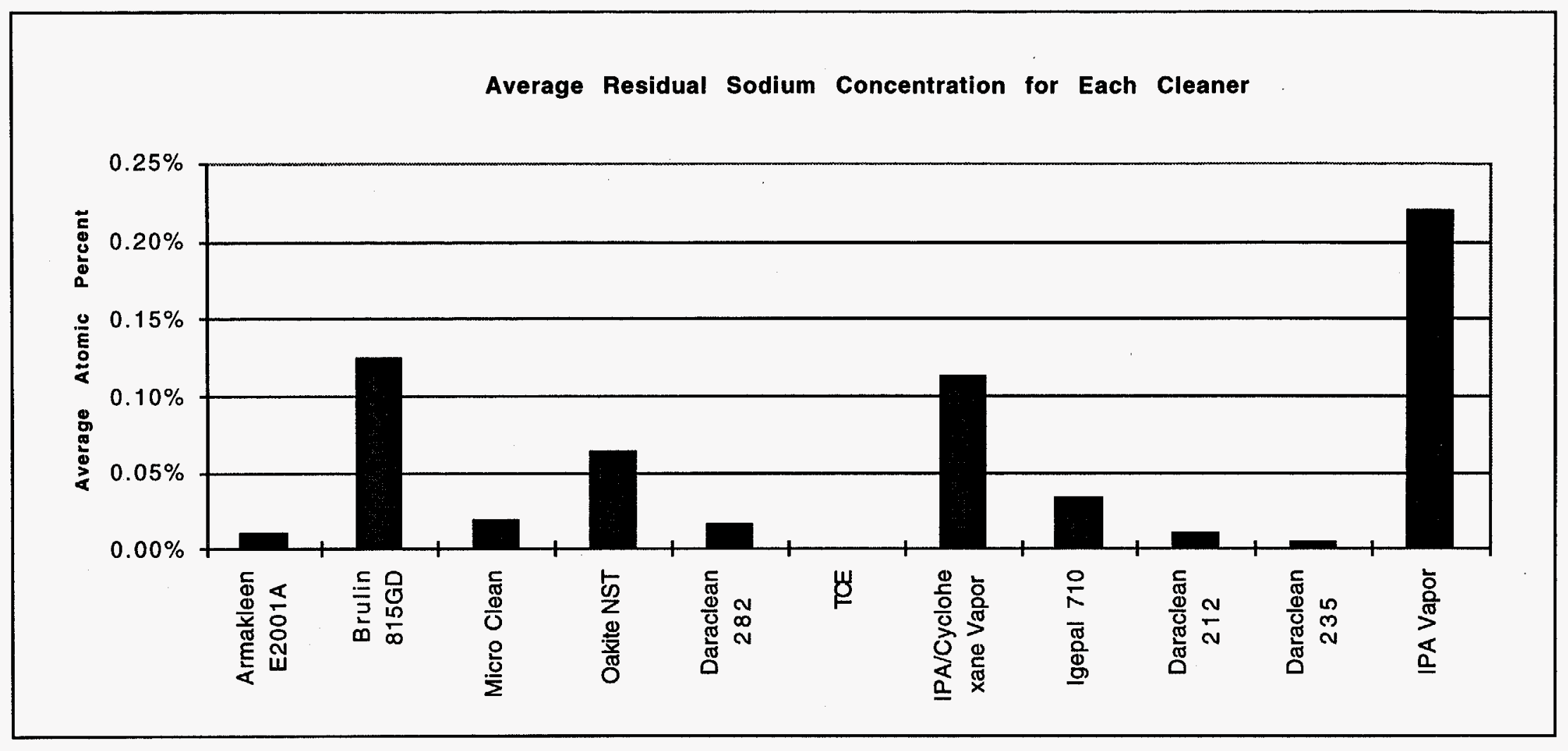

Figure 33 - Average Residual Sodium 


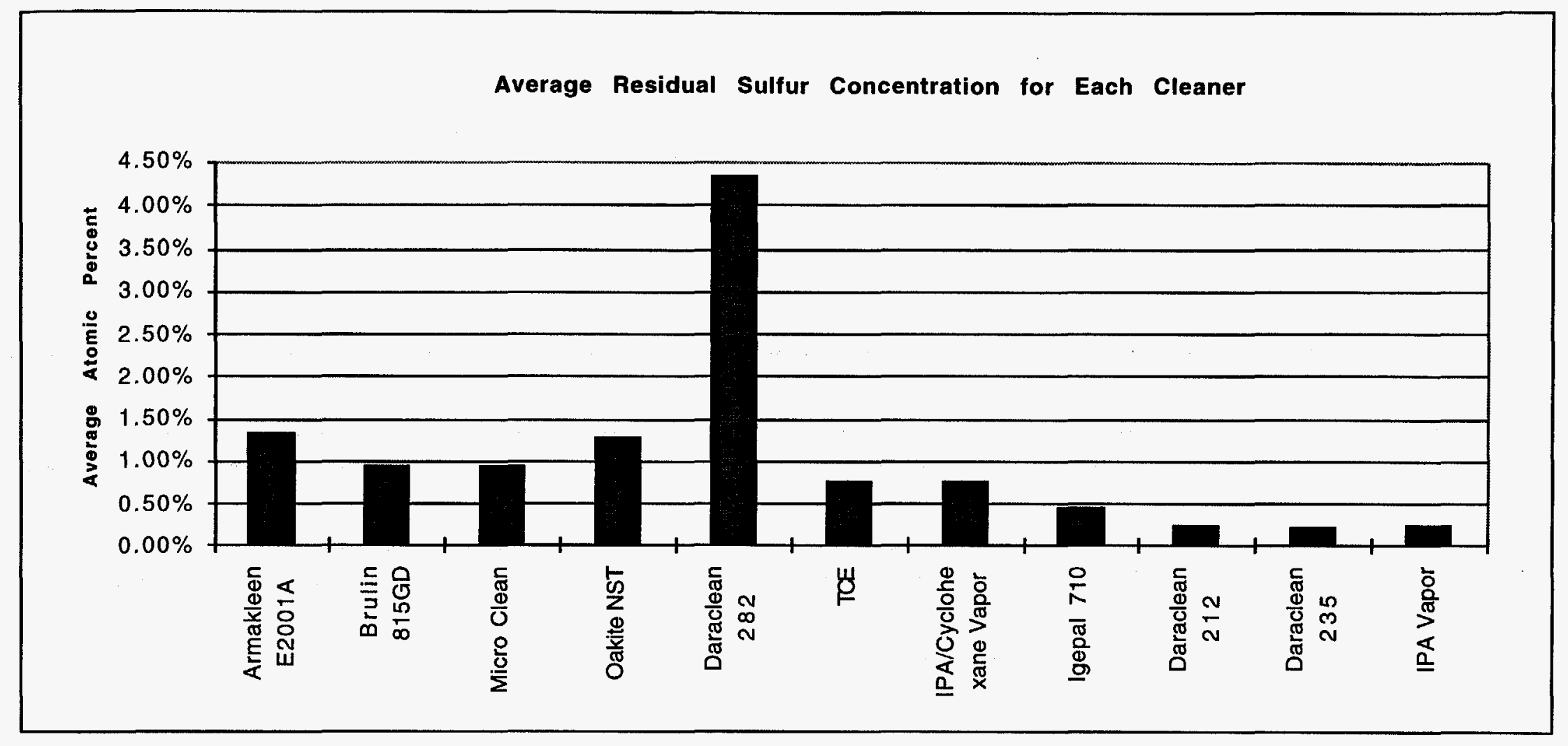

Figure 34 - Average Residual Sulfur 


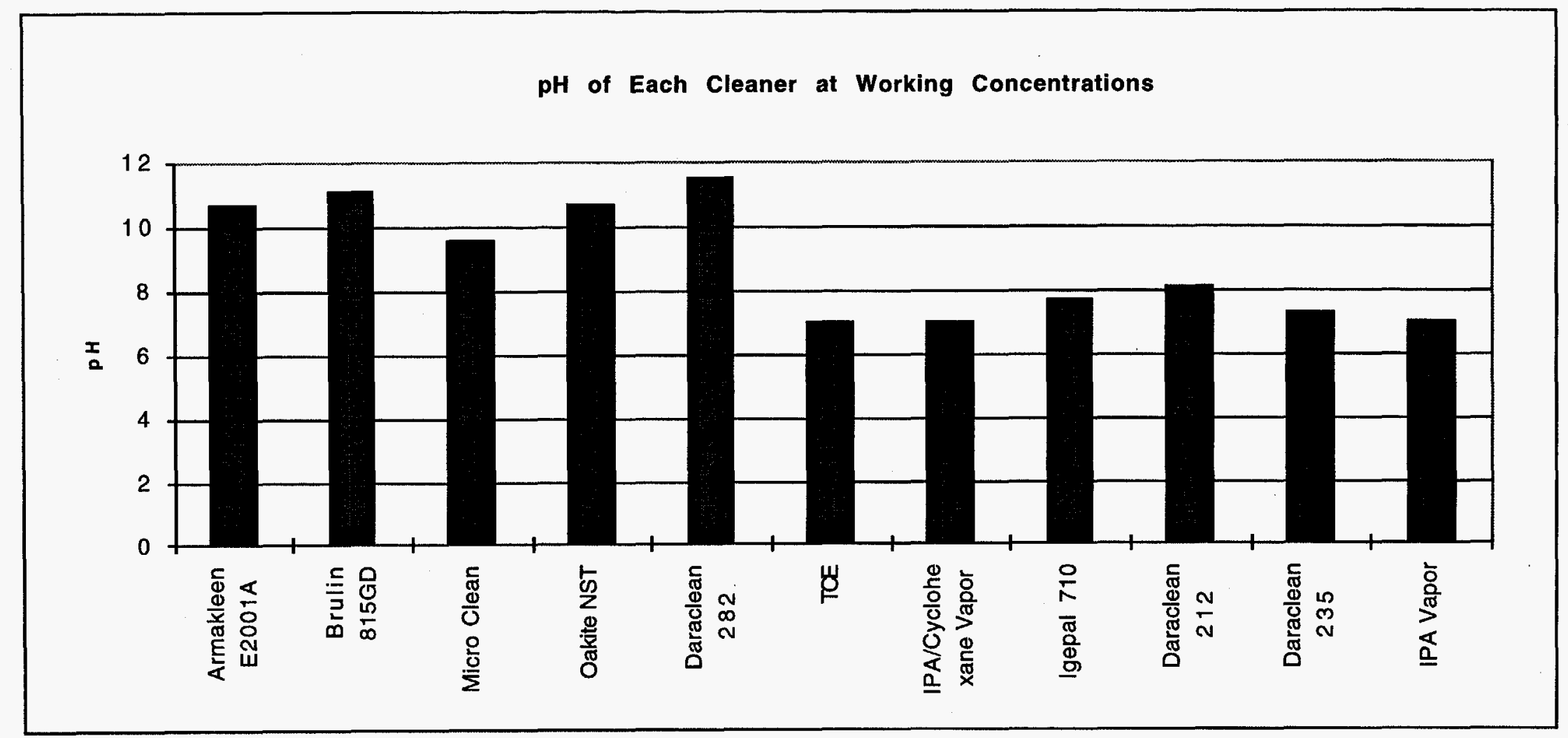

Figure 35 - pH of Each Cleaner

<-----Increasing Copper (Most Clean) 


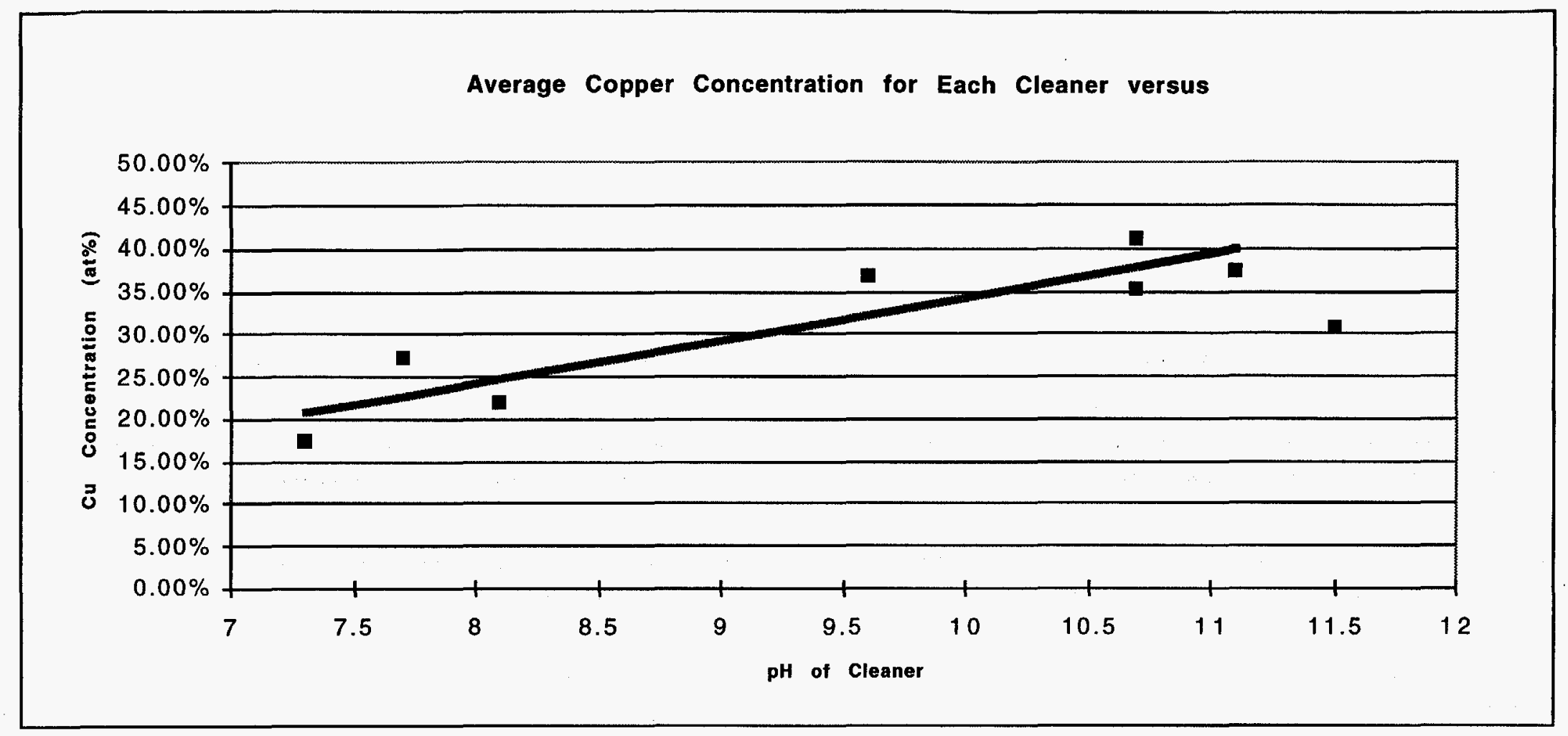

Figure 36 - Average Copper Concentration 


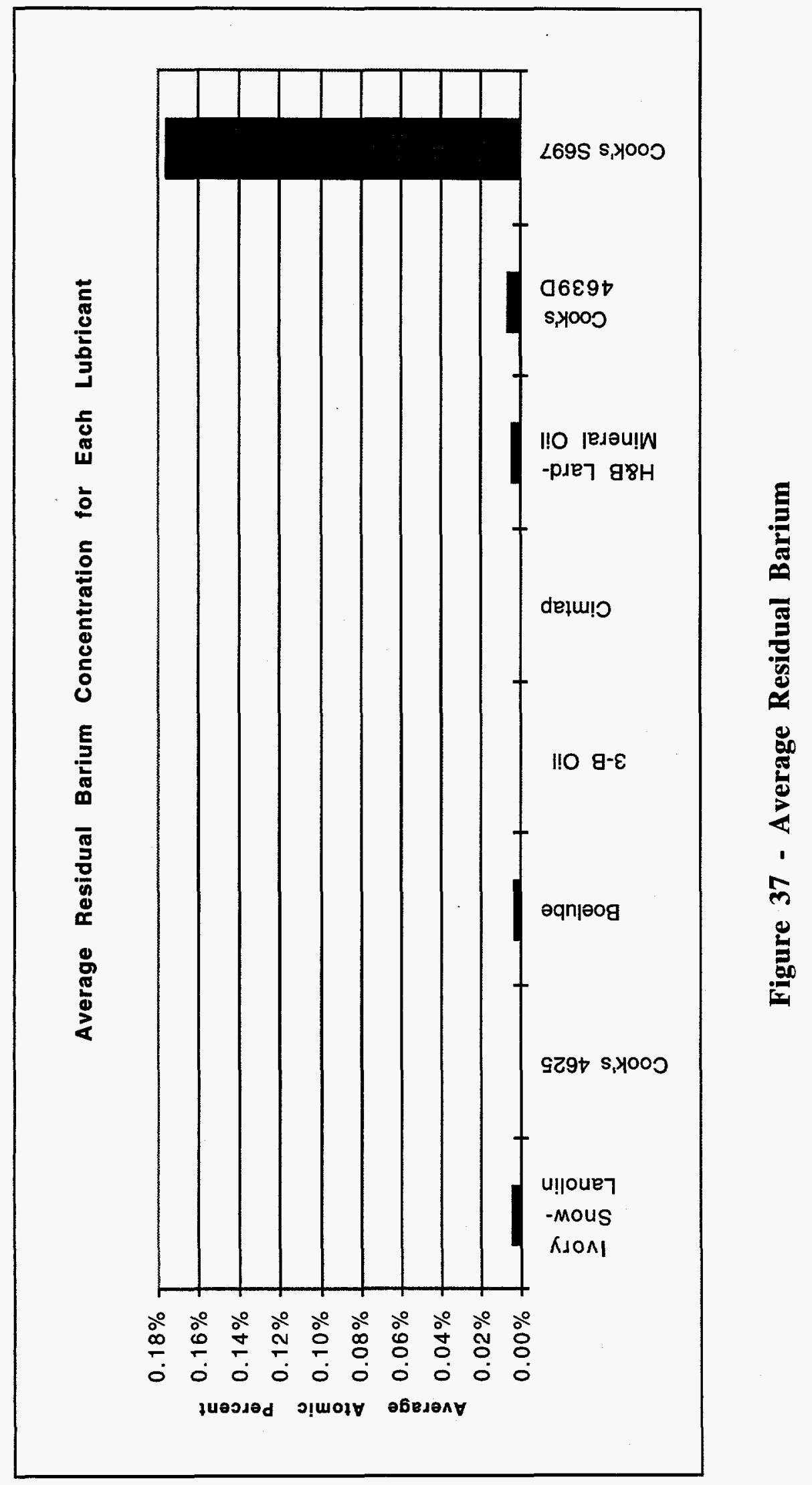




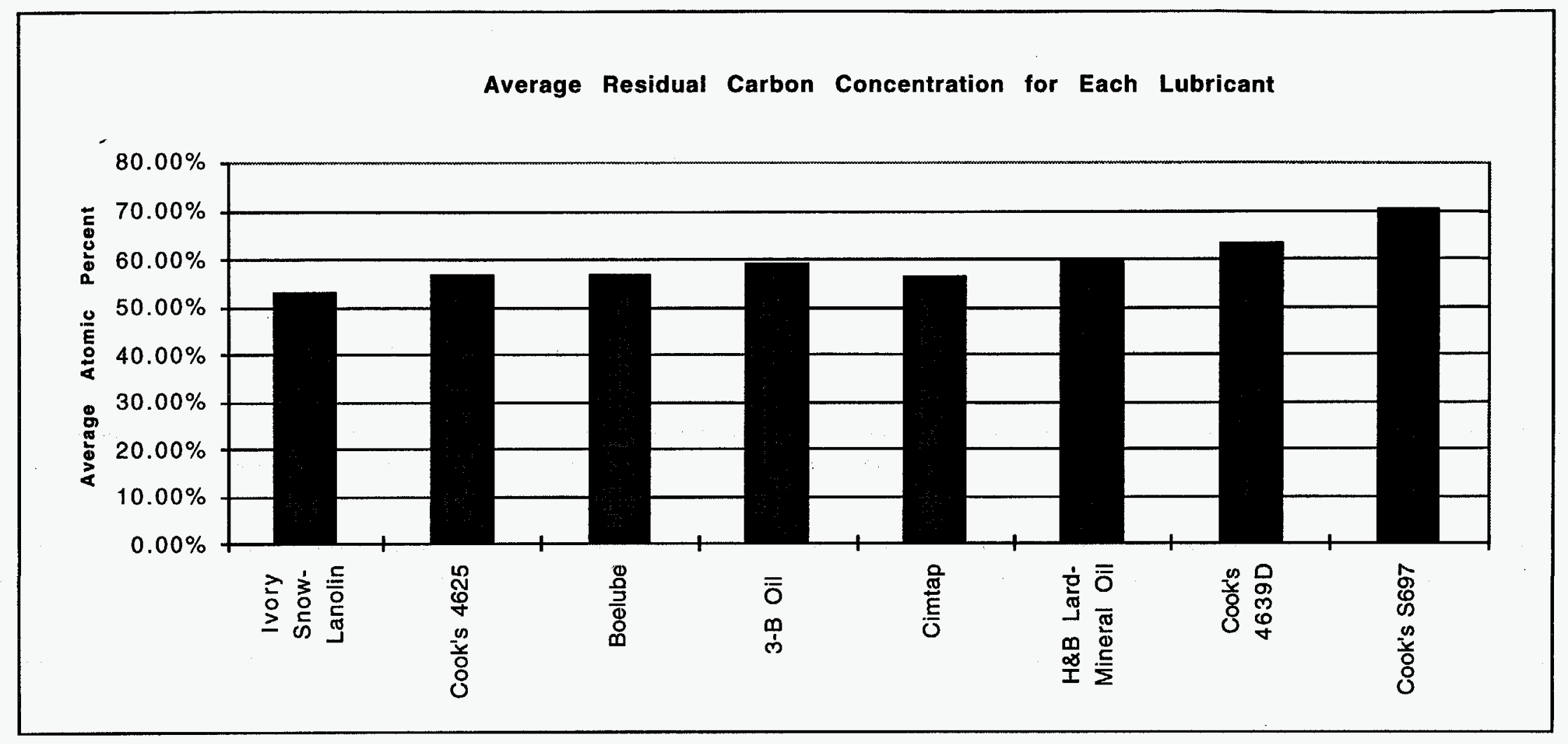

Figure 38 - Average Residual Carbon 


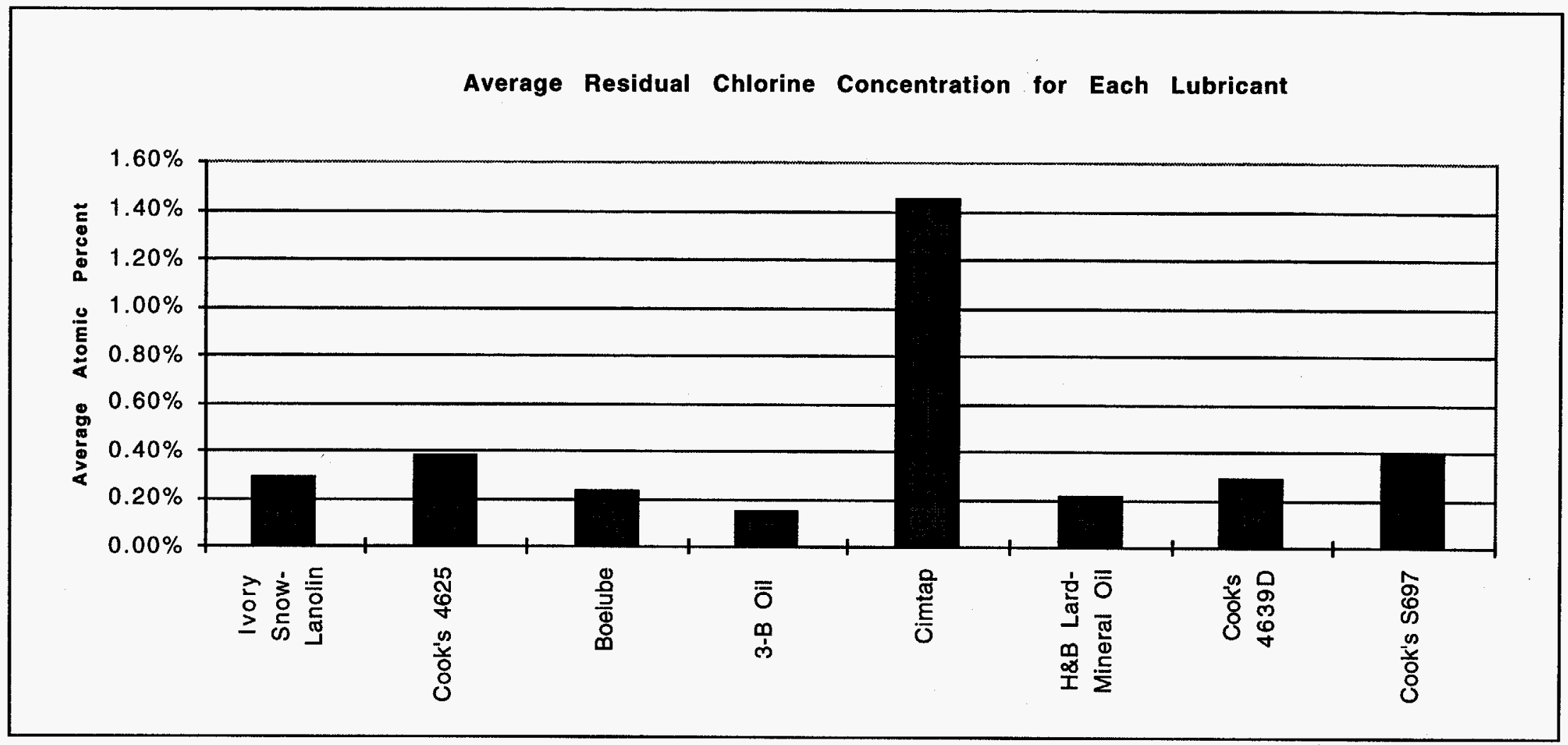

Figure 39 - Average Residual Chlorine 


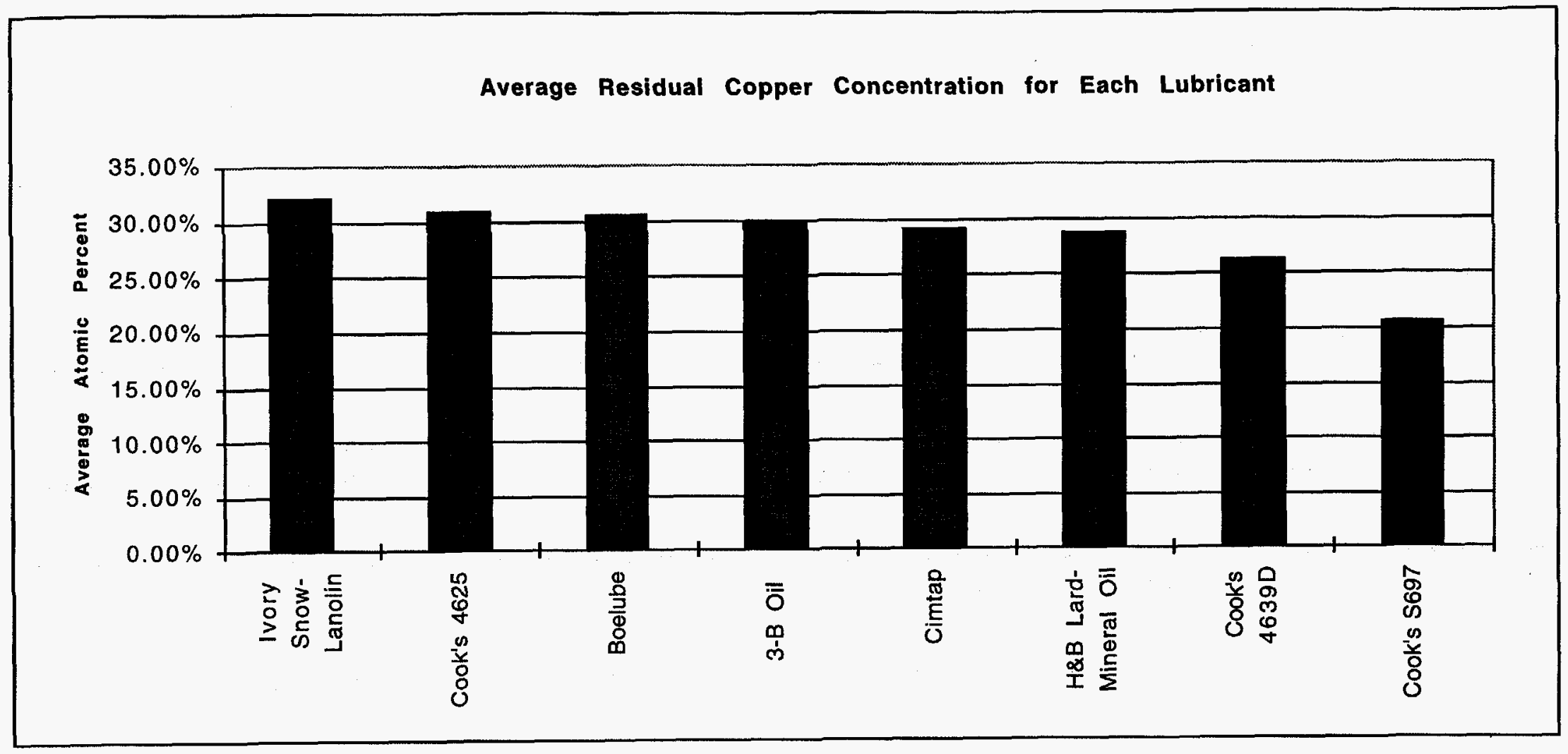

Figure 40 - Average Residual Copper 


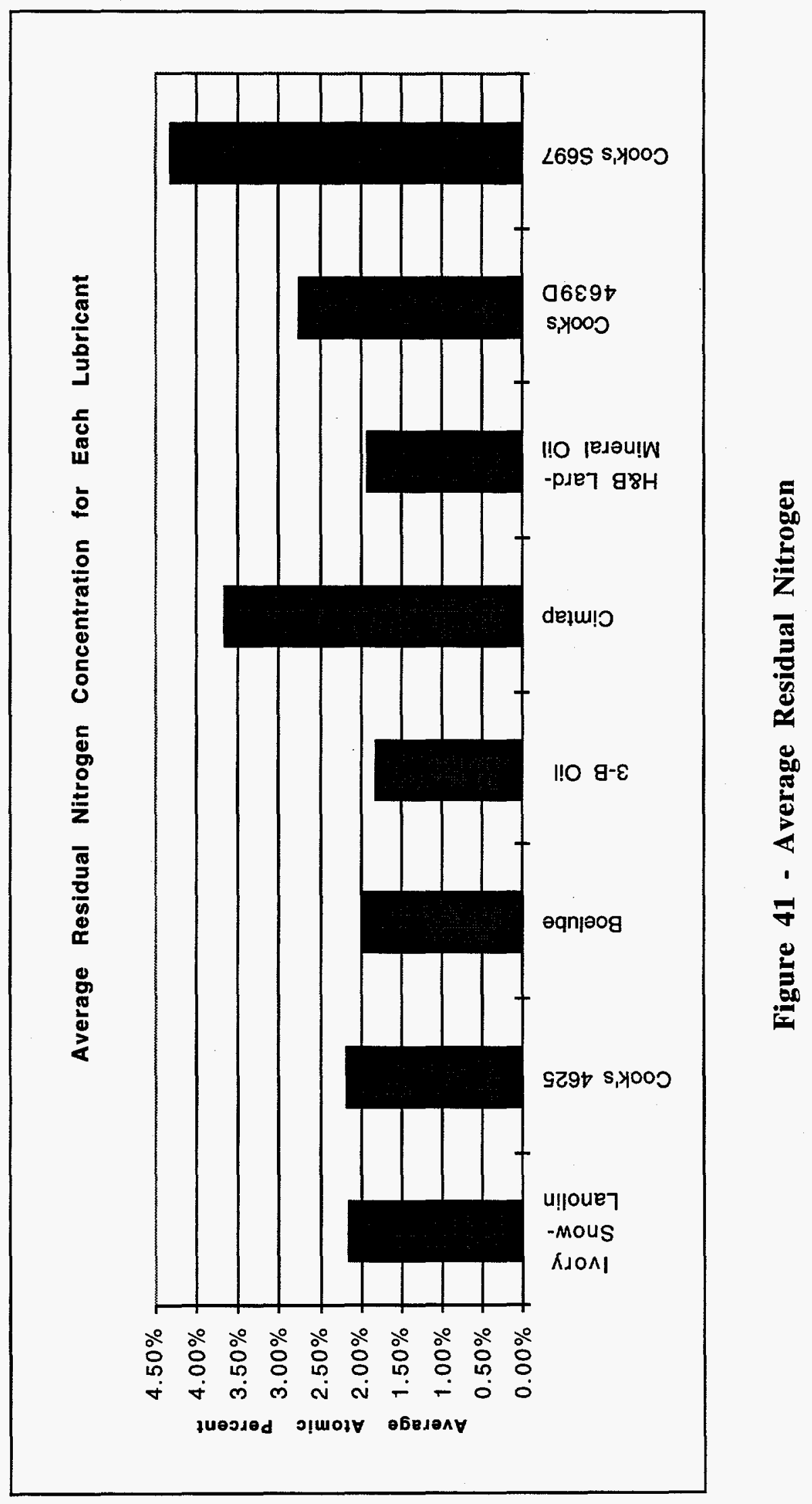

$\infty$
$\infty$
0
0 


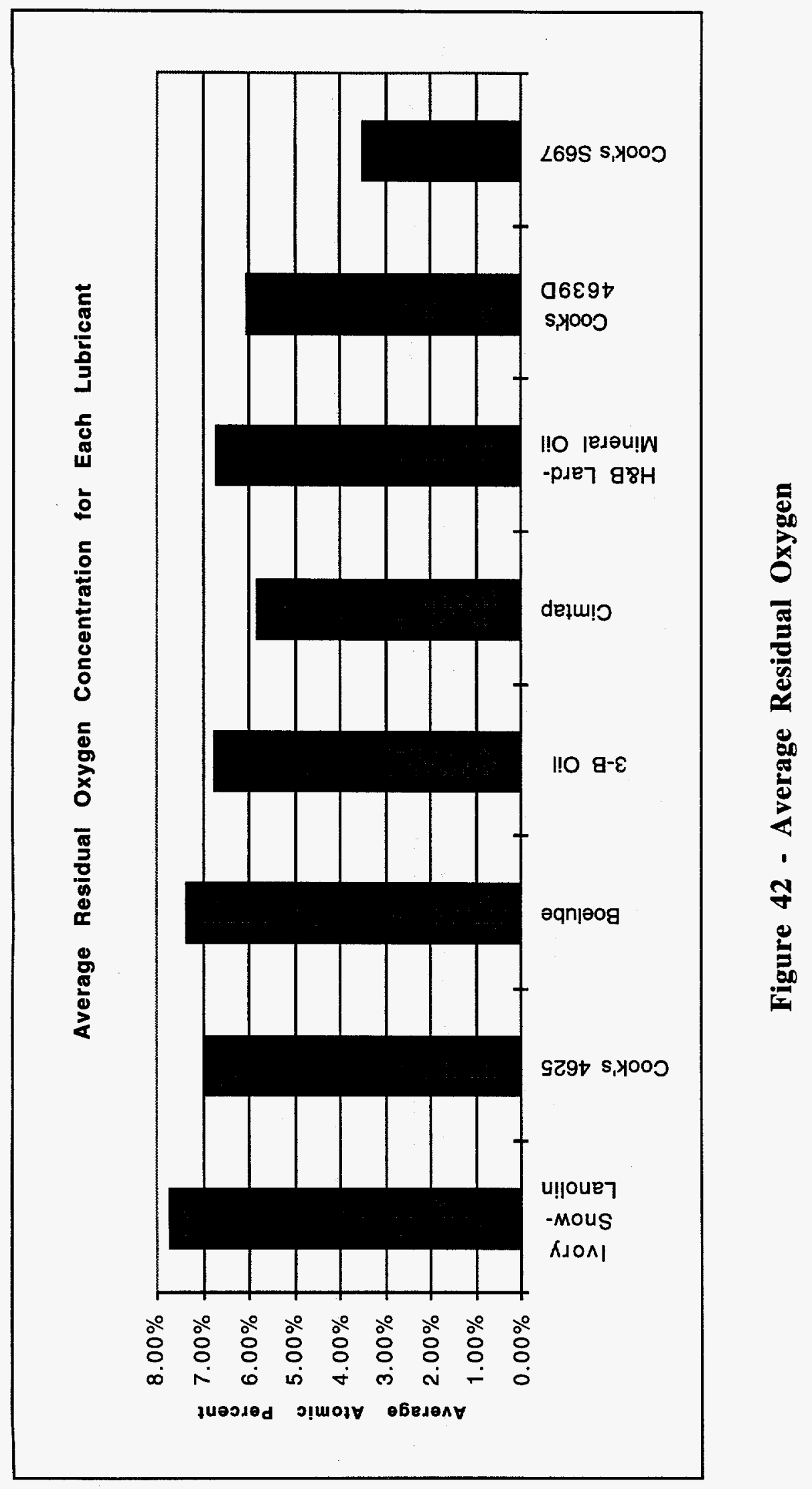

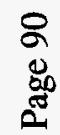




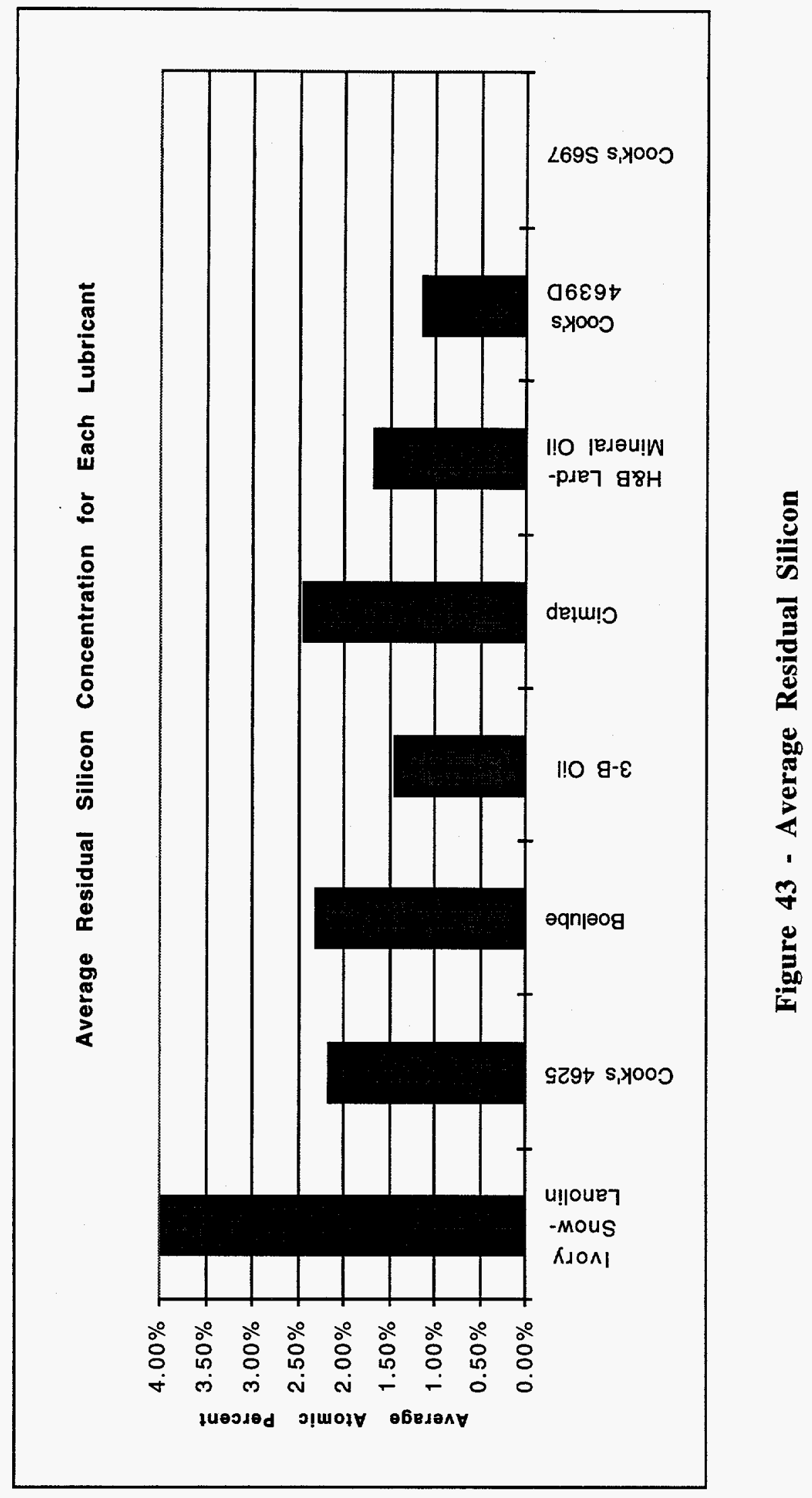




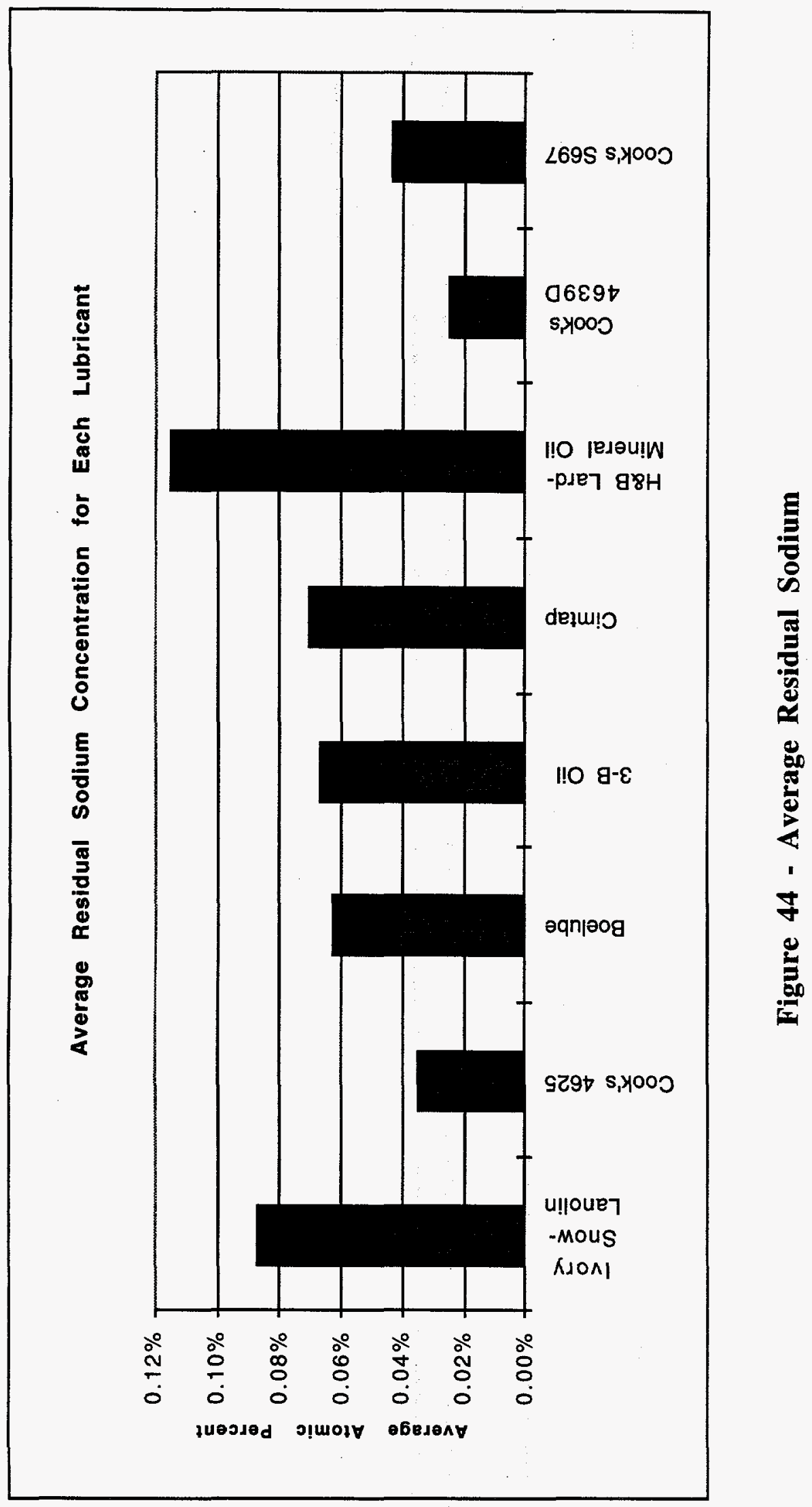




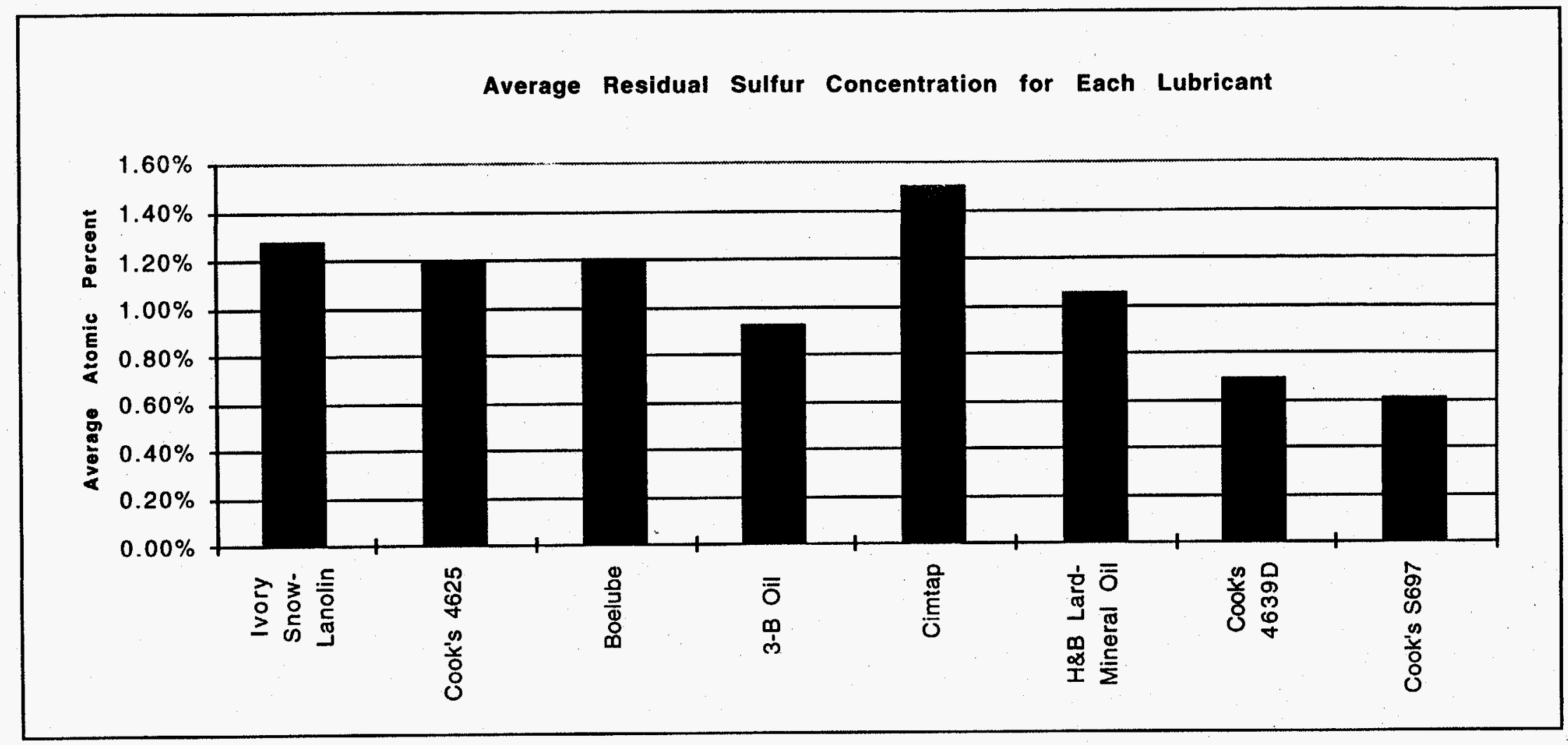

Figure 45 - Average Residual Sulfur 
Internal Distribution:

\begin{tabular}{|c|c|c|}
\hline MS0326 & D. E. Hoke & Dept. 2653 \\
\hline MS0340 & N. R. Sorensen & Dept. 1832 \\
\hline MS0367 & J. A. Ohlhausen & Dept. 1812 \\
\hline MS0367 & D. E. Peebles & Dept. 1812 \\
\hline MS0367 & C. Renschler & Dept. 1812 \\
\hline MS0479 & H. M. Jones & Dept. 5151 \\
\hline MS0501 & M. E. Smith & Dept. 2565 \\
\hline MS0501 & P. J. Wilson & Dept. 2565 \\
\hline MS0641 & R. S. Urenda & Dept. 2643 \\
\hline MS0783 & C. J. Greenholt & Dept. 9611 \\
\hline MS0857 & D. B. Appel & Dept. 2566-1 \\
\hline MS0857 & L. Beavis & Dept. 14466 \\
\hline MS0957 & G. L. Dybwad & Dept. 2411 \\
\hline MS0958 & G. De Marquis & Dept. 2472 \\
\hline MS0958 & R. Bargman-Romero & Dept. 2484 \\
\hline MS0958 & C. A. Walker & Dept. $2471-2$ \\
\hline MS0958 & D. L. Zamora & Dept. 2472 \\
\hline MS1407. & J. H. Aubert & Dept. 1815 \\
\hline MS1407 & C. Adkins & Dept. 1815 \\
\hline $\mathrm{MS} 1407$ & M. G. Montoya & Dept. 1815 \\
\hline MS1407 & E. P. Lopez & Dept. 1815 (15 copies) \\
\hline MS1411 & M. Cieslak & Dept. 1831 \\
\hline MS1411 & F. M. Hosking & Dept. 1831 \\
\hline MS9405 & D. Lindner & Dept. 5605 \\
\hline MS9018 & Central Technical Files & Dept.8523-2 \\
\hline MS0899 & Technical Library & Dept. 13414 (5 copies) \\
\hline MS0619 & Print Media & Dept. 12615 \\
\hline MSO100 & Document Processing, For DOE/OSTI & Dept. $7613-2$ (2 copies) \\
\hline
\end{tabular}

Allied Signal Inc. - Kansas City Division - 2000 East 95th Street P. O. Box 419159, Kansas City, MO 64141-6159

Mail Code XD43 G. W. Christoff Dept. 836

Mail Code 2C43 G. W. Bohnert Dept. 836

Mail Code 2B35 T. E. Hand Dept. 811

Mail Code 2C43 M. Smith Dept. 836

Los Alamos National Laboratory - Los Alamos, New Mexico 87545 MSJ552 J. Stimmel

Lawrence Livermore National Laboratory - University of California, Livermore, CA 94551 P. O. Box 808

MSL-626 M. P. Meltzer

Oak Ridge National Lab/Y-12 - P. O. Box 2009 Bear Creek Rd. Oakridge TN, 37831

L. Thompson

MESERAN Testing Laboratories - 5119 Pleasant Street, Kansas City, MO 64133

M. G. Benkovich (3 copies) 